A compilation of large subunit RNA sequences presented in a structural format

Robin R.Gutell* and George E.Fox ${ }^{1}$

Department of Microbiology, University of Illinois, Urbana, IL 61801 and ${ }^{1}$ Department of

Biochemical and Biophysical Sciences, University of Houston, TX 77004, USA

INTRODUCTION

The present review provides a summary of all the published large subunit rRNAS as of December 1987. Instead of the usual linear alignment the sequences are tabulated here as a series of secondary structure diagrams in which individual nucleotides are indicated. The reasons for this departure from past practice are several. The foremost is simply that in our experience this format is more useful. For example, considerable effort is now being expended to study the higher order structure of the large rRNAS. Thus it is common to be reading a paper only to find reference to position $X$ in sequence $Y$. With diagrams such as those provided here the reader will be able to readily identify such statements in the context of the known major outline of the secondary structure of sequence $Y$ or for that matter any other published sequence. Secondarily this collection, as is traditional, tabulates all the currently known sequences in one place. Finally we believe the collection as a whole is educational in that it will make the reader aware of the extent of secondary structure variation in the large subunit RNAs and the magnitude of work that still could be done to further refine the secondary structures by collection of appropriate additional data.

\title{
ORIGIN OF THE STRUCTURE
}

All of the structure diagrams are drawn in a format that coincides with that used for Escherichia coli. The E. coli structure itself is based on a secondary structure model first published in 1981 (1). The present version contains important unpublished modifications made by Gutell, Noller and Woese (2) and further unpublished refinements (Gutell, Noller and Woese, unpublished results; Jurka and Fox, unpublished results). All of the structures shown were established by comparative sequence analysis as discussed below. Due to data limitations some regions of some of the sequences are best regarded as of unknown structural content at this time. No attempt has been made here to compare the structures presented to the various sequence specific secondary structures that frequently accompany the publication of each sequence, though excellent agreement exists with one recently published general model (3). Likewise no putative tertiary interactions have been indicated on the figures though a few are known (Gutell, unpublished results and ref (3). In many cases there is evidence for a pseudoknot in the 
vicinity of E. coli position 2350 (Gutell, unpublished results and ref (3)) and when that evidence is favorable the interaction is indicated on the figures.

\section{COMPARATIVE SEQUENCE ANALYSIS}

For pragmatic reasons the primary tool used in constructing the individual structures has been comparative (or phylogenetic) analysis. This approach had its origin in the discovery of the cloverleaf structure for tRNA (4). It first began to reach its modern form with the analysis of 5S rRNA (5) and has emerged as a well documented procedure $(2,6-8)$ The underlying assumption is that functionally equivalent regions of the large rRNAs from phylogentically diverse sources will have biologically equivalent structures. The procedure begins by aligning the primary sequences using conserved sequence segments as a guide. Next the various columns of bases are individually intercompared to detect compensating base changes that maintain Watson-crick complementarity between the potential pairing regions. If an individual helical element is independently tested several times it is considered phylogenetically proven.

The comparative method has certain limitations that the reader should appreciate in perusing the figures presented here. First and foremost is the need for sequences that exhibit the structure being studied. For highly conserved features this may be the entire data base. In other cases features may be extremely variable so that particular versions are only found in individual phylogenetic groups, mammamalian mitochondria for example. Secondly the feature must exhibit sequence variation within the subset of sequences that contain the feature. Without such variation a region can not be structured. Thirdly it should be recognized that the approach necessarily produces minimal structures. It is the nature of the method to allow the identification of additional features as the data base grows. Thus, for example, the continuing refinement of the E. coli structure discussed above. Finally it should be appreciated that it is very difficult to assess the significance of base pairs that that can extend a particular helix in some organisms but not all. Such base pairs are strongly supported by thermodynamic arguements but conflict with the comparative concept. The proper resolution in such circumstances may have to wait until such time that more high resolution structure data is available.

\section{CURRENT DATA BASE}

As of late in 1987 there were 40 distinct complete large subunit RNA sequences published and at least $f$ ive extensive partial sequences in which at least 500 bases of the large subunit RNA have been sequenced (We have not exhaustively searched for these). In addition in some instances sequence information is available from more than one large subunit RNA gene from the same organism. Multiple rRNA genes frequently exhibit heterogeneity in sequence and this phenomenona may be of more than academic interest. The present collection does not address this matter however and in those few instances where information from more than one large subunit rRNA gene is available we have arbitrarily picked one sequence for inclusion 
here. The 40 known sequences provide a diverse sample covering the three major urkingdoms; eubacteria, archaebacteria and eukaryotes as well as the organelles. Table 1 lists the sequences, the common name of the RNAs involved, the total length of the large subunit RNA inclusive of fragments such as 5.8S and 4.5S rRNAs, at least one relevant GENBANK/EMBL accession numbers if the sequence is in the data bases, a highly abbreviated reference and a key to the complete references that accompany this text.

HOW TO READ THE DIAGRAMS

The structure diagrams were drawn to a single scale so that they may be readily superimposed or intercompared. This was accomplished by a computer program described elsewhere (6). Each diagram encompasses two pages with a crossover point to the next page indicated. In most bacterial cases a possible helical structure exists between the $5^{\prime}$ and $3^{\circ}$ termini of the molecule. It is uncertain whether this helix is present in the functional RNA or is simply a remnant of processing. In any event the reader needs to be aware that when it is possibly present it appears on both halves of the figure. Extensive base numbering occurs on the E. coli diagram. On the other sequence diagrams only occasional numbers are included. These occasional numbers refer to the specific sequence on which they appear. In those cases in which more than one molecule is include (eg 5.85 and 28 SNAS) each is numbered separately.

When a region contains no known structure it is drawn by the computer program as a circular loop. In order to maintain the scale and layout of the drawings it is not always possible to draw large uncharacterized regions as unstructured loops. When this occurs the region of unknown structure is included as a detached linear array 1 isted from $5^{\prime}$ to $3^{\prime}$. The Homo sapiens and other eukaryotic cytoplasmic sequences contain many examples of this, though the same phenomenon will also be seen on mitochondrial and chloroplast diagrams. These linear arrays are labeled with a bold letter and the positions included in the array indicated. A second bold letter specifies where in the sequence the linear array belongs. These bold letters are used in a consistent fashion so that a large unstructured area at the same location in several diagrams always receives the same bold letter. In a few instances the uncharacterized array is small enough to be shown as a loop in some but not all the diagrams. In those instances a bold letter is used to label the loops so that it is obvious that an equivalent unstructured region is present.

The reader should not conclude that the regions assigned bold letters are the only unstructured regions. Whenever room exists the computer program draws the unstructured regions as a large loop. A letter has only been assigned if the computer has used the linear array display in at least one case. Many of the unlabeled unstructured regions are rather large. obvious examples can be seen by examining any of the mammalian mitochondria structlires. Thus in many of the sequences presented here local regions which are often substantial in size are shown as unstructured. These regions clearly have a different 


\section{Nucleic Acids Research}

Table 1. Listing of Large Subunit RNA Sequences that have been completely or extensively sequenced.

\begin{tabular}{|c|c|c|c|c|c|c|}
\hline ORGANISM & RNA TYPE & LENGTH & SHORT REFERENCE & ACCESSION & FIGURE * & REFERENCE * \\
\hline \multicolumn{7}{|l|}{ A: EUBACTERIA } \\
\hline 1. Escherichia coli & $23 \mathrm{~S}$ & 2904 & PNAS 77: 2011980 & J01695 & 1 & 17 \\
\hline 2. Pseuxiomonas aezuginosa & 235 & 2893 & NAR $15: 71821987$ & Y00432 & 2 & 18 \\
\hline 3. Bacillus subtil is & $23 S$ & 2927 & GENE 37: 2611985 & $\mathrm{~K} 00637, \mathrm{M} 10606$ & 3 & 19 \\
\hline 4. Bacillus stearothermophilus & $23 S$ & 2928 & DNA 3: 3471984 & - & 4 & 20 \\
\hline \multirow{2}{*}{\multicolumn{7}{|c|}{$\begin{array}{l}\text { 5. Anacystis nidulans } \\
\text { Chloroplasts }\end{array}$}} \\
\hline & & & & & & \\
\hline $\begin{array}{l}\text { 6. Zea mảys } \\
\text { 7. Nicotiana tabacum } \\
\text { 8. Marchantia polymorpha } \\
\text { 9. Chlorella ellipsoidea }\end{array}$ & $\begin{aligned} 23 S \& 4.5 S \\
23 S \& 4.5 S \\
23 S \& 4.5 S \\
\\
23 S\end{aligned}$ & $\begin{array}{l}2981 \\
2907 \\
2914 \\
3207\end{array}$ & $\begin{array}{l}\text { NAR 9: } 28531981 \\
\text { ENB 124: } 131982 \\
\text { Nature } 322: 5721986 \\
\text { Cur.Gen. } 11: 3471987\end{array}$ & $\begin{array}{l}\mathrm{X} 01365 \\
\mathrm{~J} 01446, \mathrm{~J} 01447 \\
\mathrm{X} 04465, \mathrm{X} 01647 \\
-\end{array}$ & $\begin{array}{l}6 \\
7 \\
8 \\
9\end{array}$ & $\begin{array}{l}22 \\
23 \\
24 \\
14\end{array}$ \\
\hline Mitochondria & & & & & & \\
\hline $\begin{array}{l}\text { 10. Zea mays } \\
\text { 11. Oenothera berteriana } \\
\text { 12. Aspezgillus nidulans } \\
\text { 13. Saccharamyces cerevisiae } \\
\text { 14. Schizo. pambe } \\
\text { 15. Paramecium primaurelia } \\
\text { 16. Paramecium tetraurelia } \\
\text { 17. Homo sapiens } \\
\text { 18. Mouse } \\
\text { 19. Rat } \\
\text { 20. Bovine } \\
\text { 21. Xenopus laevis } \\
\text { 22. Drosophila yakuba } \\
\text { 23. Aedes albopictus (mosquito) } \\
\text { 24. Crithidia fasciculata } \\
\text { 25. Trypanosama brucei } \\
\text { 26. Leishmania tarentolae }\end{array}$ & 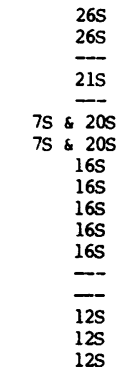 & $\begin{array}{l}3549 \\
3265 \\
2768 \\
3273 \\
2705 \\
2634 \\
2631 \\
1559 \\
1582 \\
1559 \\
1571 \\
1640 \\
1326 \\
1335 \\
1141 \\
1152 \\
1157\end{array}$ & $\begin{array}{l}\text { PLASMID 11: } 1984 \\
\text { CUr.Gen. 9: } 1985 \\
\text { NAR 10: } 47951982 \\
\text { NAR 11: } 3391983 \\
\text { ENB 169: } 5271987 \\
\text { NAR 9: } 63911981 \\
\text { JBC 259: } 51731984 \\
\text { Nature 290: } 4571981 \\
\text { Ce11 22:157 } 1980 \\
\text { NAR 9:41391981 } \\
\text { JMB 156: } 6831982 \\
\text { JBC 260: } 97591985 \\
\text { NAR 13: } 40291985 \\
\text { NAR 12: } 77711984 \\
\text { NAR 13: } 41711985 \\
\text { NAR 13: } 41711985 \\
\text { NAR 13: } 23371985\end{array}$ & 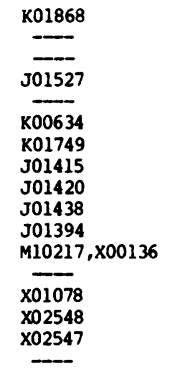 & $\begin{array}{l}11 \\
12 \\
13 \\
14 \\
15 \\
-17 \\
18 \\
19 \\
20 \\
21 \\
22 \\
23 \\
25 \\
26 \\
27\end{array}$ & $\begin{array}{l}25 \\
26 \\
27 \\
28 \\
29 \\
30 \\
31 \\
32 \\
33 \\
34 \\
35 \\
36 \\
37 \\
38 \\
39 \\
39 \\
40\end{array}$ \\
\hline \multicolumn{7}{|l|}{ B: ARCHAEBACTERIA } \\
\hline $\begin{array}{l}\text { 27. Haloooccus morrhuae } \\
\text { 28. Halobacterium halobium } \\
\text { 29. Methanooccus vanniellii } \\
\text { 30. Methanobacterium }\end{array}$ & $\begin{array}{l}235 \\
235 \\
23 s\end{array}$ & $\begin{array}{l}2927 \\
2905 \\
2958\end{array}$ & 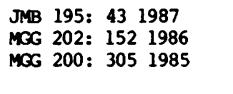 & $\overline{x 03047, x 00872}$ & $\begin{array}{l}29 \\
30 \\
31\end{array}$ & $\begin{array}{r}3 \\
41 \\
42\end{array}$ \\
\hline $\begin{array}{l}\text { themoautotrophicum } \\
\text { 31. Desulfurococcus mobil is } \\
\text { 32. Thermoproteus tenax }\end{array}$ & $\begin{array}{l}23 S \\
23 S \\
23 S\end{array}$ & $\begin{array}{l}3019 \\
3077 \\
3031\end{array}$ & $\begin{array}{ll}\text { JNB 195: } 43 & 1987 \\
\text { JMB 195: } 431987 \\
\text { NAR 15: } 4821 \quad 1987\end{array}$ & $\overline{Y 00346}$ & $\begin{array}{l}32 \\
33\end{array}$ & $\begin{array}{r}3 \\
3 \\
43\end{array}$ \\
\hline \multicolumn{7}{|l|}{ C: EUKARYOTIC CYTOPLASMIC } \\
\hline 33. Saccharanyces cerevisiae & $5.8 S \& 25 S$ & 3549 & $\begin{array}{l}\text { NAR 9: } 6953 \quad 1981 \\
\text { JBC 248: } 3860 \quad 1973\end{array}$ & J01355 & 35 & $\begin{array}{l}44 \\
45\end{array}$ \\
\hline $\begin{array}{l}\text { 34. S. carlsbergens is } \\
\text { 35. Homo sapiens }\end{array}$ & $\begin{array}{l}5.8 S \& 26 S \\
5.8 S \& 28 S\end{array}$ & $\begin{array}{l}3550 \\
5184\end{array}$ & $\begin{array}{l}\text { NAR 9: } 69351981 \\
\text { PNAS 82: } 76661985 \\
\text { NAR 4: } 2495 \quad 1977\end{array}$ & $\begin{array}{l}\text { V01285 } \\
\text { K03433,K03434 }\end{array}$ & $\overline{36}$ & $\begin{array}{l}46 \\
47 \\
48\end{array}$ \\
\hline 36. Mouse & $5.8 S \& 285$ & 4869 & $\begin{array}{l}\text { NAR 12: } 35631984 \\
\text { NAR 10: } 52731982\end{array}$ & $x 00525$ & 37 & $\begin{array}{l}49 \\
50\end{array}$ \\
\hline 37. Rat & $5.8 S \& 28 S$ & 4943 & $\begin{array}{l}\text { NAR 11: } 78191983 \\
\text { NAR 12: } 36771984 \\
\text { RIBOSOMES } 86: 391\end{array}$ & $\begin{array}{l}\text { X01069, K01591 } \\
\text { X00521 }\end{array}$ & 38 & $\begin{array}{l}51 \\
52 \\
16\end{array}$ \\
\hline 38. Xenopus laevis & $5.8 S \& 28 S$ & 4270 & $\begin{array}{l}\text { NAR 11: } 77951983 \\
\text { JBC 260: } 97591985\end{array}$ & $\mathrm{x} 00136$ & 39 & $\begin{array}{l}53 \\
54\end{array}$ \\
\hline $\begin{array}{l}\text { 39. Oriza sativa } \\
\text { 40. Caenohabditis elegans } \\
\text { 41. Physarum polycephalum }\end{array}$ & $\begin{array}{l}5.8 S \& 25 S \\
5.8 S \& 26 S \\
5.8 S \& 26 S\end{array}$ & $\begin{array}{l}3541 \\
3662 \\
3943\end{array}$ & $\begin{array}{l}\text { GENE 37: } 2551985 \\
\text { NAR 14: } 23451986 \\
\text { PNAS 80:3163 } 1983 \\
\text { NAR 10: } 23791982\end{array}$ & $\begin{array}{l}\text { M11585 } \\
\text { X03680 } \\
\text { Vo1159 }\end{array}$ & $\begin{array}{l}40 \\
41 \\
42\end{array}$ & $\begin{array}{l}55 \\
56 \\
57 \\
58\end{array}$ \\
\hline \multicolumn{7}{|l|}{ Major Partial Sequences" } \\
\hline $\begin{array}{l}\text { 43. Mycoplasma PG50 } \\
\text { 44. Apis mellifera mito. } \\
\text { 45. Dictylostell ium discoidium } \\
\text { 46. Lytechinus variegatus } \\
\text { 47. Chimpanzee }\end{array}$ & $\begin{array}{l}\frac{23 S}{5.8 S \& 28 S} \\
5.8 S \& 28 S \\
28 S\end{array}$ & $\begin{array}{r}869 \\
1267 \\
3471 \\
664 \\
1429\end{array}$ & $\begin{array}{lll}\text { NAR 15: } 1327 & 1987 \\
\text { NAR 15: } 2388 & 1987 \\
\text { NAR 12: } 4171 & 1984 \\
\text { NAR 12: } & 1737 & 1984 \\
\text { PNAS 82: } & 766 & 1985\end{array}$ & $\begin{array}{l}\overline{--} \\
\mathrm{x} 00601 \\
\mathrm{X00350} \\
\mathrm{K} 03433\end{array}$ & $\begin{array}{l}-- \\
- \\
-\end{array}$ & $\begin{array}{l}59 \\
60 \\
61 \\
62 \\
47\end{array}$ \\
\hline
\end{tabular}

* Lengths indicated represent the portion of the molecule for which sequence has been published. 
structure than is seen in E. coli or some of the other molecules but we do not as yet know what it is.

This should not be seen as bothersome but rather as defining an opportunity to obtain data from additional organisms in order to allow resolution of the problem area. In many cases the difficulty stems from the fact that too few sequences are available or too little sequence variation has been displayed in the known sequences to deduce a structure. In a few cases time did not permit a though analysis and a recognizeable structural Eeature may have been overlooked. Also the reader should realize that the comparative approach is a convergent one. The current model should at best be perceived as a minimal one awaiting the discovery of additional interactions. Thus small two and three base helices may ultimately be found even in regions in which considerable structure has already been identified as more data accumulates.

5.8S RNA, 4.5S RNA AND OTHER LARGE SUBUNIT FRAGMENTS

It is one of the pecularities of the large subunit RNA that it is sometimes genetically fragmented. The most well known example is the $5.8 \mathrm{~S}$ rRNA and its equivalents that are found in most eukaryotic organisms. This RNA has been shown $(9,10)$ to be homologous to approximately the first 150 positions of the $E$. coli $23 S$ rRNA. Although genetically distinct it interacts with the large subunit RNA through base pairing. In effect then the two together form a single RNA with a backbone nick in one of its loops. The same phenomenon is also seen at the $3^{\prime}$ end of several chloroplast large subunit RNAs where the last 100 or so bases are separately encoded as a 4.5S RNA (11). In this case the homology to the E. coli $3^{\prime}$ terminus is obvious but the the mechanism by which the $4.5 \mathrm{~S}$ IRNA and the main large subunit RNA component are held together is not. The most extreme case of this fragmentation phenomenon that is known is in Crithidia Easciculata where the large subunit RNA is actually assembled from six fragments plus a 5.8S IRNA (12). These various fragmentation phenomenon are indicated on the diagram by labels that indicate where the respective $5^{\prime}$ and $3^{\prime}$ ends are located. The Crithidia fragments are labeled with the same lower case letters that were used in the original publication (12) and numbered as if they were a single large RNA.

\section{OVERLAY DIAGRAMS AND COLLECTION ARRANGEMENT}

It is very useful in comparing structures to produce overlay diagrams that display one structure relative to another. Several such diagrams are included here. In each case the underlying structure is that of E. coli. Where the E. coli is unique it can be seen as a light gray. The bold structure is that of the other organism indicated in the legend. Base numbers on these diagrams always refer to E. coli. These overlay figures show immediately where the sites of structural variation between the two RNAs are located. The overlay figures are used to introduce the various sections of the collection. In each case a particularly representative overlay is chosen so that the major variations in the group relative to $E$. coli can be seen. The collection begins with the five eubacterial sequences. 
These are virtually identical structurally and therefore no overlay figure is included. They are followed by the four chloroplast figures which again follow the virtually identical structural pattern. The Anacystis sequence used was arbitrarily that of Douglas and Doolittle (13). The plant chloroplasts all have a detached $4.5 \mathrm{~S}$ at the $3^{\prime}$ terminus but the alga, Chlorella ellipsoidea does not. The $C$. ellipsoidea sequence also is unusal in that it is claimed to contain an intron (14). We believe that this assertion is not convincingly established and thus the putative intron is shown on Figure 9 a as an insertion region of class D. Several large subunit sequences have an insertion at this location. If the c. ellipsoidea insertion is in fact an intron this would be very atypical as none of the known large subunit introns correspond with common insertion regions. It is possibile that experimental difficulties may have arisen due to the propensity of large subunit RNAs such as E. coli 23S rRNA (15) to readily fragment. The location of this fragmentation site has been localized in E. coli (1) to the region of the RNA that corresponds to that which contains the putative intron in C. ellipsoidea.

The largest portion of the collection contains the mitochondrial sequences. These are assembled into three groups each prefaced by a separate overlay figure. The first and most internally variable group are those with large mitochondrial RNAs as typified by the overlay of zea mays, Fig. 10. These mitochondrial RNAs resemble the eubacterial ones in size and structure more than any of the other mitochondria do. Nevertheless they are marked by considerable varibility even within the group. One unifying feature is the presence of an unstructured region $H$ in the vicinity of E. coli position 1400 in all cases. Structures are provided for all of these RNAs except Paramecium tetraaurelia which is virtually identical to P. primaurelia, Fig. 15. and Schizosaccharomyces pombe which was published after the structures were completed. The second major mitochondrial group are the rather small 165 RNAs that are found in most higher organisms. Although much smaller, as the human overlay shows, Fig. 16, considerable structural similarity with the eubacterial RNAs continues to exist. Finally the three kinetoplast mitochondrial 125 ERNAs follow. Here as is indicated by the overlay, Fig. 24, virtually none of the structure in the $5^{\prime}$ half of the molecule is preserved, though considerable structural conservation does exist in the $3^{\prime}$ half of the molecule.

The remaining figures are devoted to the archaebacteria and eucaryotic cytoplasm. As indicated by the Halococcus morrhuae structural overlay, Fig. 28, the archaebacteria exhibit significant variation that exceeds anything that is seen among the eubacteria alone. Close examination of the archaebacterial figures also reveals that unlike the eubacteria, the archaebacteria, do exhibit some variation within the group as a whole. A figure is not included for Thermoproteus tenax because this sequence was inadvertantly overlooked. The main theme from the eucaryotic cytoplasmic sequences sems to be growth in size. Although not all the RNAs exhibit the effect to the same extent it is clear that several regions seem to be favored for macroscopic insertions of new material. As indicated by the Saccharomyces cerevisiae overlay, Fig. 34, the main theme of 
secondary structure is again repeated in the eukaryotic cytoplasmic RNAs. Excluding the large insertions, the eukaryotic RNA structure is remarkably like that of the eubacteria and archaebacteria. The sequence of $S$. carlsbergenesis $26 \mathrm{~S}$ rRNA is very similar to that of $S$. cerevisiae and thus is not shown as a separate figure. In the case of rat, the corrected sequence (16) has been chosen for the figure presented here.

AVAILABILITY AND ACCURACY OF THE DATA

The sequences presented here are maintained in aligned data bases according to phylogenetic type. Due to the numerous macroscopic insertions and deletions no attempt is made to maintain a single aligned data base of all the sequences. We therefore cannot provide such an aligninent on electronic medium. We can however provide individual sequences. Alternatively the interested reader may get sequences directly from the electronic databases. When base ambiguity existed the IUPAC nomenclature recommendations were followed. Post-transcriptional modifications have not been indicated since these have not been determined in most cases. The reader should be aware however that the large rRNAs do have a number of such modified nucleotides. In the case of the 5.8S rRNAs which mostly have been sequenced at the RNA level the post-transcriptional modifications are frequently known, though not indicated here. The sequences presented here and the position number labels have been extensively checked but nevertheless may contain an occasional error. The structures themselves are the best we currently have available. Although occasionally a helix indicated may be in error it is far more likely that one will have been overlooked. Readers are invited to inform us about errors and ommissions of published sequences.

\section{ACKNOWLEDGEMENTS}

Dr. Robin Gutell's efforts in this undertaking were supported by NIH grant \#GM-17129 to Dr. Harry F. Noller of the University of Santa Cruz and NASA grant NSG-7044 to Dr. Carl R. Woese at the University of Illinois. Dr. George E. Fox's efforts were supported by NASA grant NSG-7440 and NIH grant GM-37655.

*Present address: GENPROBE Inc., 9880 Campus Point Drive, San Diego, CA 92121, USA

\section{REFERENCES}

1. Noller,H.F., Kop,J.A., Wheaton,V., Brosius,J., Gutell,R.R., Kopylov,A.M., Dohme,F., and Herr,W. (1981) Nucl. Acids Res. 9,6167-6189.

2. Noller,H.F. (1984) Ann. Rev. Biochem. 53, 119-162.

3. Leffers,H., Kjems,J., Ostergaard,L., Larsen,N., and Garrett,R.A. (1987) J. Mol. Biol. 195,43-61.

4. Holley,R.W., Apgar,J., Everett,G.A., Madison,J.T., Marquise,M., Merrill,S.H., Penswick,J.R., and Zamir,A., (1965) Science 147, 1462-1465.

5. Fox,G.E. and Woese,C.R. (1975) J.Mol.Evol. 6, 61-76.

6. Gutell,R., Weiser,B., Woese,C.R., and Noller,H.F. (1985) Prog. Nucl. Acids Res. Mol. Biol. 32,155-216.

7. Fox,G.E.. (1985) in "The Bacteria" (C.R. Woese and R.S. Wolfe, eds.) 9,257-310. 
8. Olsen,G.J. (1983) Ph.D. thesis, Univ. Colorado

9. Nazar,R.N. (1980) FEBS Lett. 119,212-214.

10. Walker,W.F. (1981) FEBS Lett. 126,150-151.

11. Mackay,R.M. (1981) FEBS Lett. 123,17-18.

12. Spencer,D.F., Collings,J.C., Schnare,M.N., and Gray, M.W., (1987) EMBO J. 6,1063-1071.

13. Douglas,S.E. and Doolittle,W.F. (1984) Nucleic Acids Res. $12,3373-3386$.

14. Yamada,T., and Shimaji,M. (1987) Curr.Genet. 11, 347-352.

15. Allet,B., and Rochaix,J.D., (1979) Cell 18,55-60

16. Wool,I.G. (1986) in Hardesty,B. and Kramer,G. (eds.), Structure, Function and Genetics of Ribosomes, Springer-Verlag, pp.391-412.

17. Brosius,J., Dull,T.J., and Noller,H.F. (1980) Proc. Natl. Acad. Sci. USA 77,201-204.

18. Toschka,H.Y., Hopfl,P., Ludwig,W., Schleifer,K.H., Ulbrich, N. and Erdmann,V.A. (1987) Nucleic Acids Res. 15,7182.

19. Green, C.J., Stewart, G.C., Hollis, M.A., Vold, B.S. and Bott, K.F. (1985) Gene 37,261-266.

20. Kop, J., Wheaton, V., Gupta, R., Woese, C.R. and Noller, H.F. (1984) DNA 3:347-357.

21. Kumano,M., Tomioka,N. and Sugiura,M. (1983) Gene 24,219-225.

22. Edwards,K. and Kossel,H. (1981) Nucleic Acids Res. 9, 2853-2860.

23. Takaiwa,F. and Sugiura,M. (1982) Eur.J.Biochem. 124,13-19.

24. Ohyama,K., Fukuzawa,H., Kohchi,T., Shirai,H,., Sano,T., Sano,S., Umesono,K., Shiki,Y., Takeuchi,M., Chang,Z., Aota,S., Inokuchi,H., Ozeki,H. (1986) Nature 322, 572-574.

25. Dale,R.M.K., Mendu,N., Ginsburg,H. and Kridl,J.C. (1984) Plasmid 11,141-150.

26. Manna,E. and Brennicke,A. (1985) Curr. Genet. 9,505-515.

27. Kochel,H.G. and Kuntzel,H. (1982) Nucleic Acids Res. 10, 4795-4801.

28. Sor,F. and Fukuhara,H. (1983) Nucleic Acids Res. 11,339-348

29. Lang,B.F., Cedergren,R., and Gray,M.W. (1987) Eur. J. Biochem. 169, 527-537.

30. Seilhamer,J.J. and Cummings,D.J. (1981) Nucleic Acids Res. 9,6391-6406.

31. Seilhamer,J.J., Gutell,R.R., and Cummings,D.J., (1984) J. Biol. Chem. 259, 5173-5181.

32. Anderson,S., Bankier,A.T., Barrell,B.G., de Bruijn,M.H.L., Coulson, A.R., Drouin,J., Eperon,I.C., Nierlich,D.P., Roe, B.A., Sanger,F., Schreier,P.H., Smith,A.J., Staden,R. and Young,I.G. (1981) Nature 290, 457-465.

33. van Etten,R.A., Walberg,M.W., and Clayton,D.A. (1980) Cell $22,157-170$.

34. Saccone,C., Cantatore,P., Gadaleta,G., Gallerani,R., Lanave, C.. Pepe,G. and Kroon,A.M. (1981) Nucleic Acids Res. 9.4139-4148.

35. Anderson,A., de Bruijn,M.H.L., Coulson,A.R., Eperon,I.C., Sanger,F. and Young,I.G. (1982) J. Mol. Biol. 156, 683-717.

36. Roe, B.A., Ma, D-P., Wilson, $\mathrm{R}: \mathrm{K}$, , and Wong, J.F-H. (1985) J. Biol. Chem. 260,9759-9774.

37. Clary,D.O. and Wolstenholme,D.R. (1985) Nucleic Acids Res. $13,4029-4045$.

38. HsuChen,C-C., Kotin,R.M. and Dubin,D.T. (1984) Nucleic Acids Res. $12,7771-7785$. 
39. Sloof,P., Van den Burg,J., Voogd,A., Benne,R., Agostinelli, M., Borst,P., Gutell,R., and Noller,H. (1985) Nucleic Acids Res. 13,4171-4190.

40. de la Cruz, V.F., Simpson, A.M., Lake, J.A. and Simpson, L. (1985) Nucleic Acids Res. 13,2337-2354.

41. Mankin, A.S. and Kagramanova, V.K. (1986) Mol. Gen. Genet. 202,152-161.

42. Jarsch,M. and Bock, A. (1985) Mol. Gen. Genet. 200, 305-312.

43. Kjems,J., Leffers,H., Garrett,R.A., Wich,G., Leinfelder,W.. and Bock,A. (1987) Nucleic Acids Res. 15,4821-4835.

44. Georgiev,O.I., Nikolaev,N., Hadjiolov,A.A., Skryabin,K.G., Zakharyev,V.M. and Bayev,A.A. (1981) Nucleic Acids Res.9, 6953-6958.

45. Rubin,G.M. (1973) J. Biol. Chem. 248,3860-3875.

46. Veldman,G.M., Klootwijk,J., de Regt,V., Planta,R.J., Branlant,C., Krol,A. and Ebel,J-P. (1981) Nucleic Acids Res. 9,6935-6952.

47. Gonzalez,I.L., Gorski,J.L., Campen,T.J., Dorney,D.J., Erickson,J.M., Sylvester,J.E. and Schmickel,R.D. (1985) Proc. Natl. Acad. Sci. USA 82,7666-7670.

48. Khan,M.S.N. and Maden,B.E.H. (1977) Nucleic Acids Res. 4,2495-2505.

49. Hassouna,N., Michot,B. and Bachellerie,J-P. (1984) Nucleic Acids Res. 12,3563-3583.

50. Michot,B., Bachellerie,J.P., and Raynal,F. (1982) Nucleic Acids Res. 10,5273-5283.

51. Chan,Y.L., Olvera,J., and Wool,I.G. (1983) Nucleic Acids Res. $11,7819-7831$.

52. Hadjiolov,A.A., Georgiev,O.I., Nosikov,V.V., and Yavachev,L.P., (1984) Nucleic Acids Res. 12, 3677-3693.

53. Ware,V.C., Tague,B.W., Clark,C.G., Gourse,R.L., Brand,R.C. and Gerbi,S.A. (1983) Nucleic Acids Res. 11,7795-7817.

54. Roe,B.A., Ma,D.-P., Wilson,R.K., and Wong,J.F.H. (1985) J. Biol. Chem. 260, 9759-9774.

55. Takaiwa,F., Oono,K., Iida,Y. and Sugiura,M. (1985) Gene 37, 255-259.

56. Ellis,R.E., Sulston,J.E. and Coulson,A.R. (1986) Nucleic Acids Res. 14,2345-2364.

57. Otsuka,T., Nomiyama,H., Yoshida,H., Kukita,T., Kuhara,S., and Sakaki,y. (1983) Proc. Natl. Acad. Sci. USA 80, 3163-3167.

58. Otsuka,T. Nomiyama,H., Sakaki,Y., and Takagi,Y. (1982) Nucleic Acids Res. 10, 2379-2385.

59. Rasmussen,O.F. and Christiansen (1987) Nucleic Acids Res. 15,1327 .

60. Vlasak,I., Burgshwaiger,S. and Kreil,G. (1987) Nucleic Acids Res. 15,2388.

61. Ozaki,T., Hoshikawa,Y, Iida,Y. and Iwabuchi,M. (1984) Nucleic Acids Res. 12,4171-4184.

62. Hindenach,B.R. and Stafford,D.W. (1984) Nucleic Acids Res. 12, 1737-1747. 


\section{Nucleic Acids Research}

Secondary Structure of eubacterial 23S Ribosomal RNA: Escherichia coli
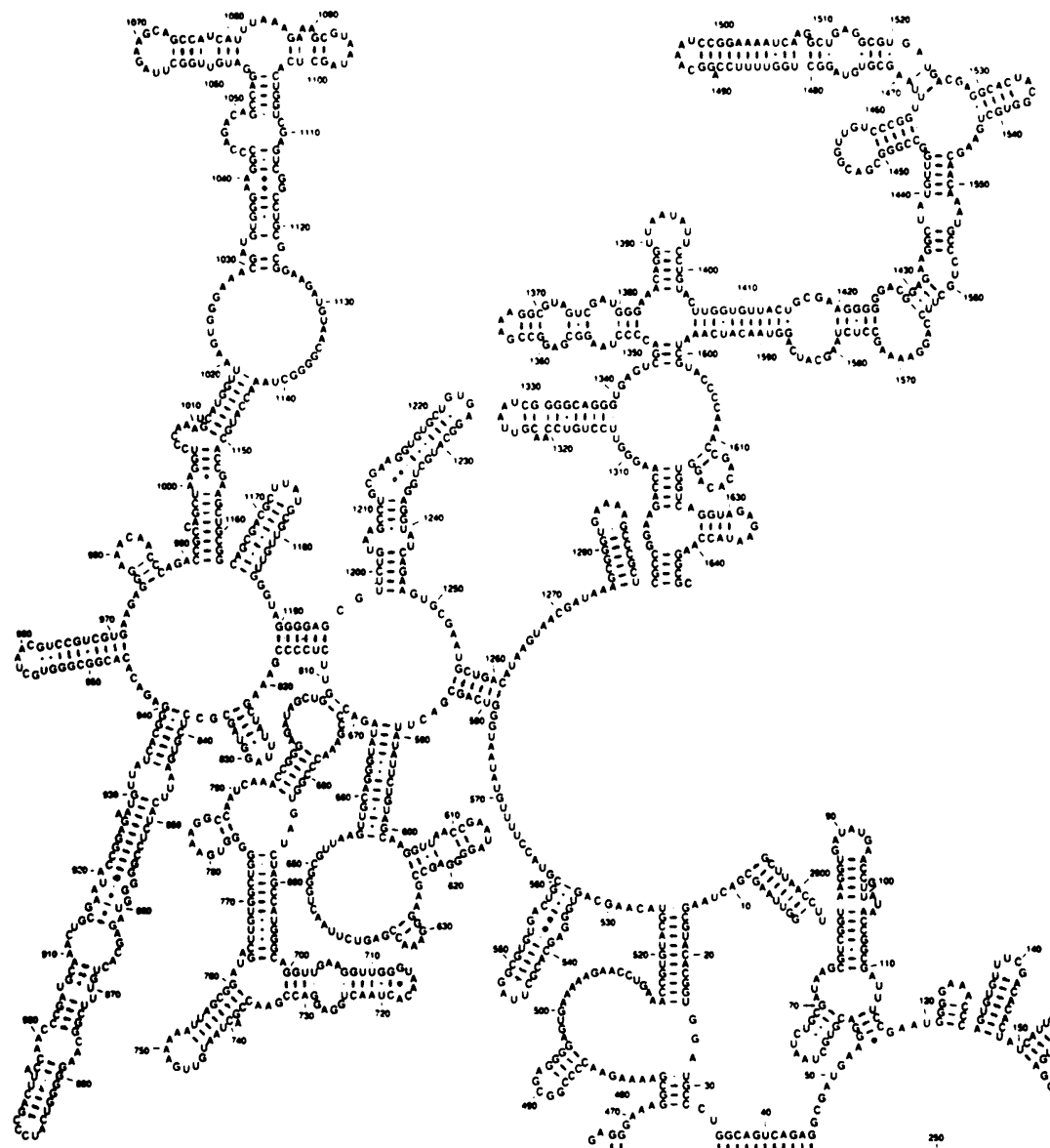

Fig. Io

Escherichio coll

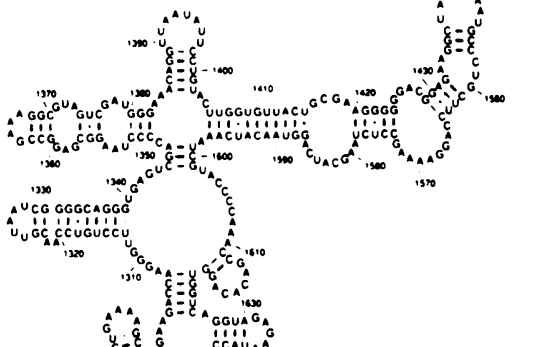

$200-8$

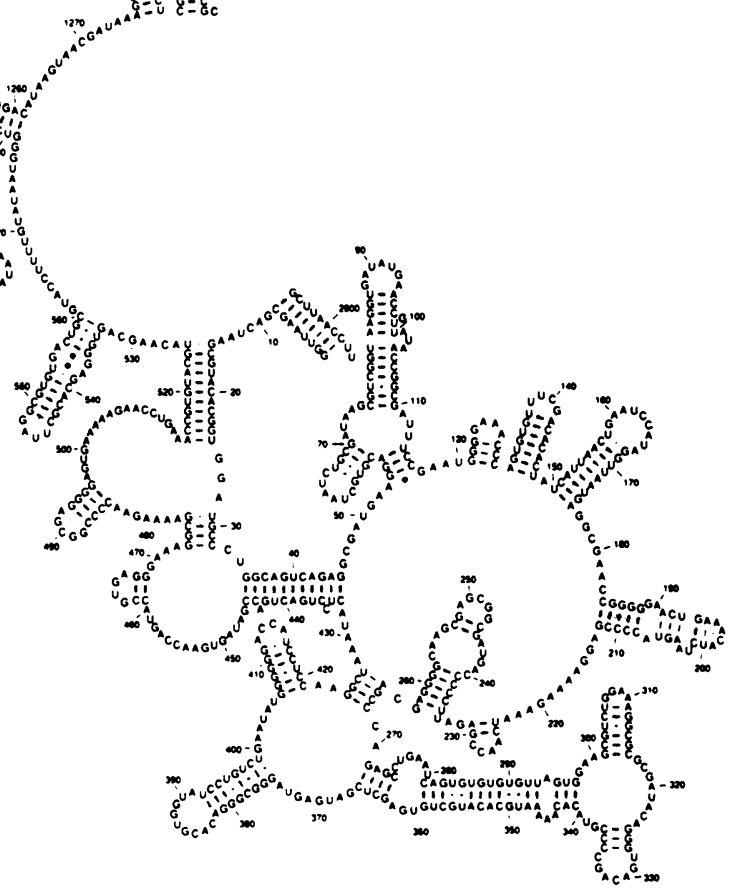




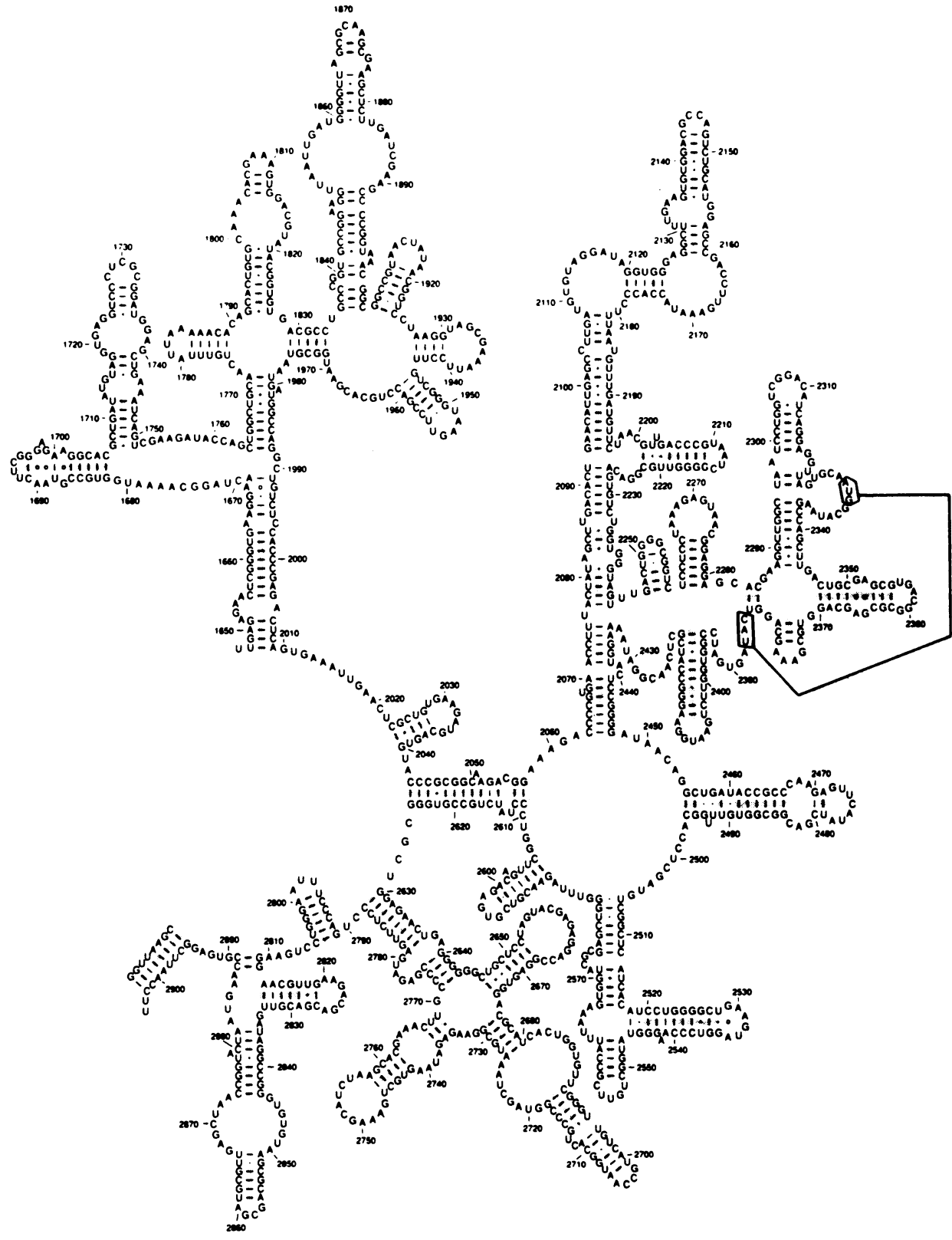

Fig. Ib

Escherichio coli 
Secondary Structure of eubacterial 23S Ribosomal RNA: 5 'half

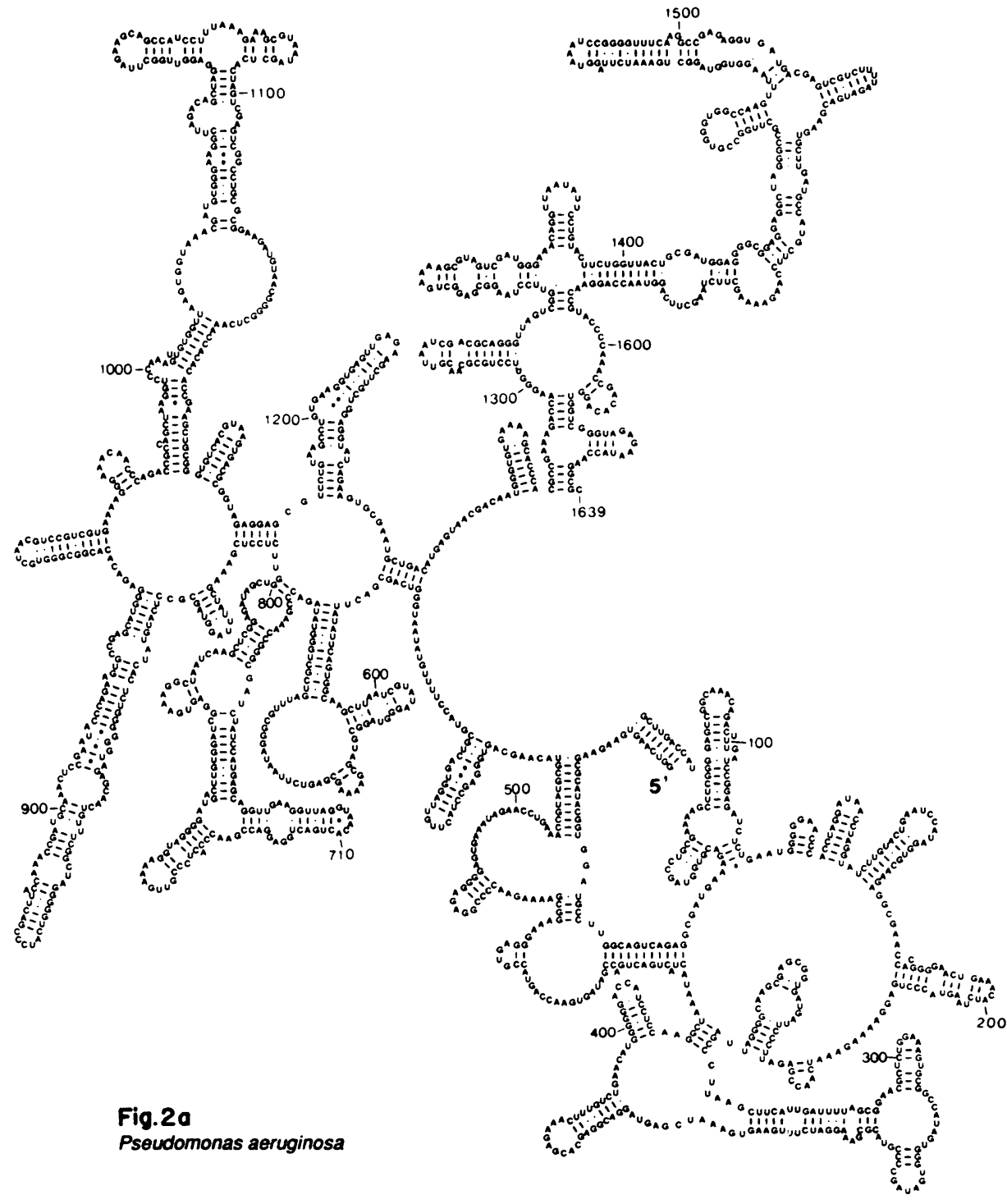


Secondary Structure of eubacterial 23S Ribosomal RNA: 3'half

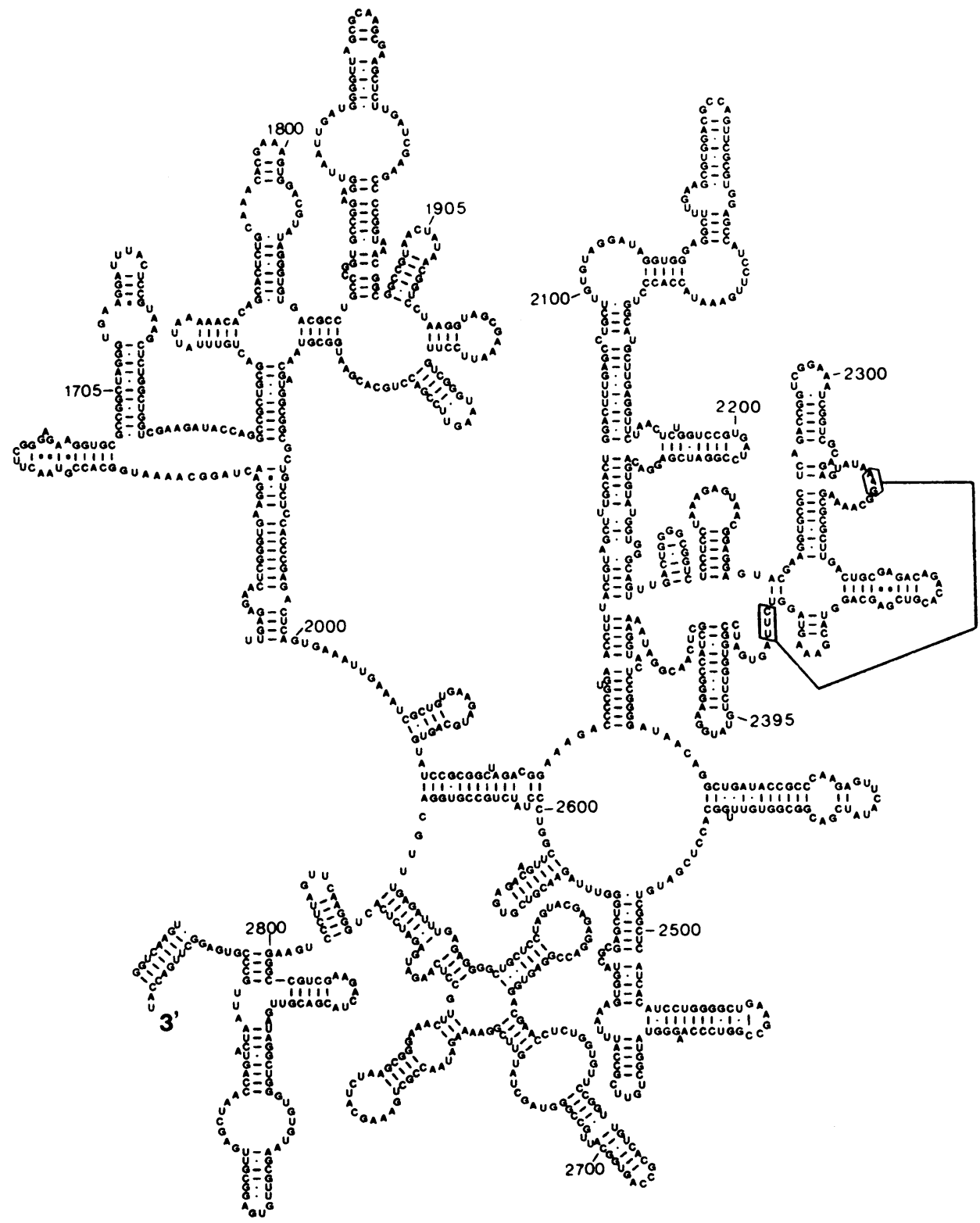

Fig.2b

Pseudomonas aeruginosa 
Secondary Structure of eubacterial 23S Ribosomal RNA: 5 'half

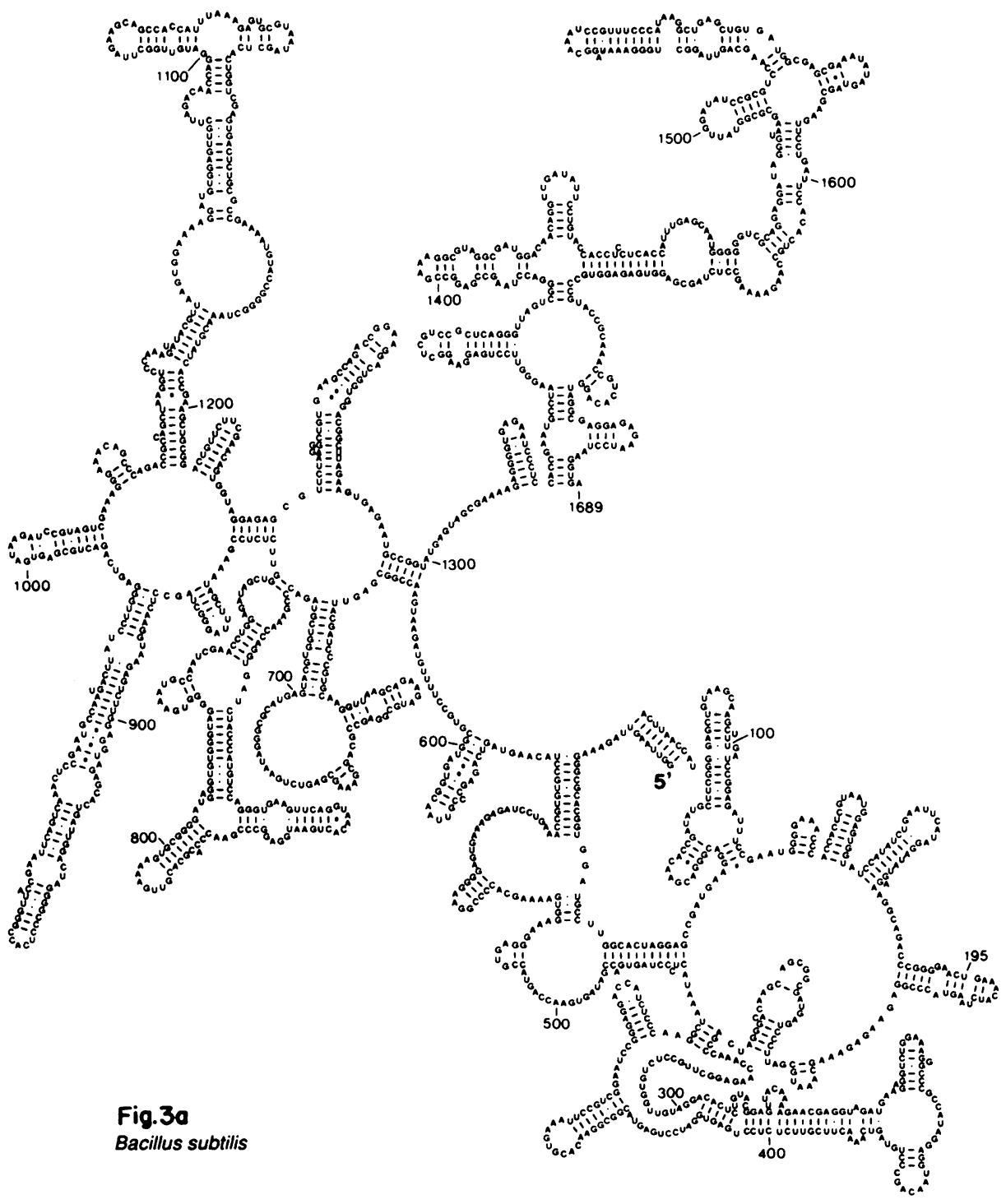


Secondary Structure of eubacterial 23S Ribosomal RNA: 3'half

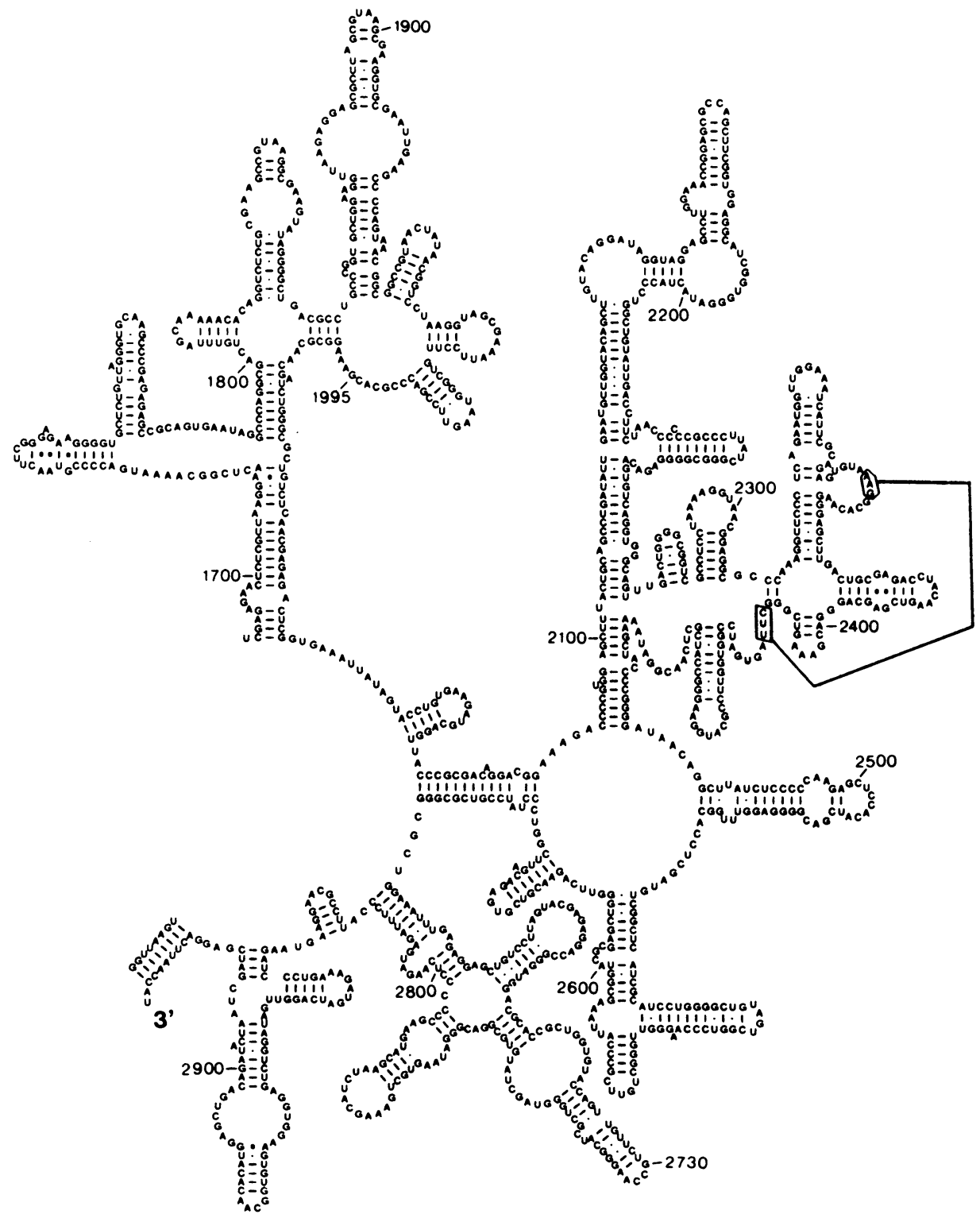

Fig.3b

Bacillus subtilis 
Secondary Structure of eubacterial 23S Ribosomal RNA: 5'half

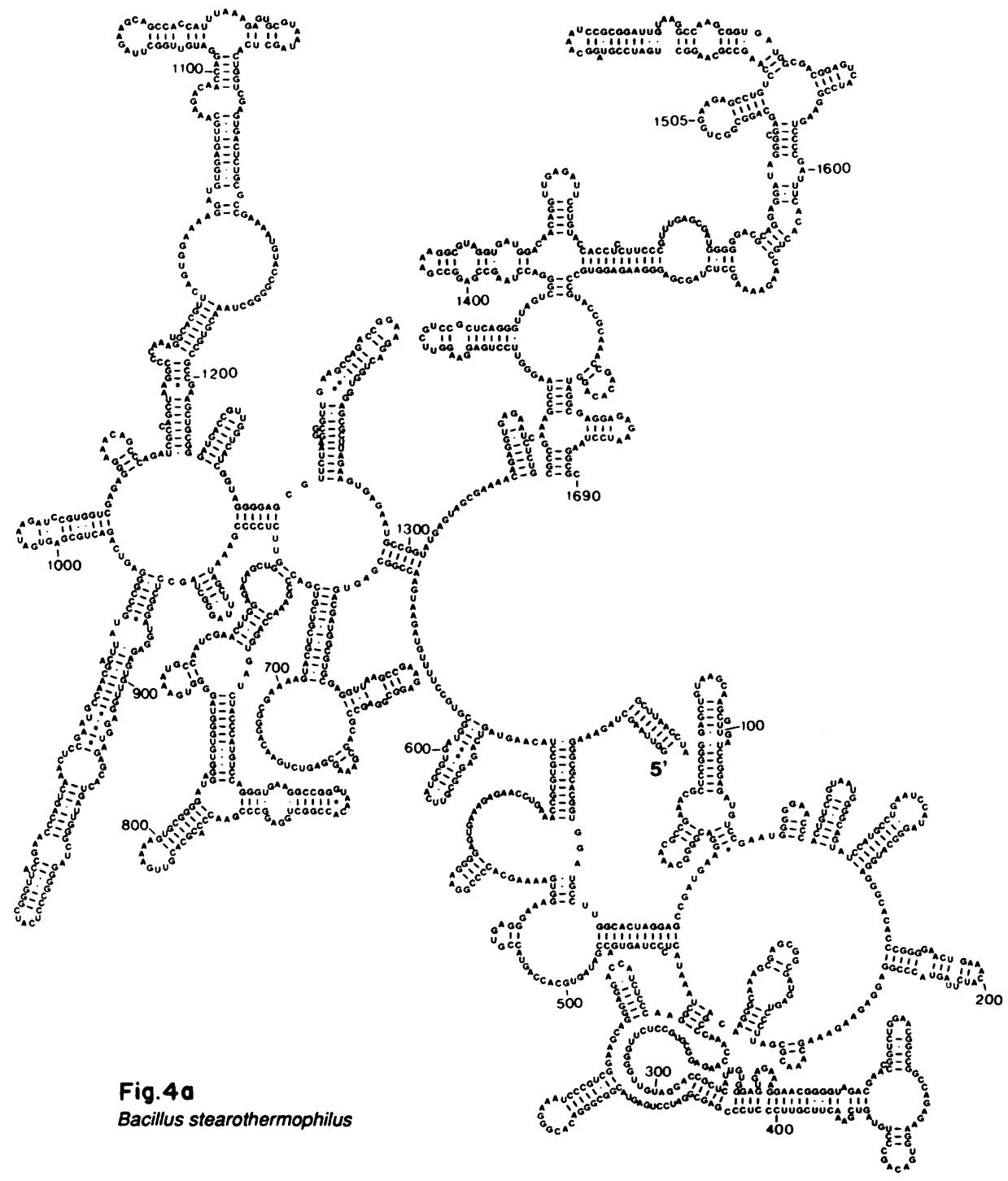


Secondary Structure of eubacterial 23S Ribosomal RNA: 3 'half

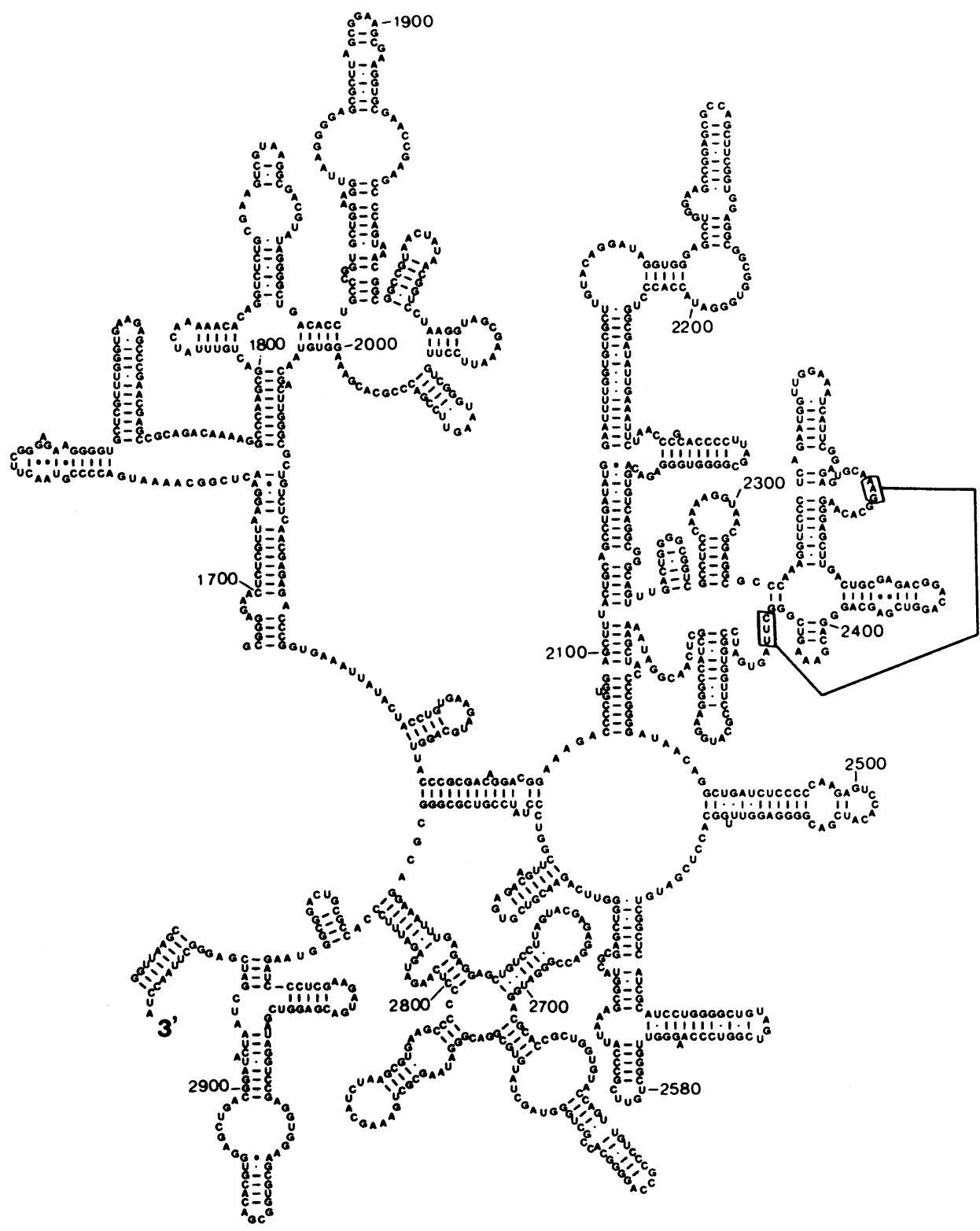

Fig.4b

Bacillus stearothermophilus 
Secondary Structure of eubacterial 23S Ribosomal RNA: 5'half

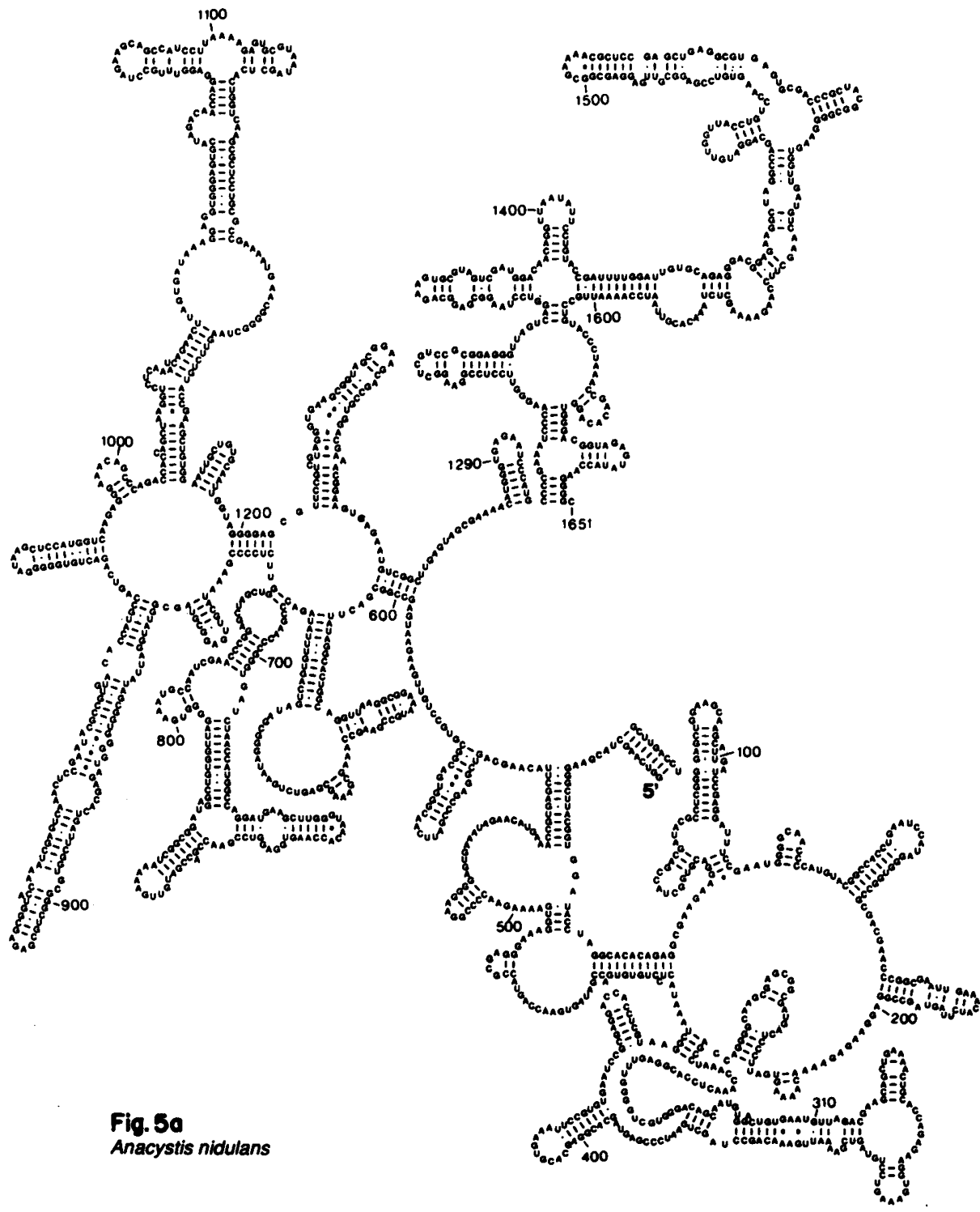


Secondary Structure of eubacterial 23S Ribosomal RNA: 3'half

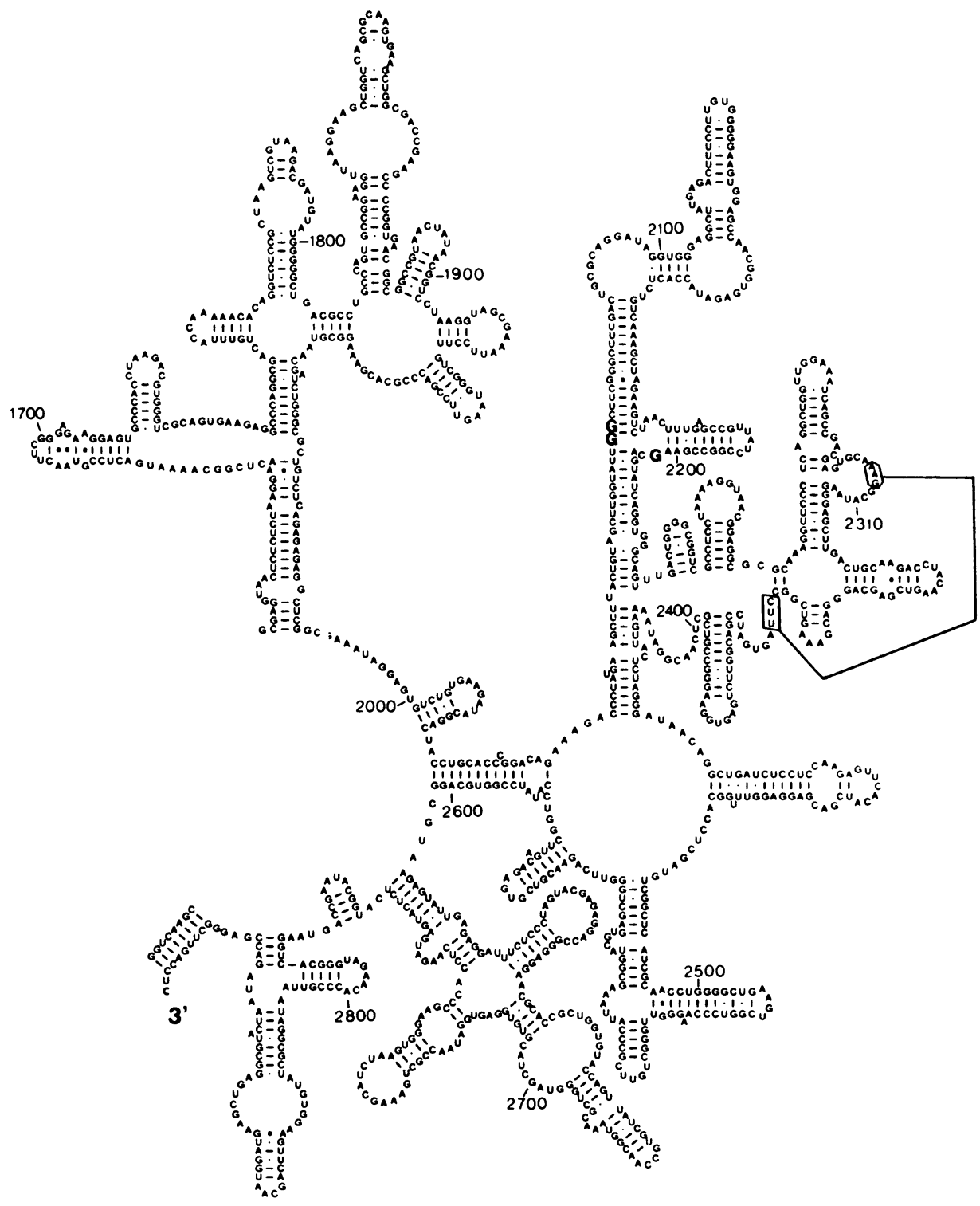

Fig.5b

Anacystis nidulans 
Secondary Structure of chloroplast 23S Ribosomal RNA: 5'half
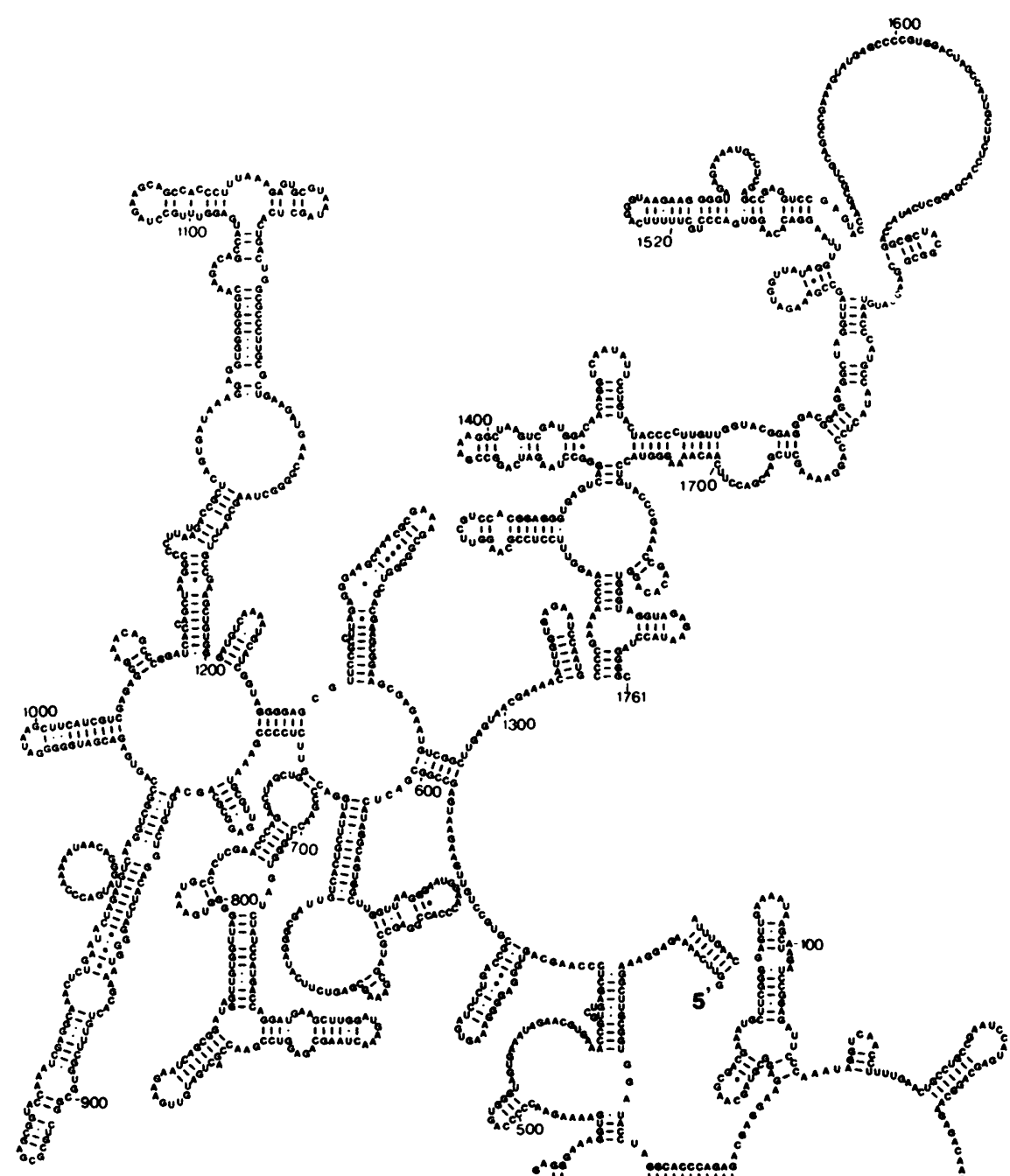

Fig.6a

Zea mays

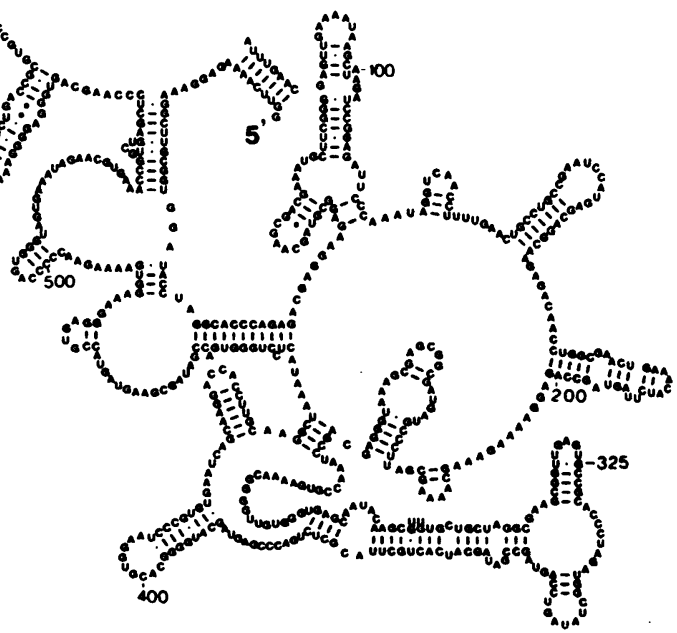


Secondary Structure of chloroplast 23S Ribosomal RNA: 3 'half

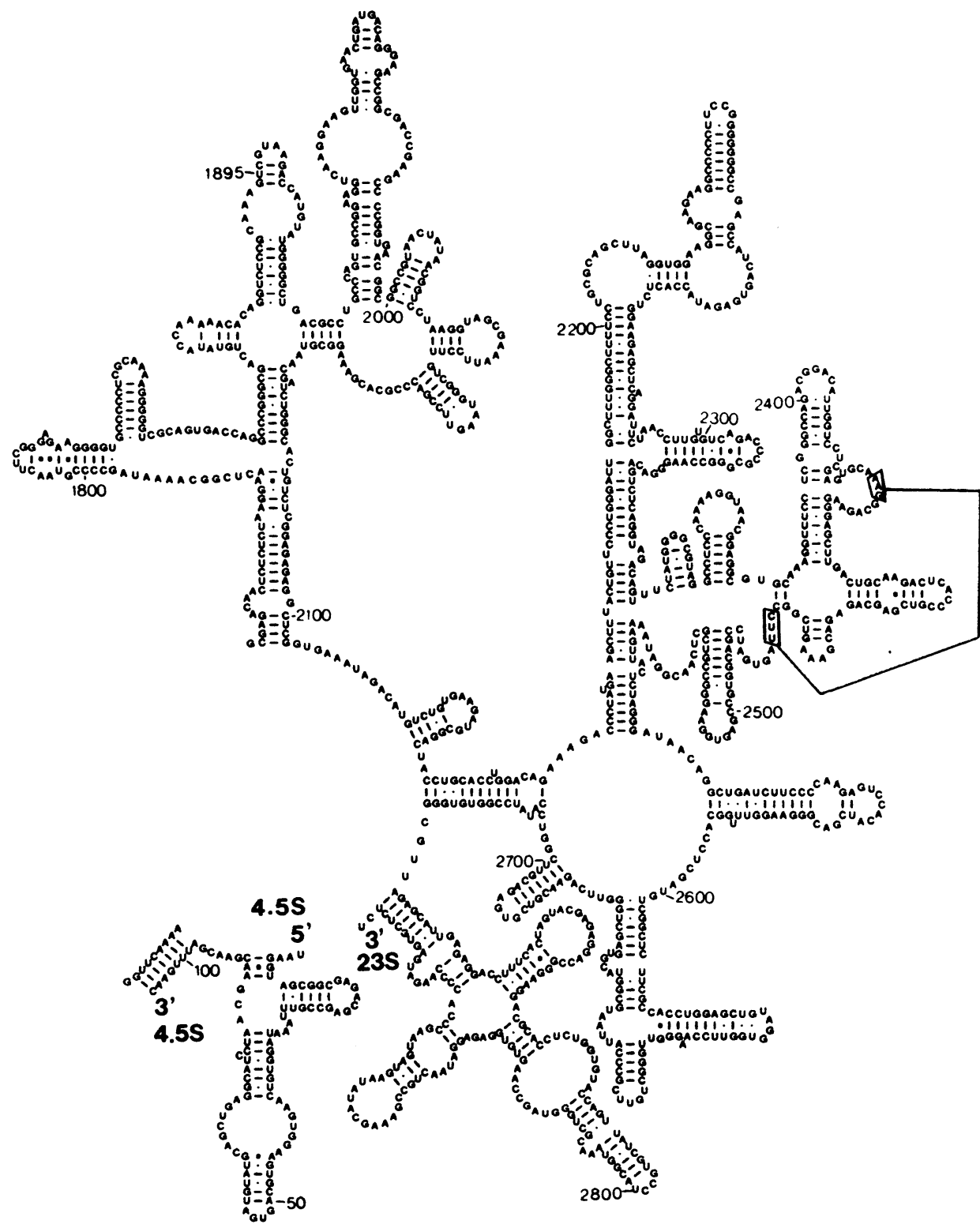

Fig.6b

Zea mays 
Secondary Structure of chloroplast 23S Ribosomal RNA: 5'half

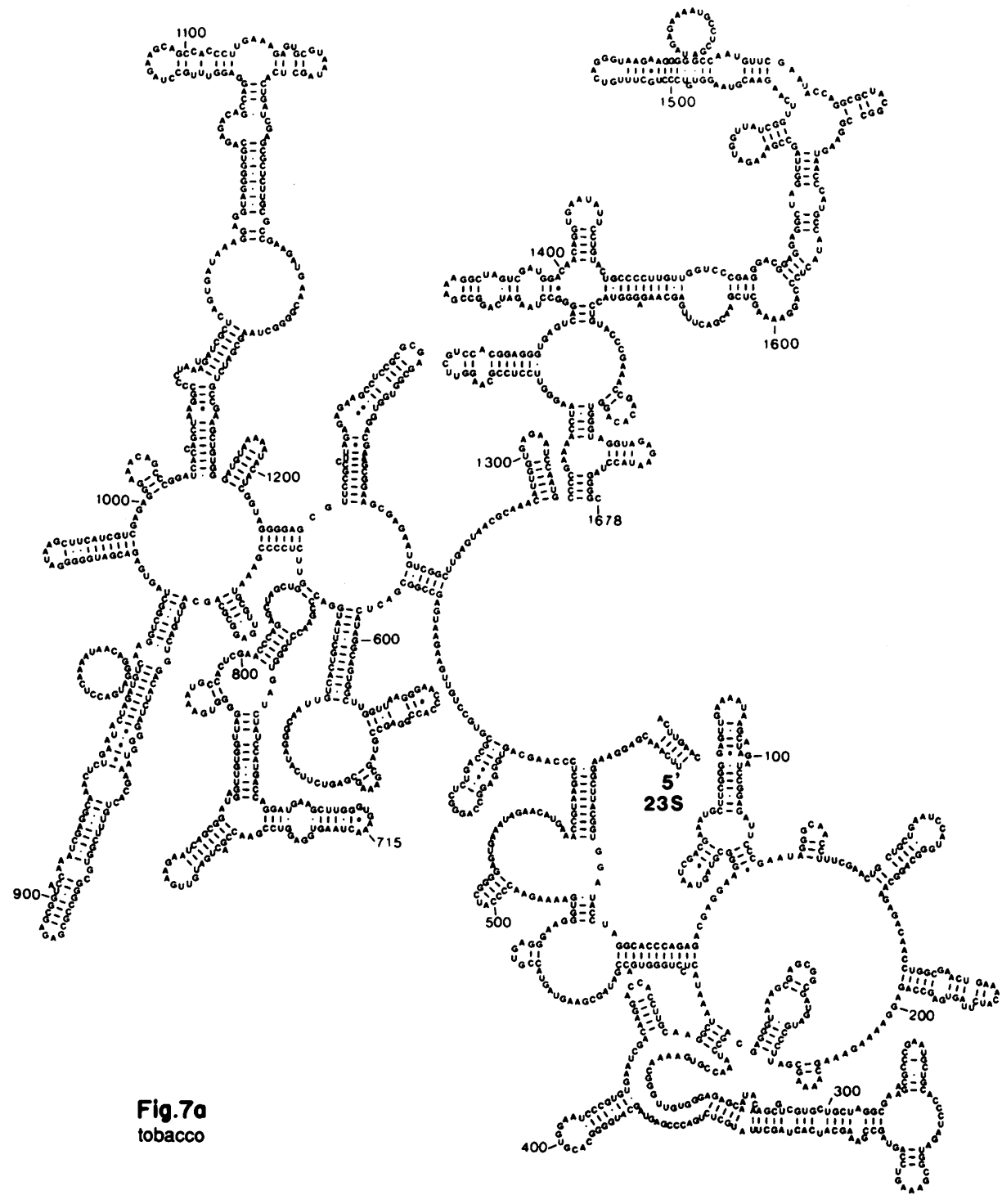


Secondary Structure of chloroplast 23S Ribosomal RNA: 3 'half

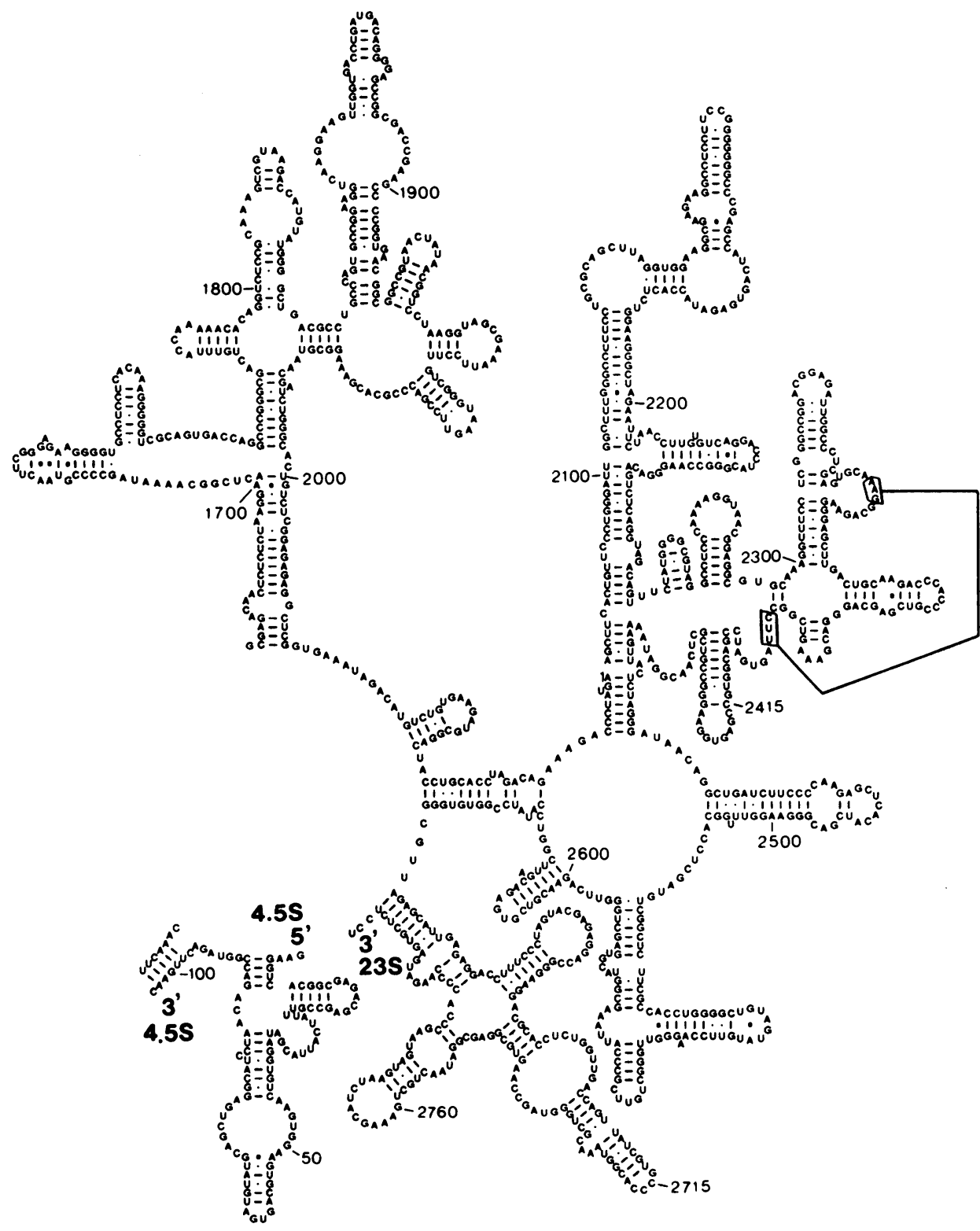

Fig. 7b

tobacco 
Secondary Structure of chloroplast 23S Ribosomal RNA: 5'half

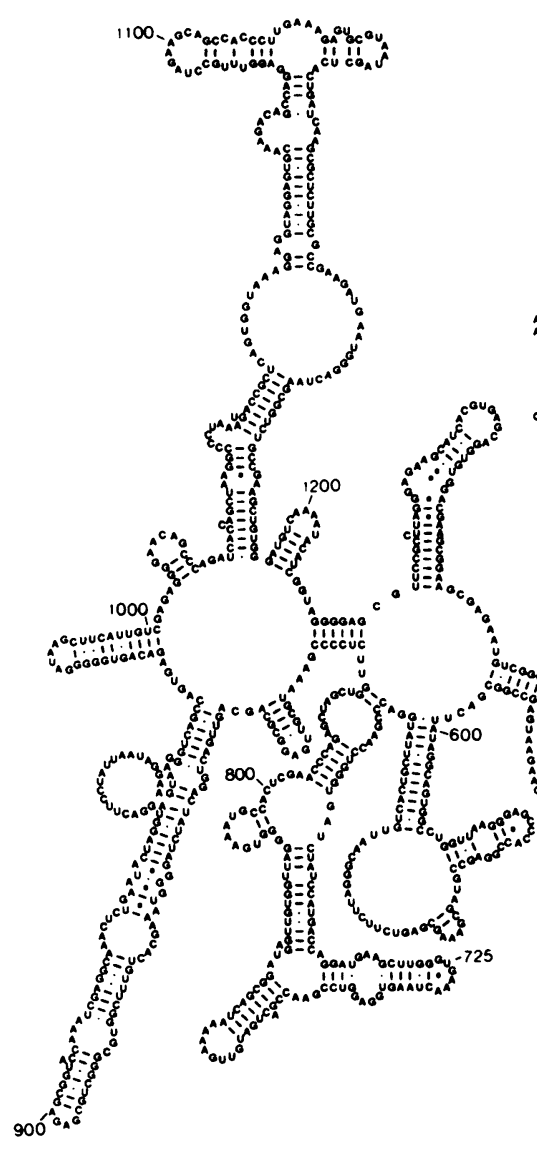

Fig.8a

Marchantia polymorpha: livenwort

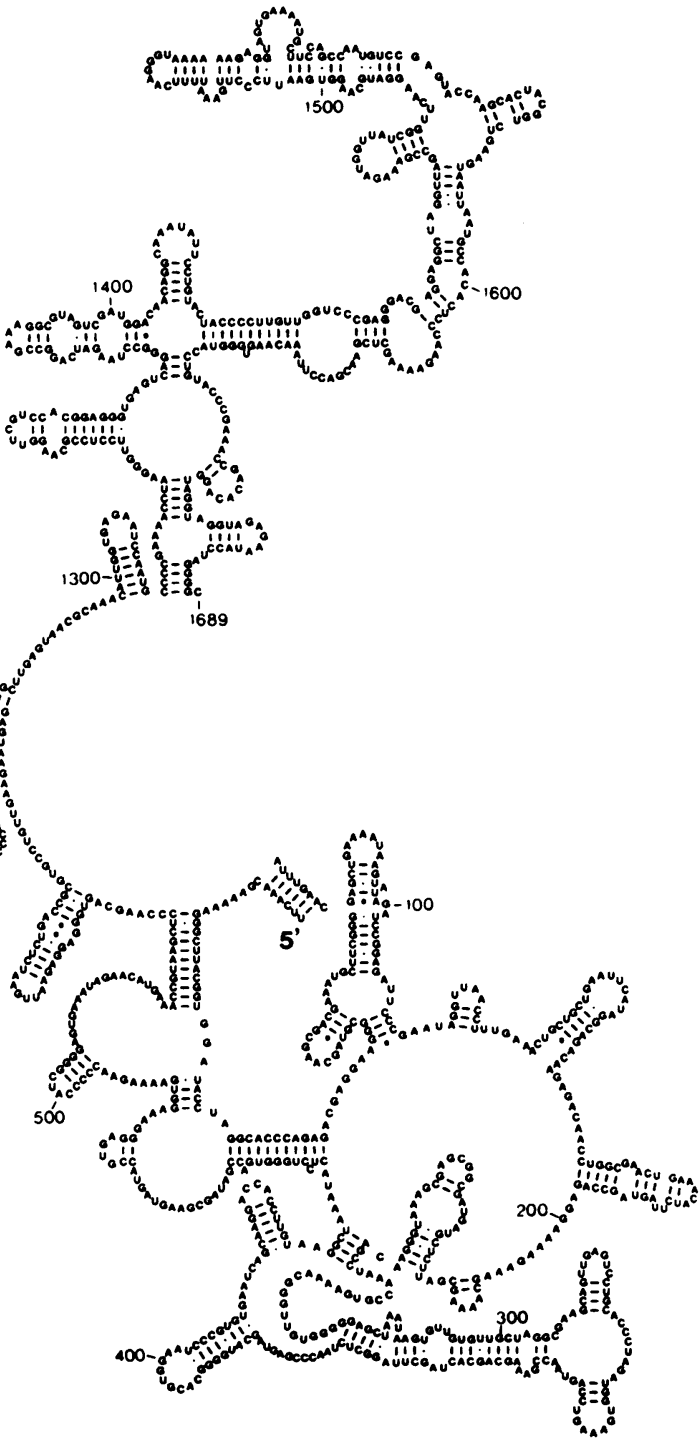


Secondary Structure of chloroplast 23S Ribosomal RNA: 3'half

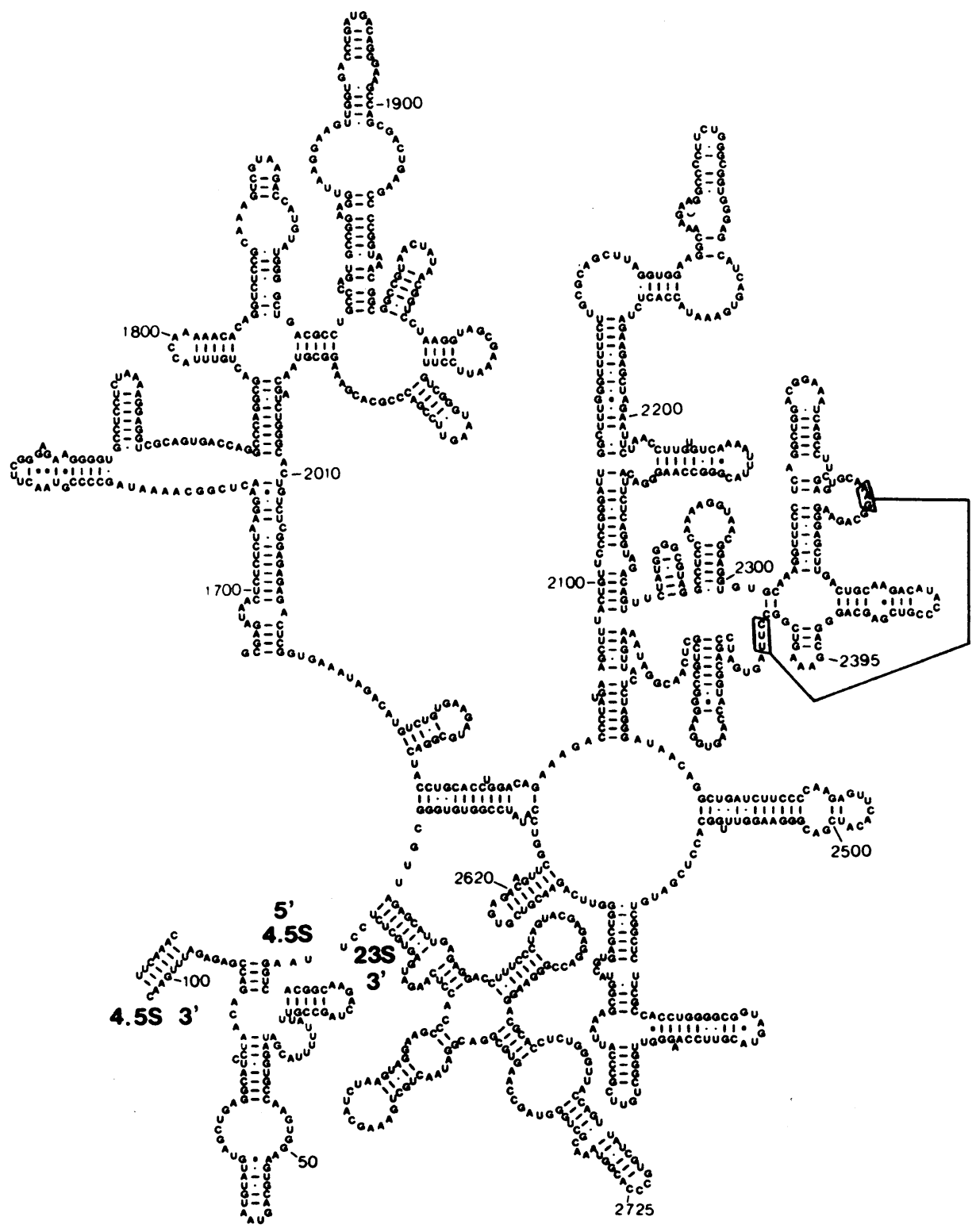

Fig. 8b

Marchantia polymorpha: liverwort 


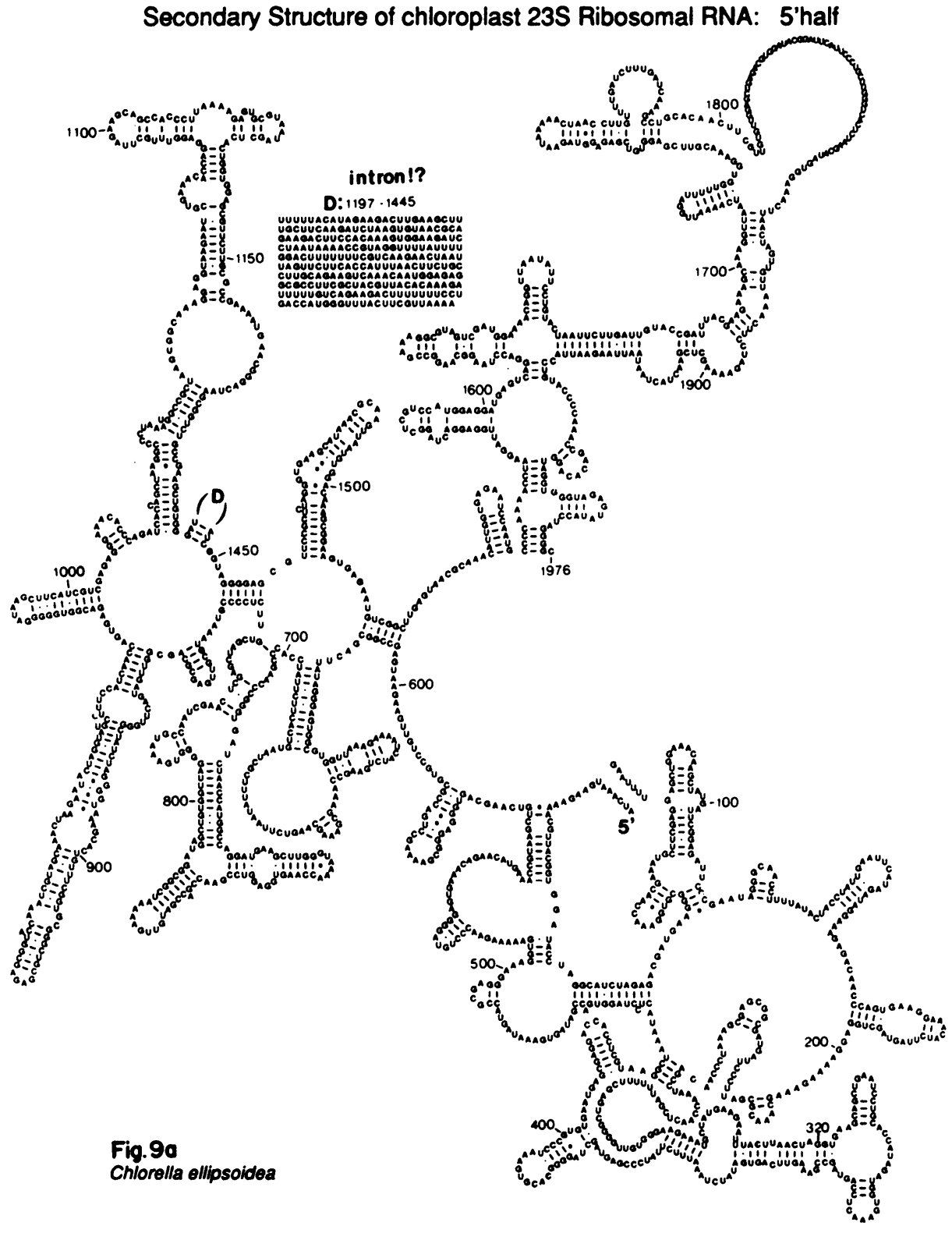




\section{Secondary Structure of chloroplast 23S Ribosomal RNA: 3'half}

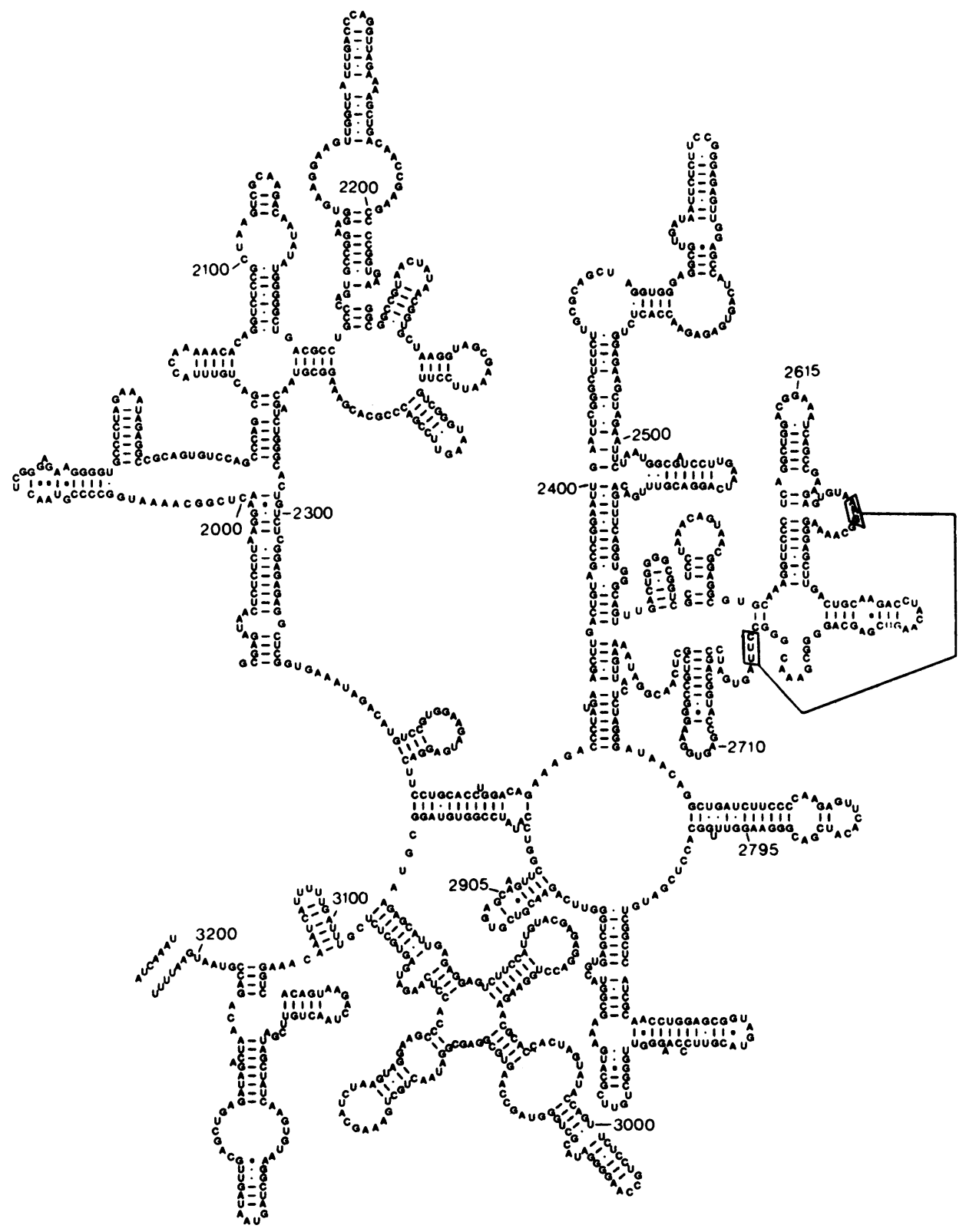

Fig.9b

Chlorella ellipsoidea 
Secondary Structure of mitochondrial 23S Ribosomal RNA: 5'half
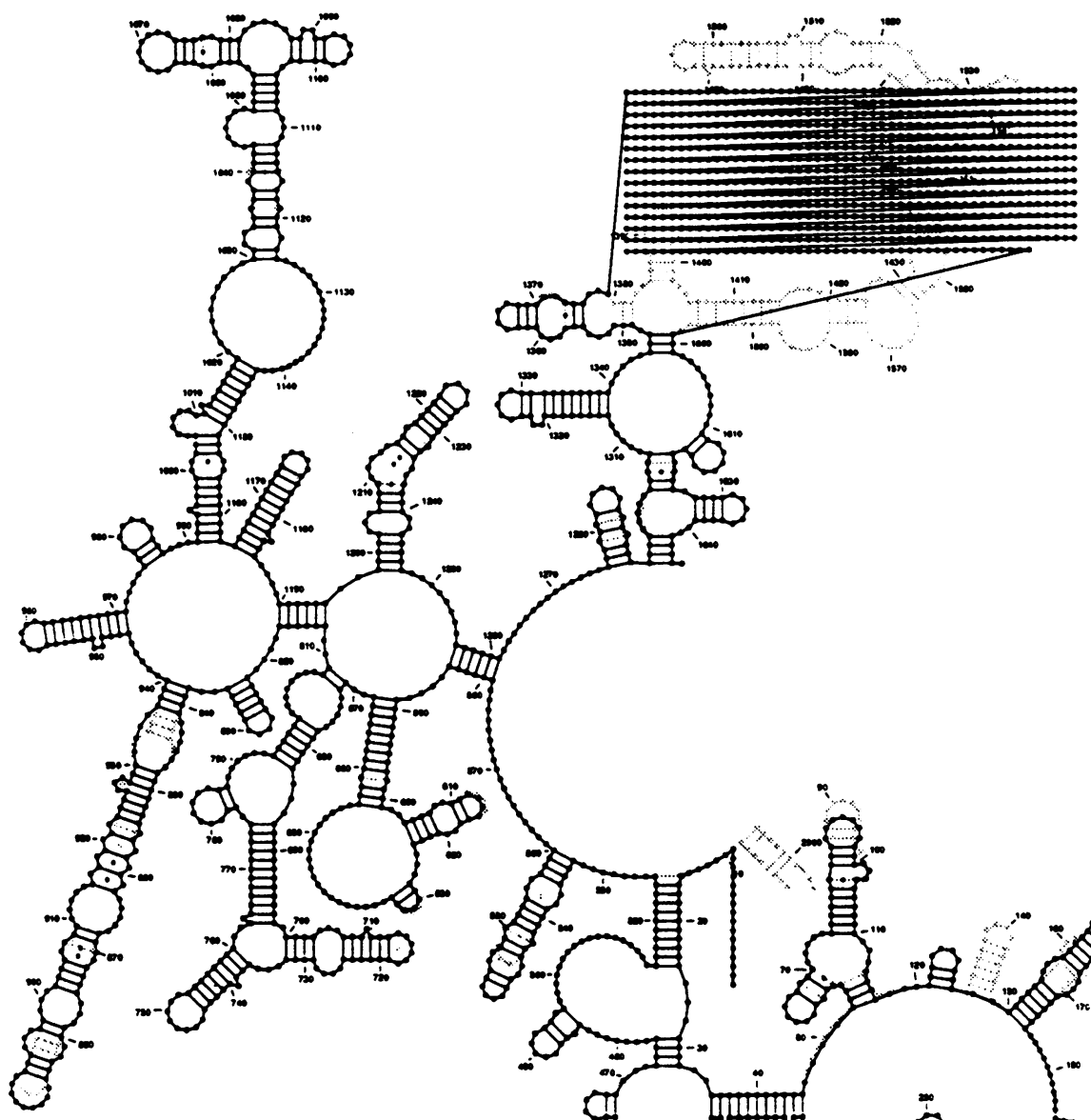

Fio.10a

Zea mays over

Escherichia coli

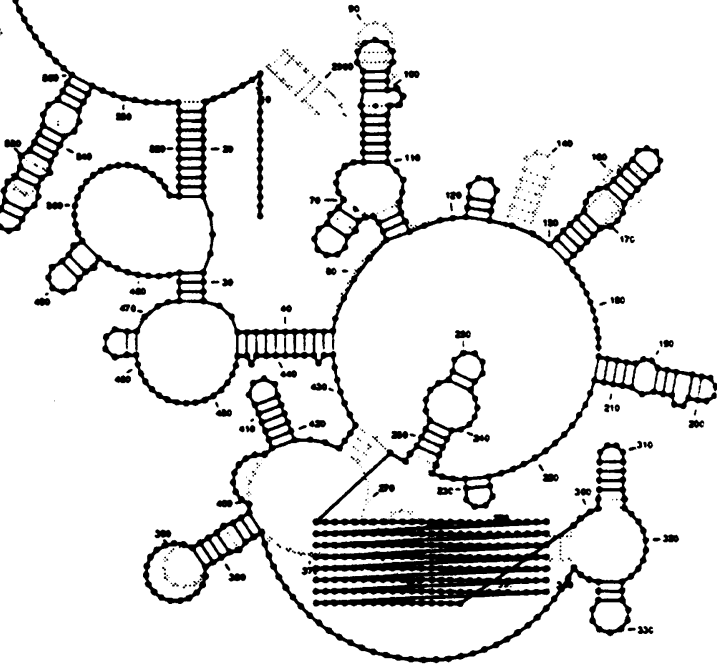


Secondary Structure of mitochondrial 23S Ribosomal RNA: 3'half

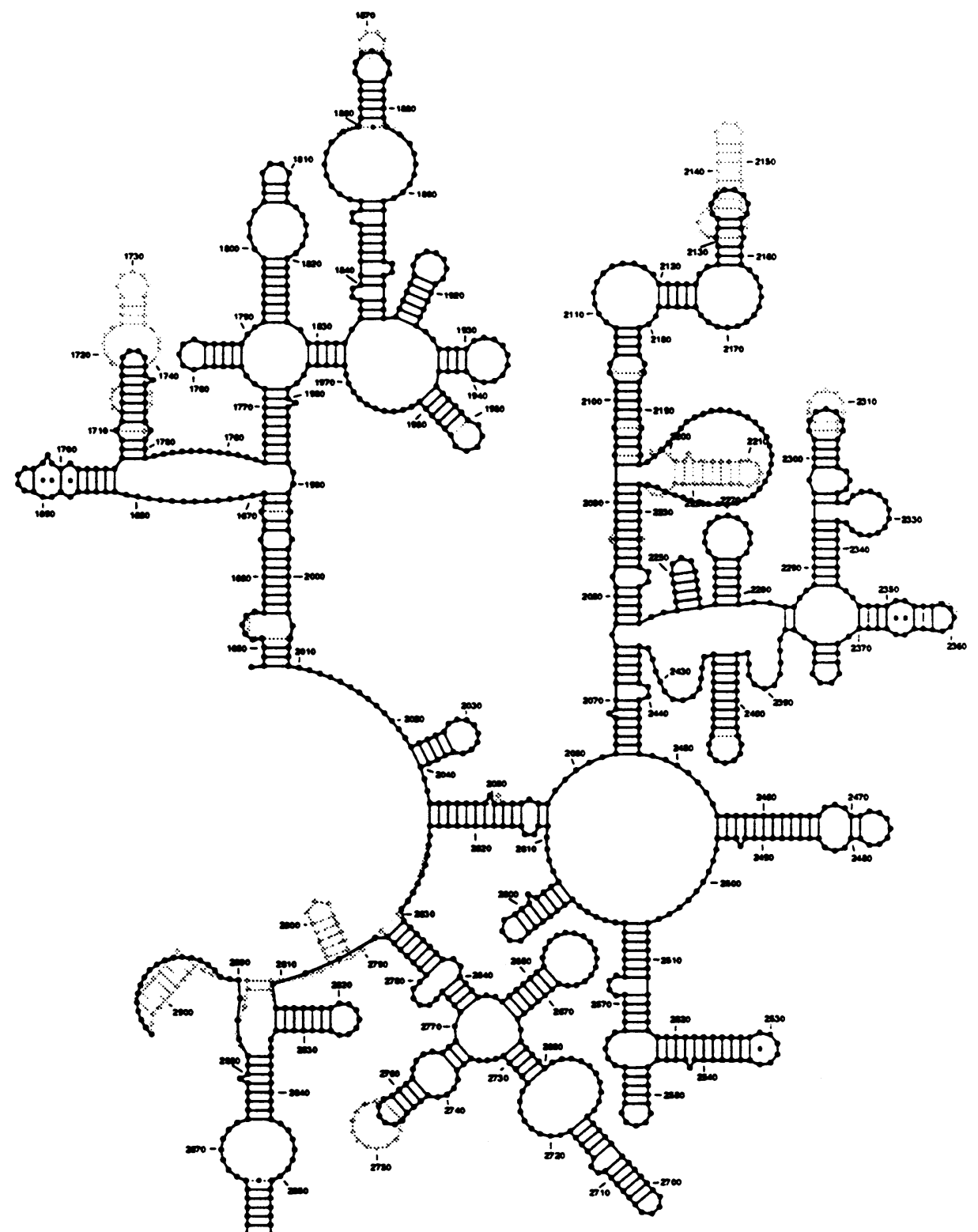

Fig.10b

Zea mays over

Escherichia coli 
Secondary Structure of mitochondrial 23S Ribosomal RNA: 5'half

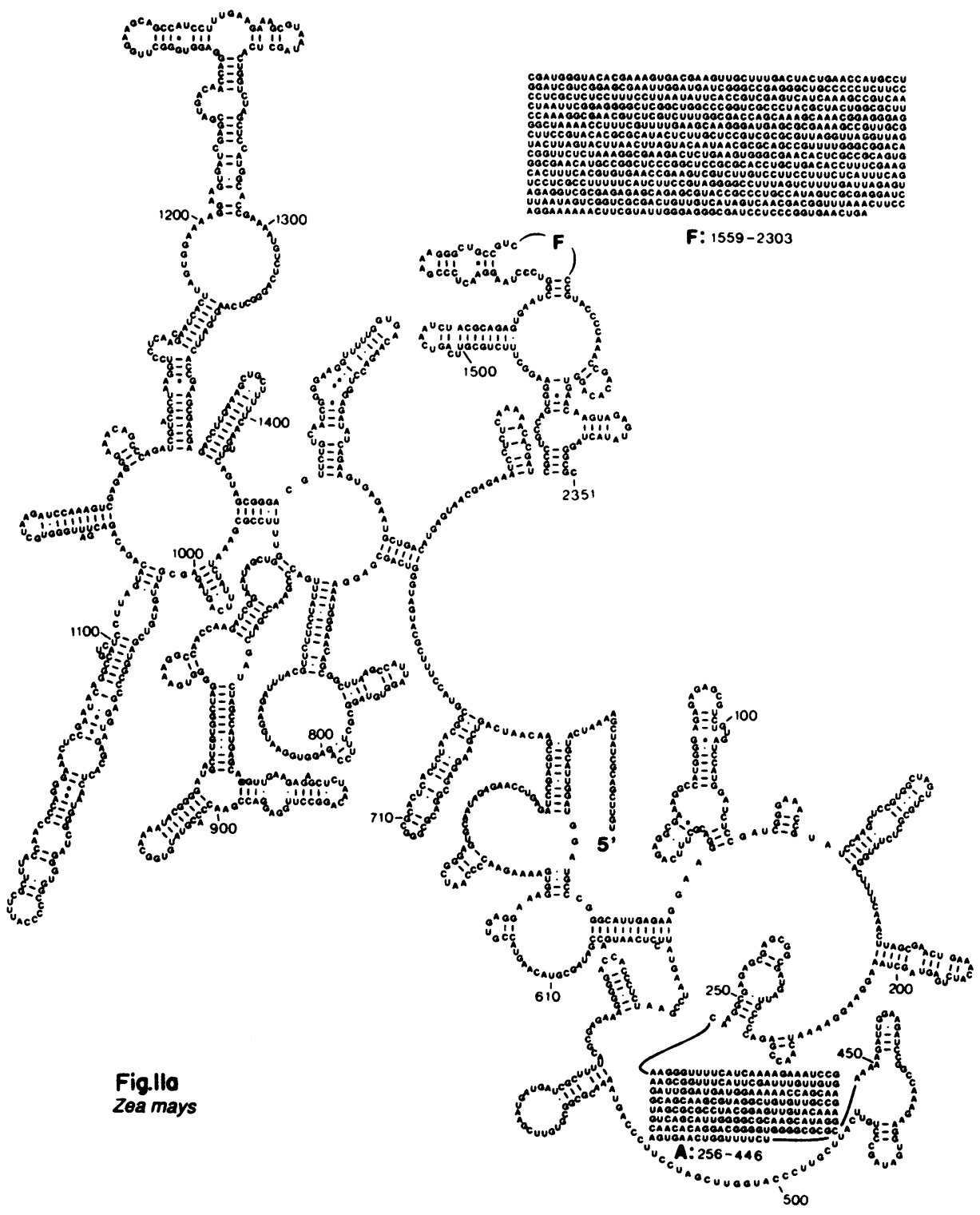


Secondary Structure of mitochondrial 23S Ribosomal RNA: 3'half

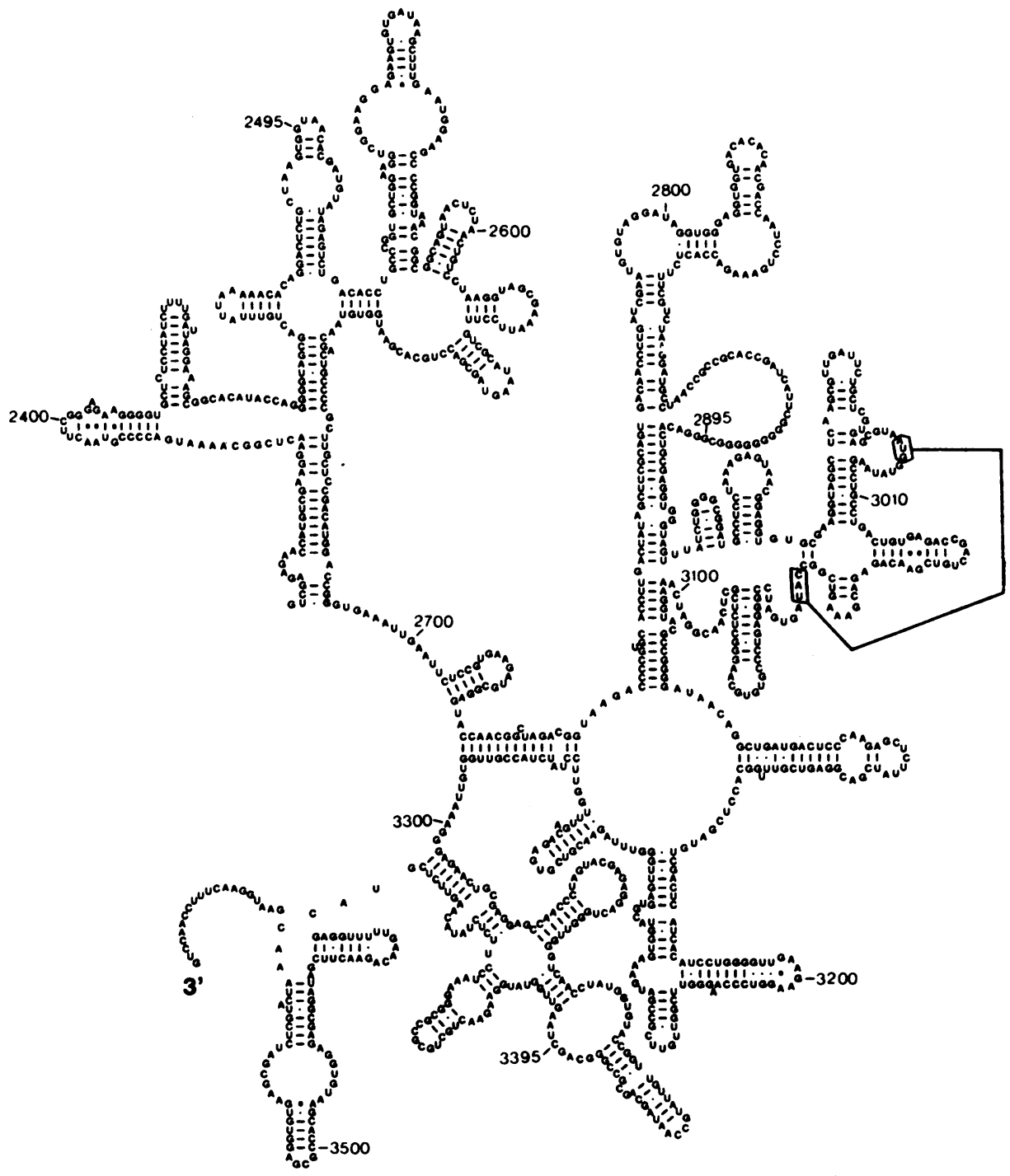

Fig.llb

Zea mays 
Secondary Structure of mitochondrial 23S Ribosomal RNA: 5 'half

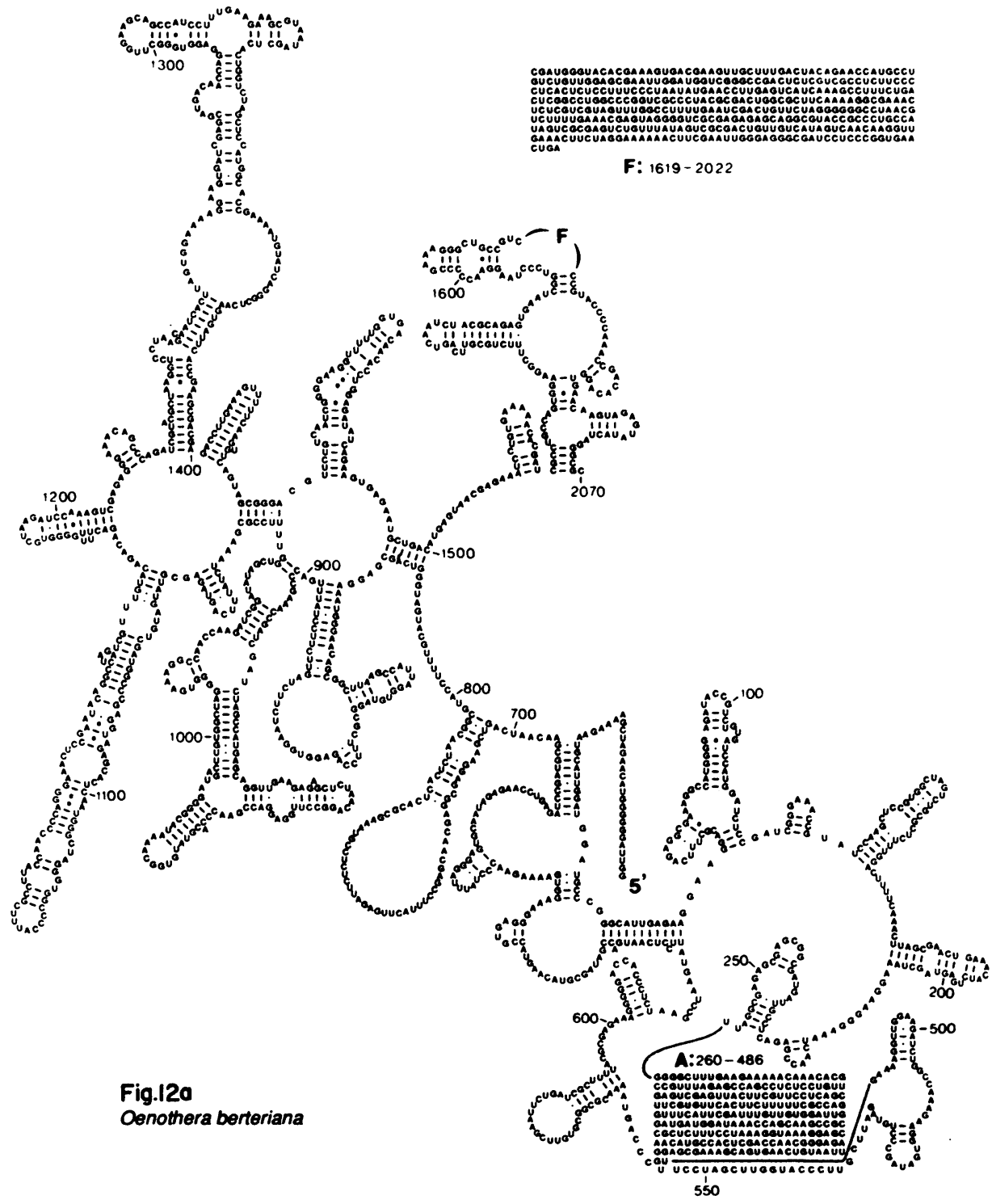


Secondary Structure of mitochondrial 23S Ribosomal RNA: 3 'half

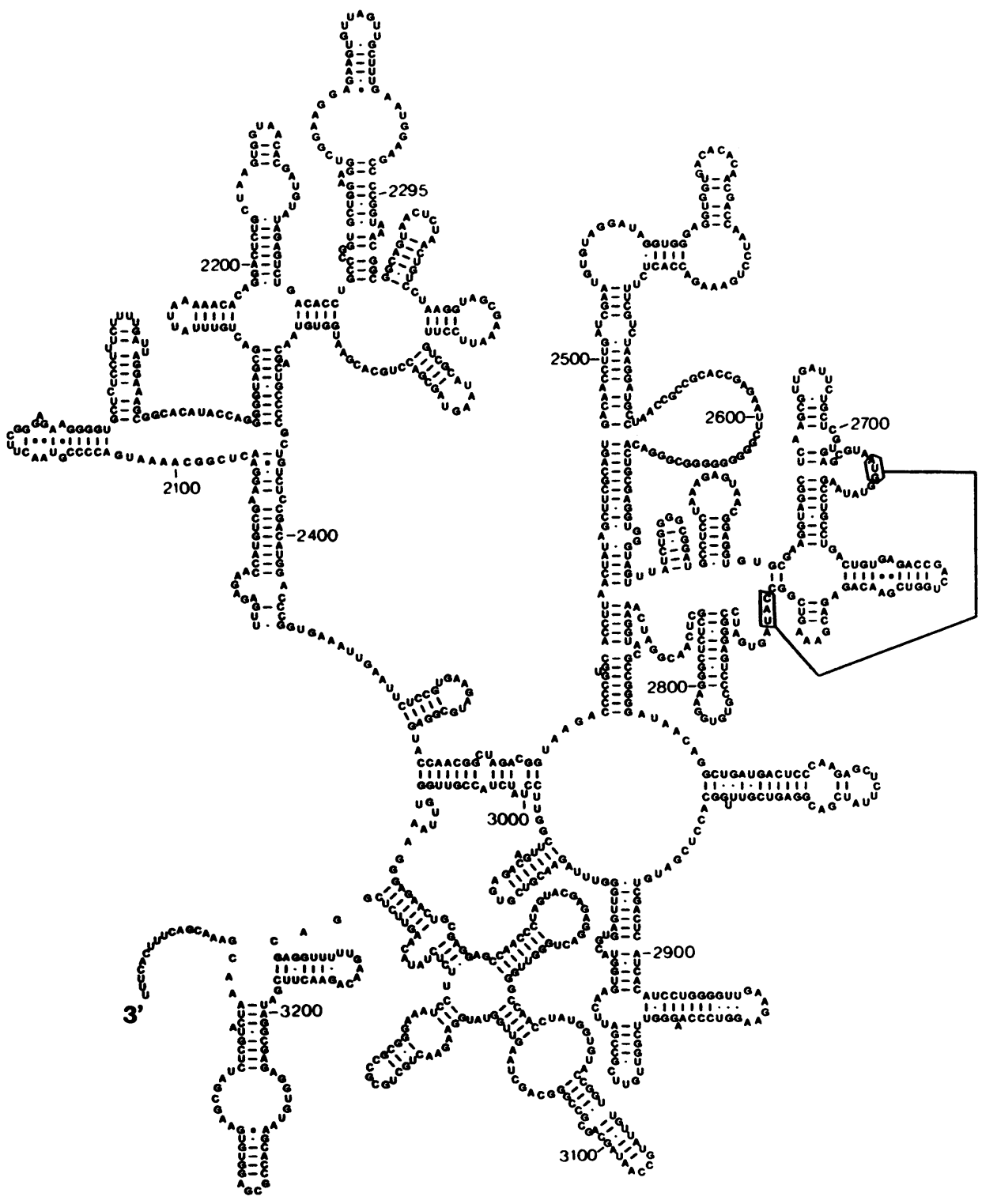

Fig.12b

Oenothera berteriana 


\section{Nucleic Acids Research}

Secondary Structure of mitochondrial 235 Ribosomal RNA: 5 'half

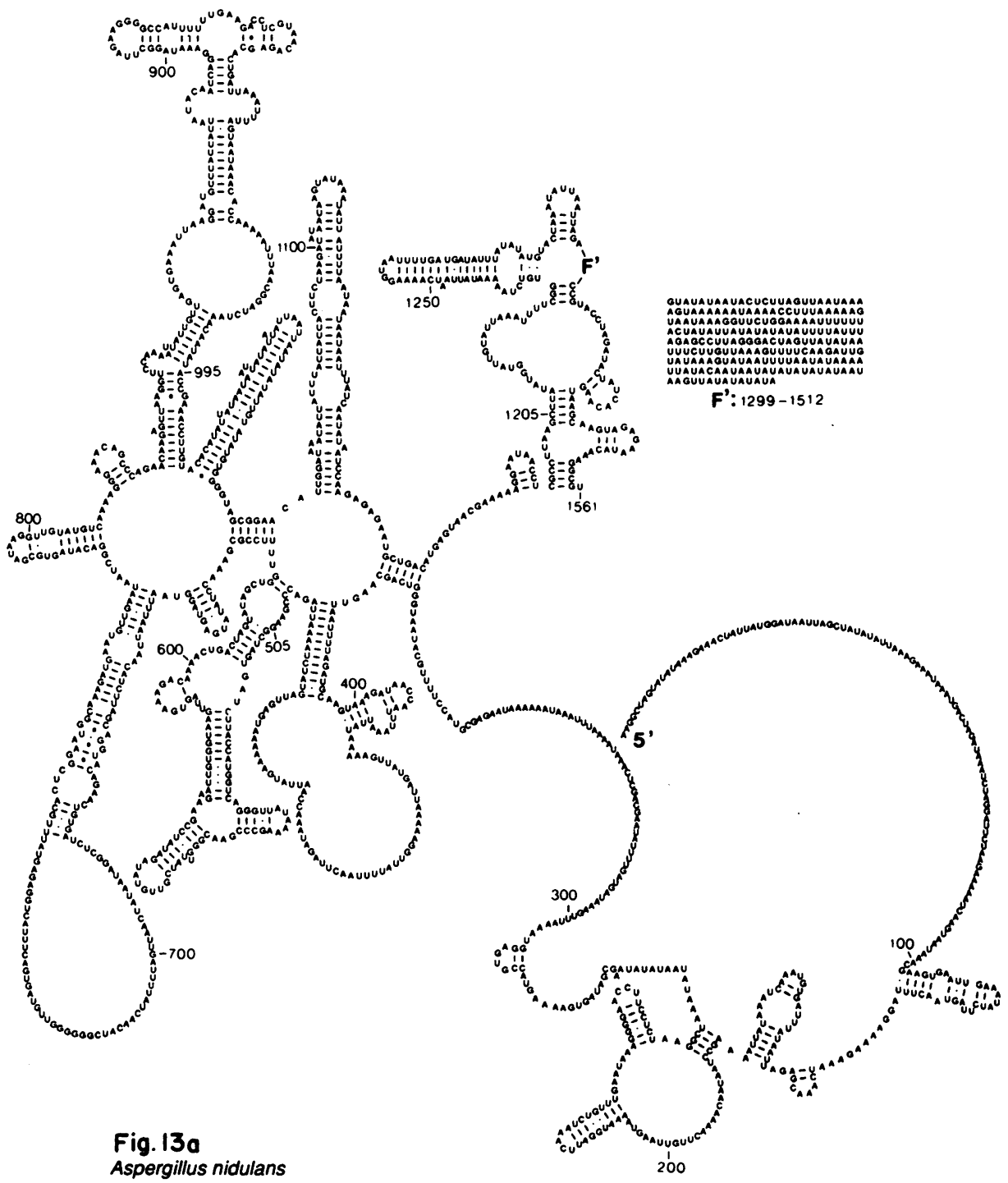


Secondary Structure of mitochondrial 23S Ribosomal RNA: 3 'half

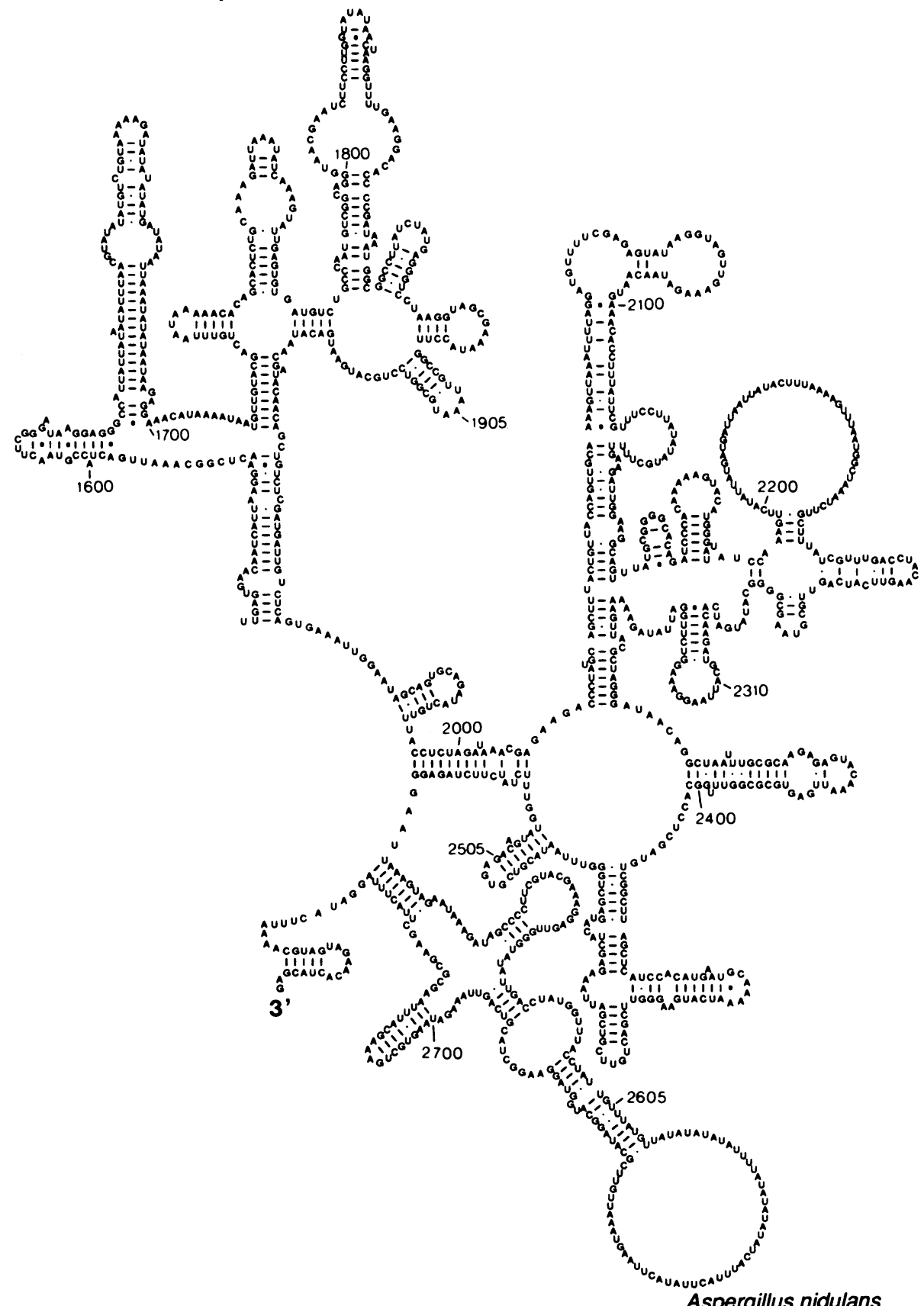

Fig. 13b 
Secondary Structure of mitochondrial 23S Ribosomal RNA: 5'half

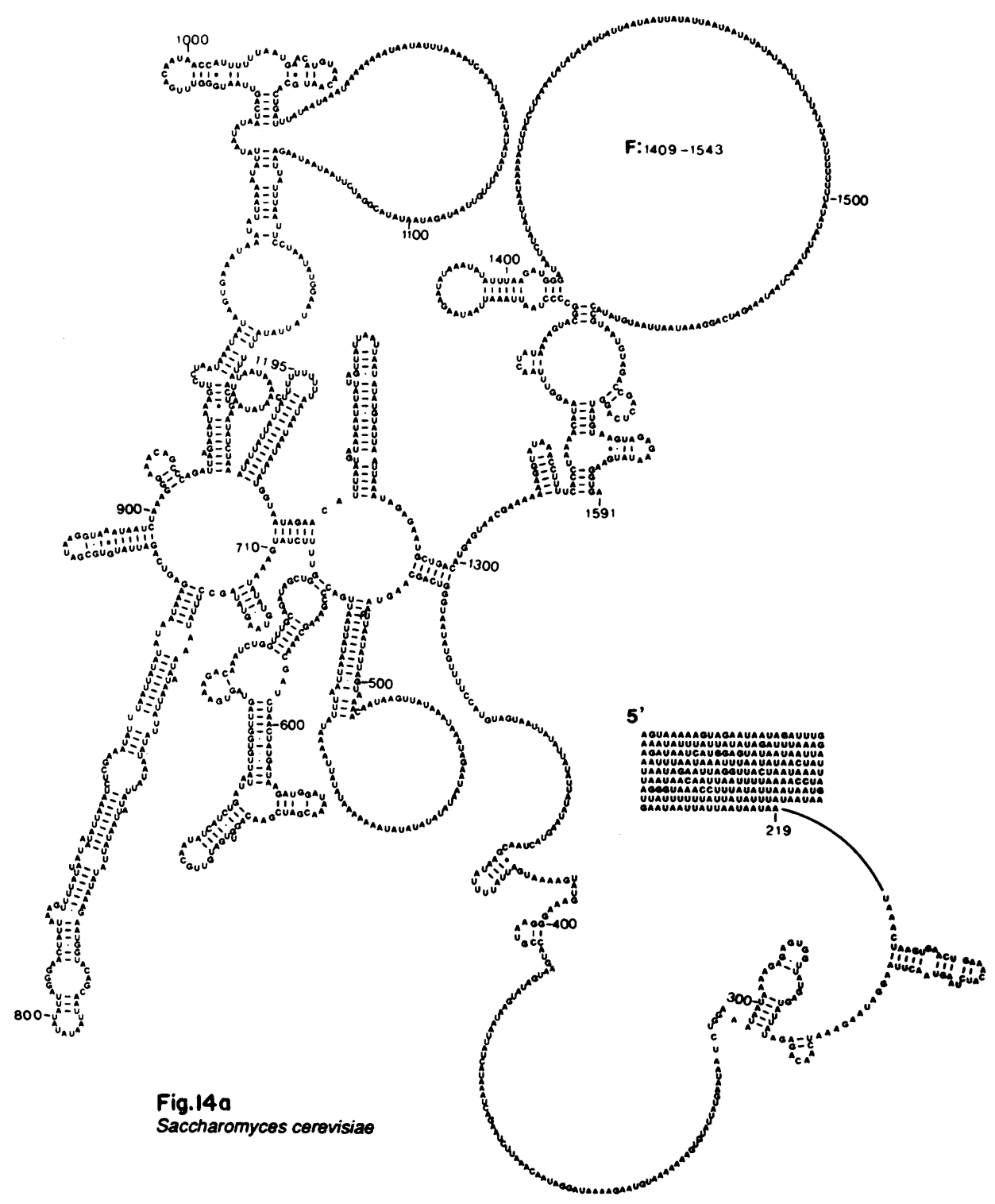


Secondary Structure of mitochondrial 23S Ribosomal RNA: 3 'half

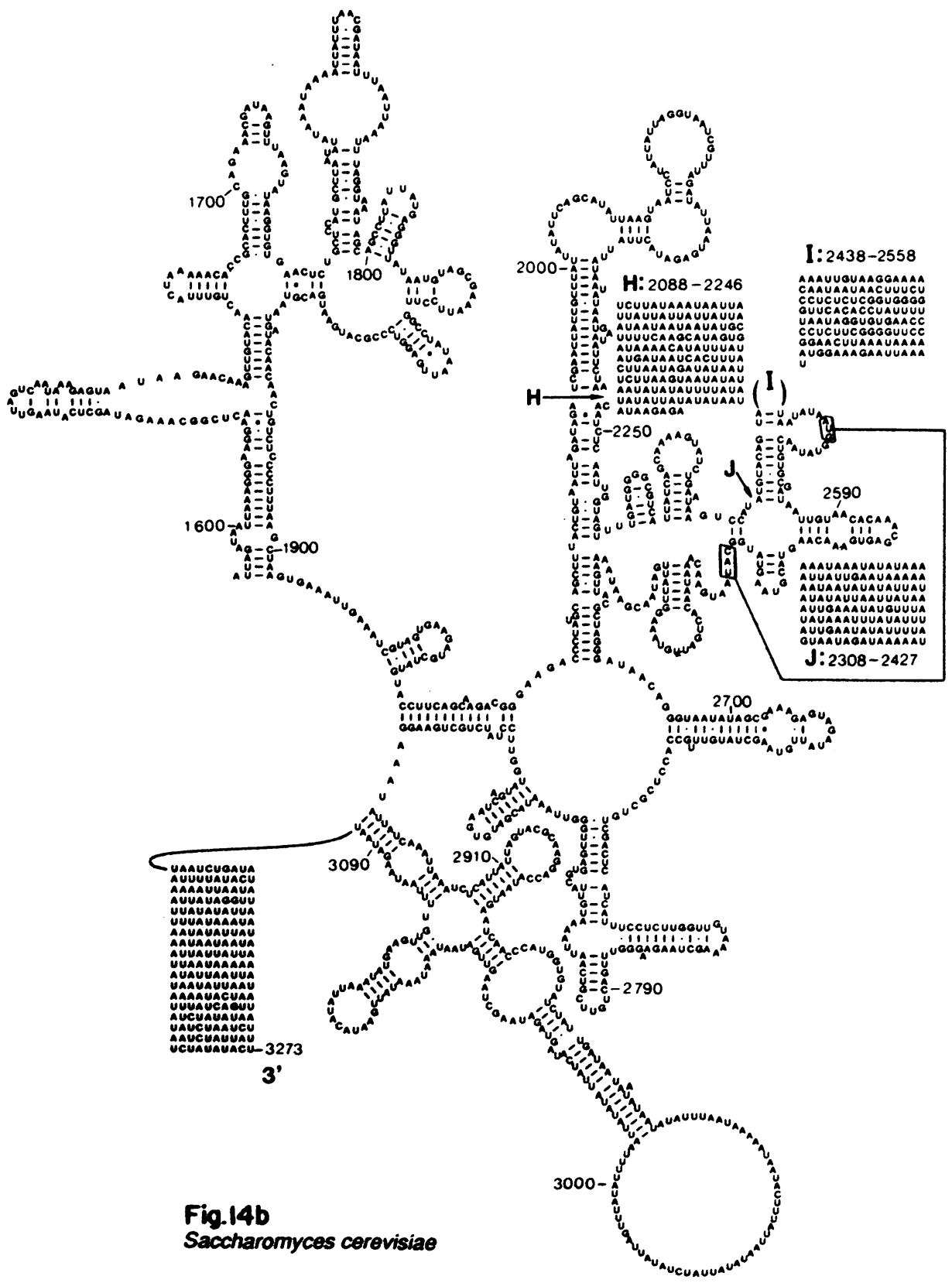


Secondary Structure of mitochondrial 23S Ribosomal RNA: 5 'half

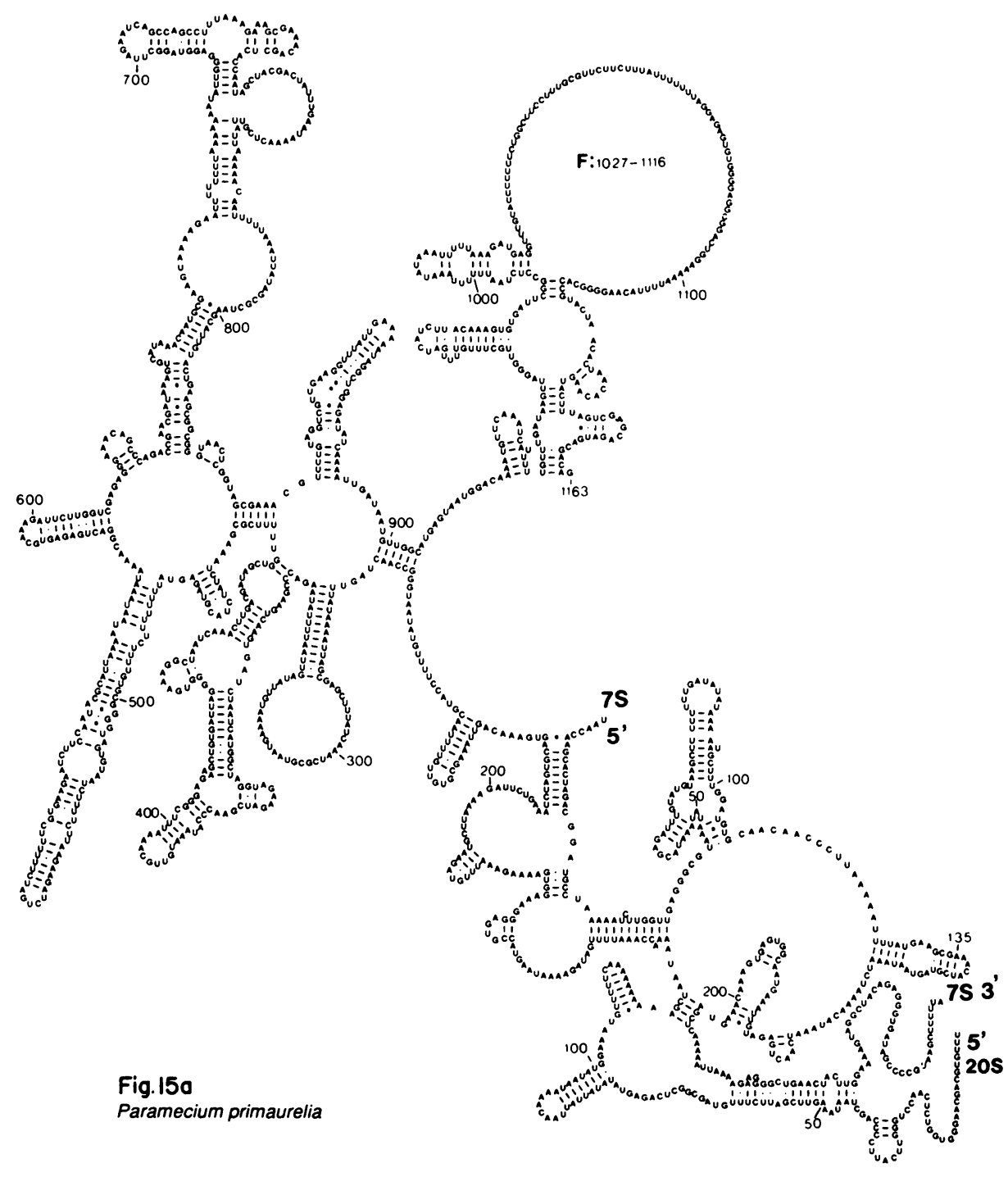


Secondary Structure of mitochondrial 23S Ribosomal RNA: 3 'half

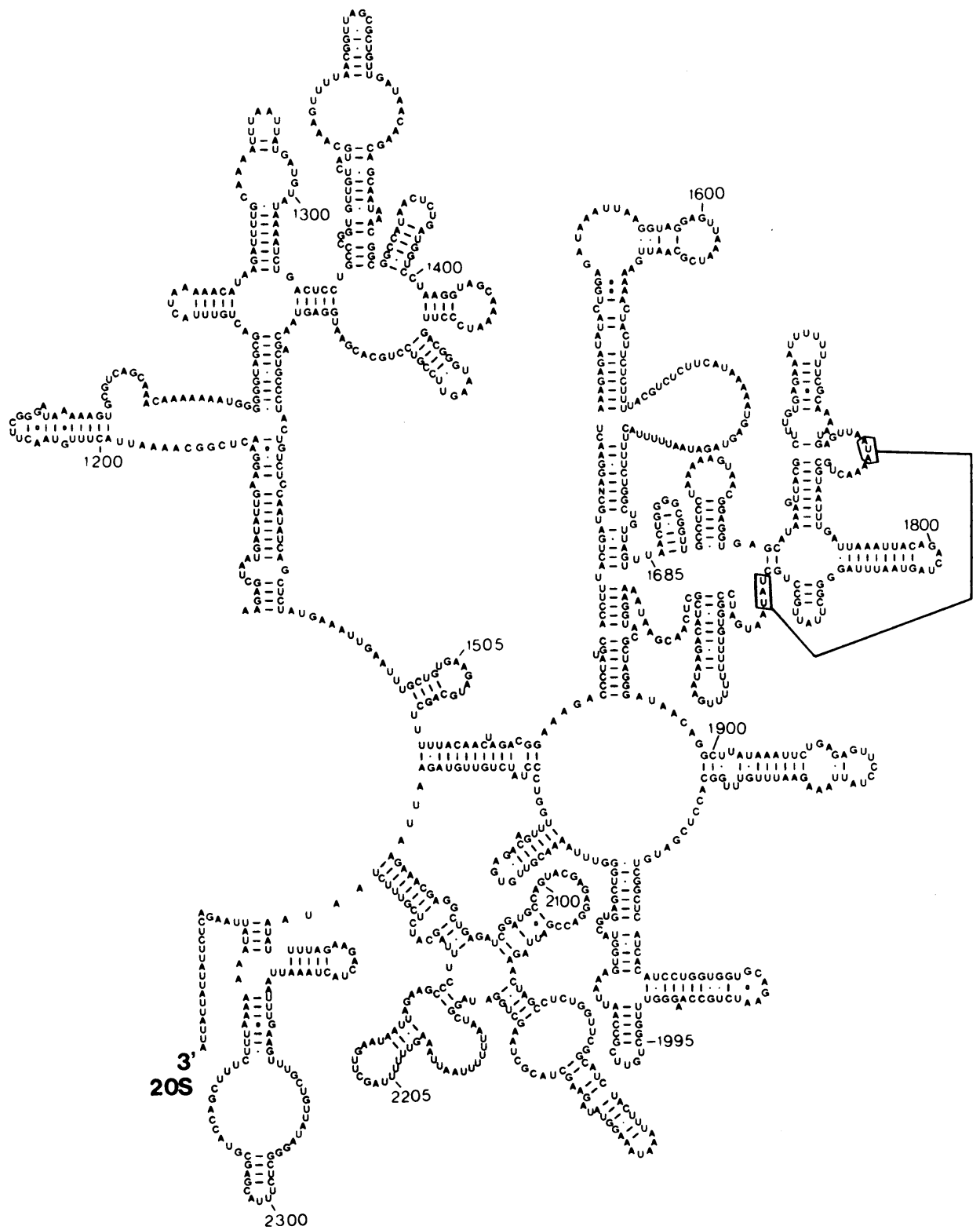

Fig. $15 b$

Paramecium primaurelia 
Secondary Structure of mitochondrial 23S Ribosomal RNA: 5'half

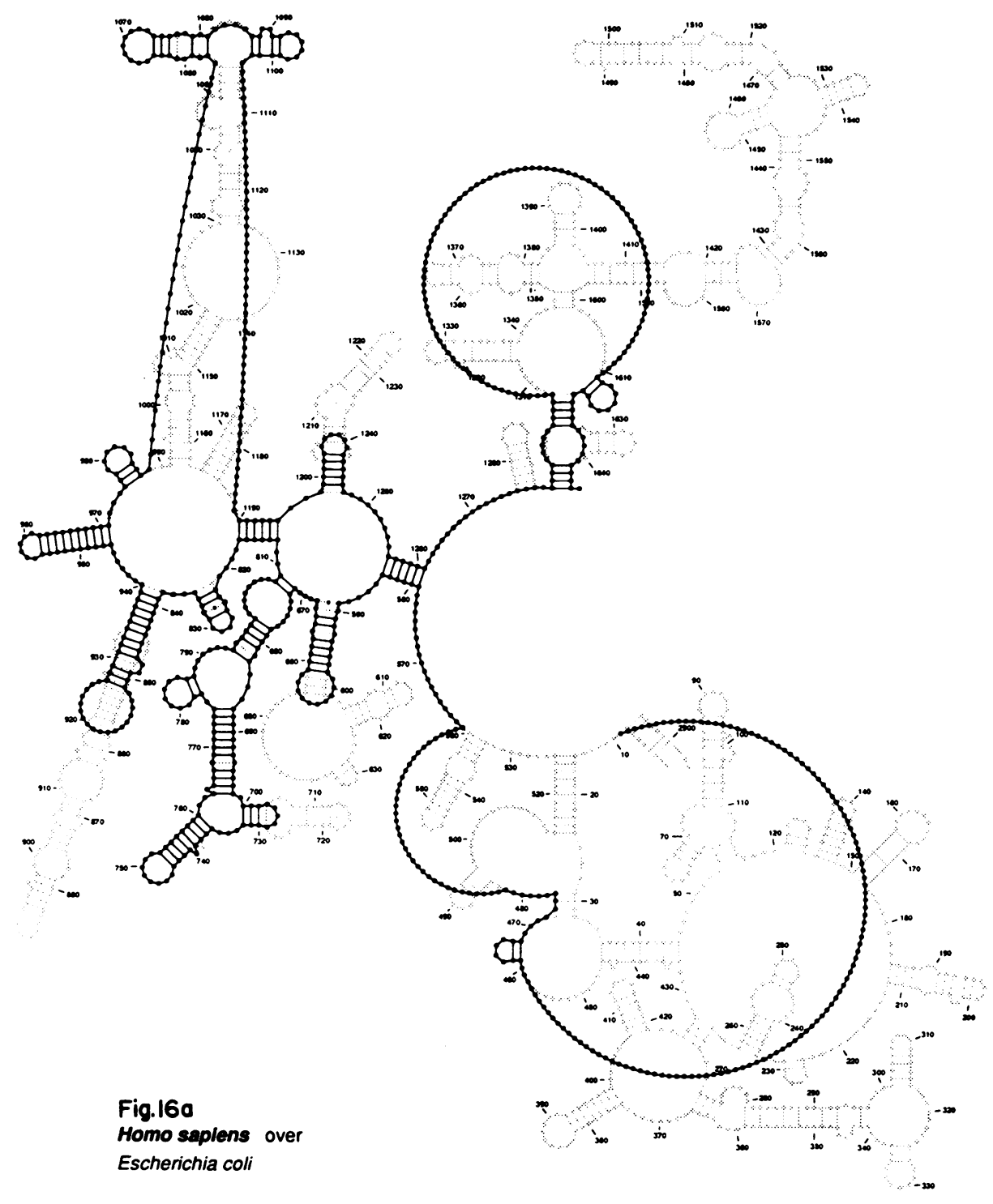


Secondary Structure of mitochondrial 23S Ribosomal RNA: 3 'half

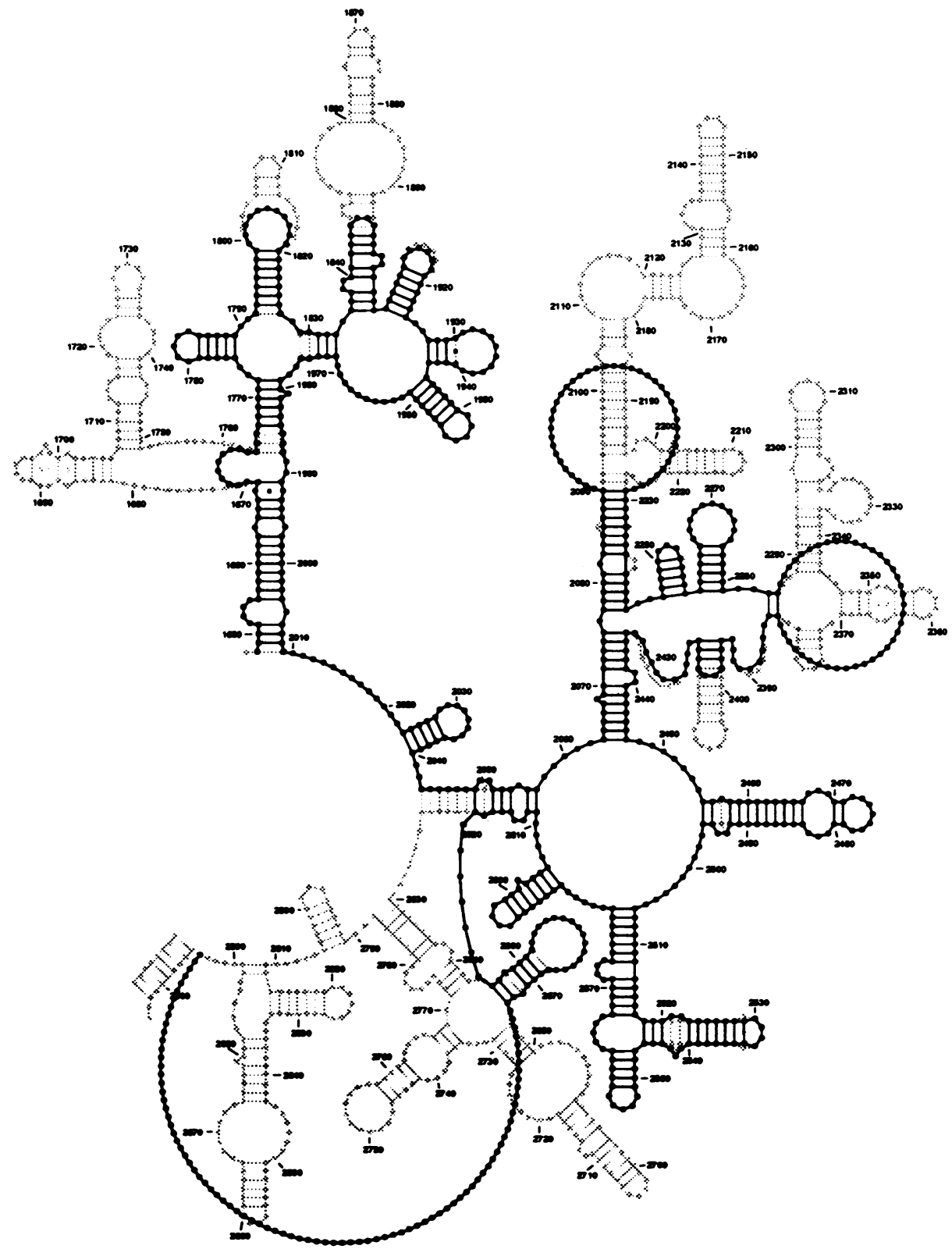

Fig.16b

Homo saplens over

Escherichia coli 


\section{Nucleic Acids Research}

Secondary Structure of mitochondrial 23S Ribosomal RNA: 5 'half

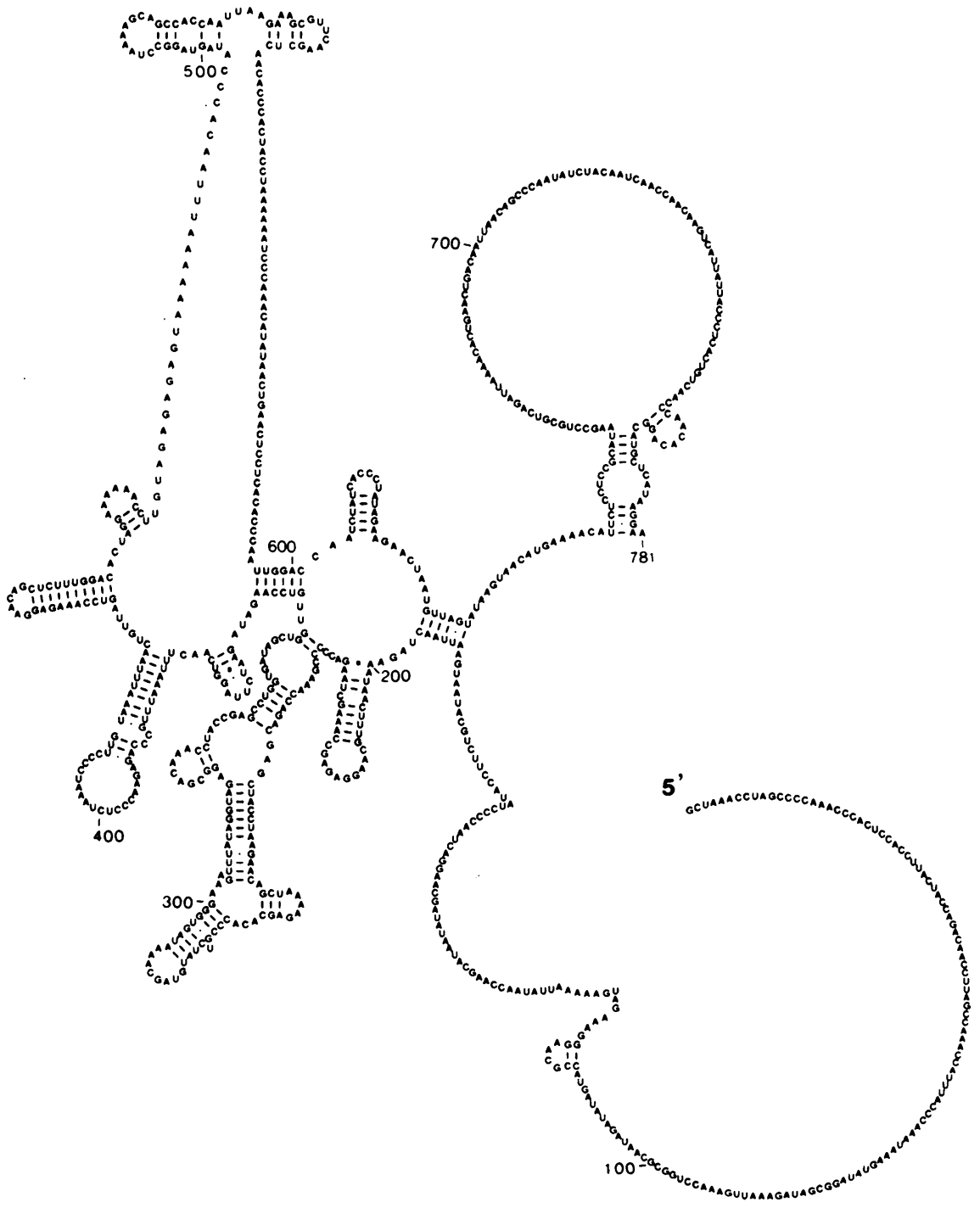

Fig.170

Homo sapiens 
Secondary Structure of mitochondrial 23S Ribosomal RNA: 3 'half

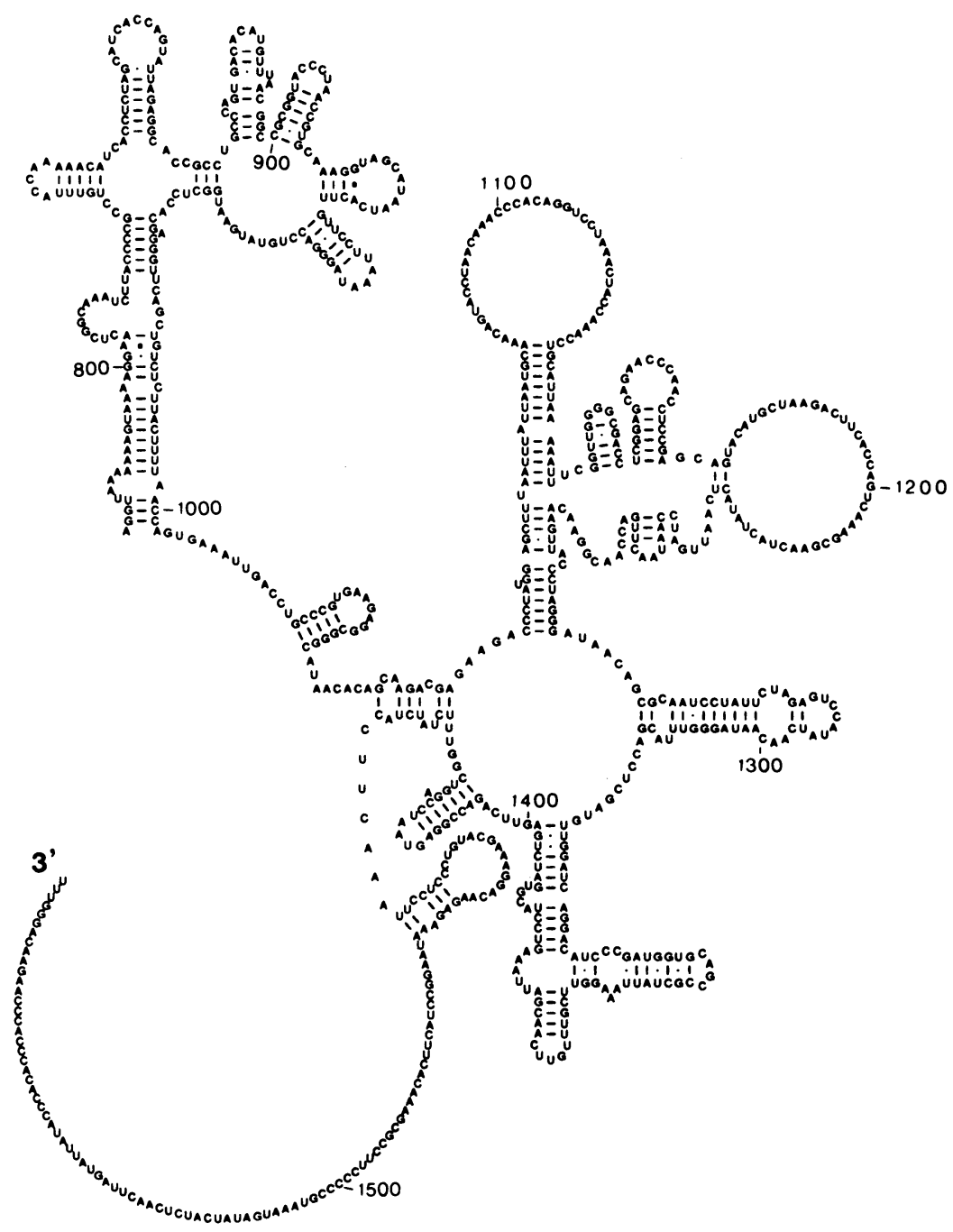

Fig. $17 b$

Homo sapiens 
Nucleic Acids Research

Secondary Structure of mitochondrial 23S Ribosomal RNA: 5 'half

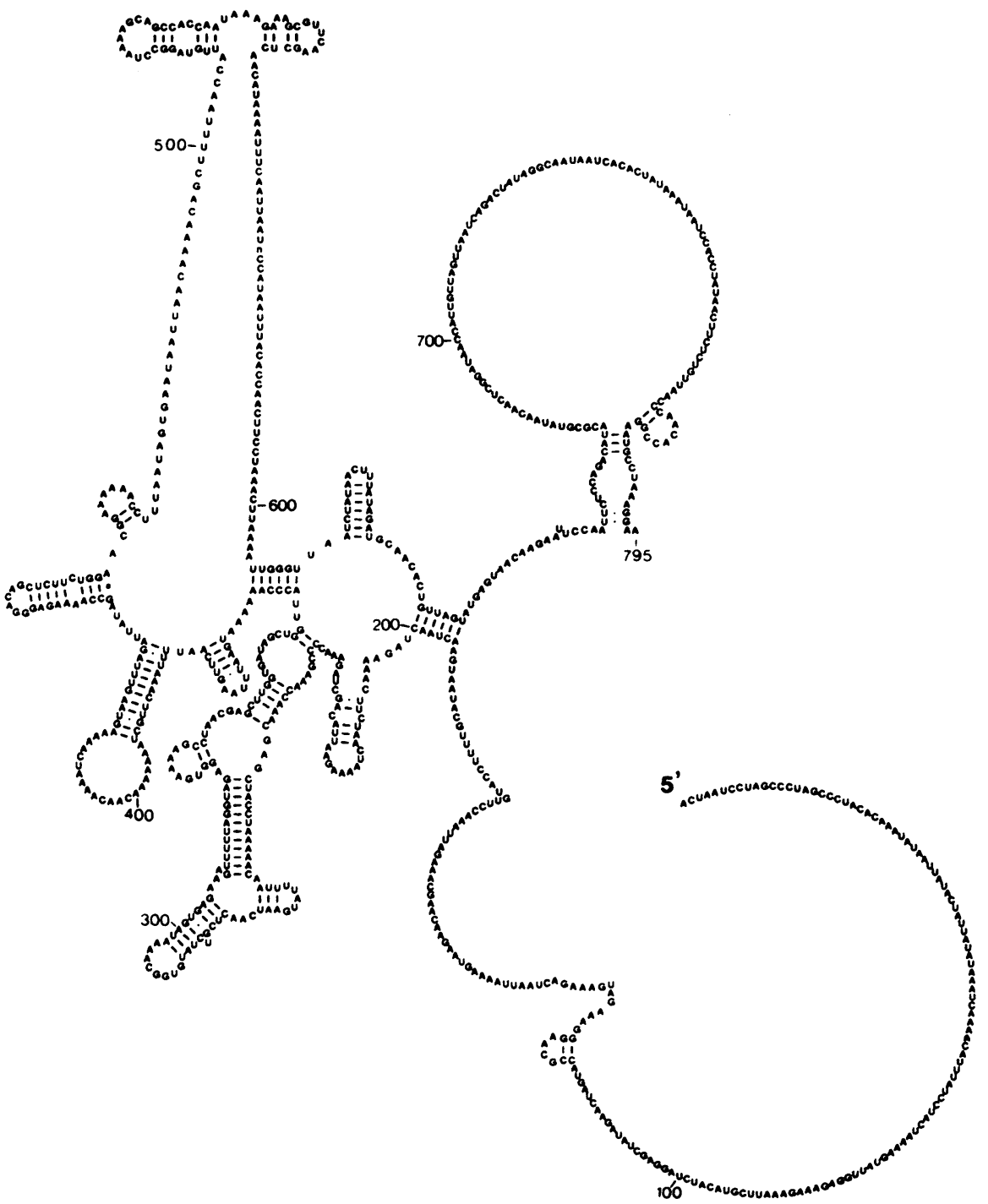

Fig.180

Mouse 
Secondary Structure of mitochondrial 23S Ribosomal RNA: 3'half

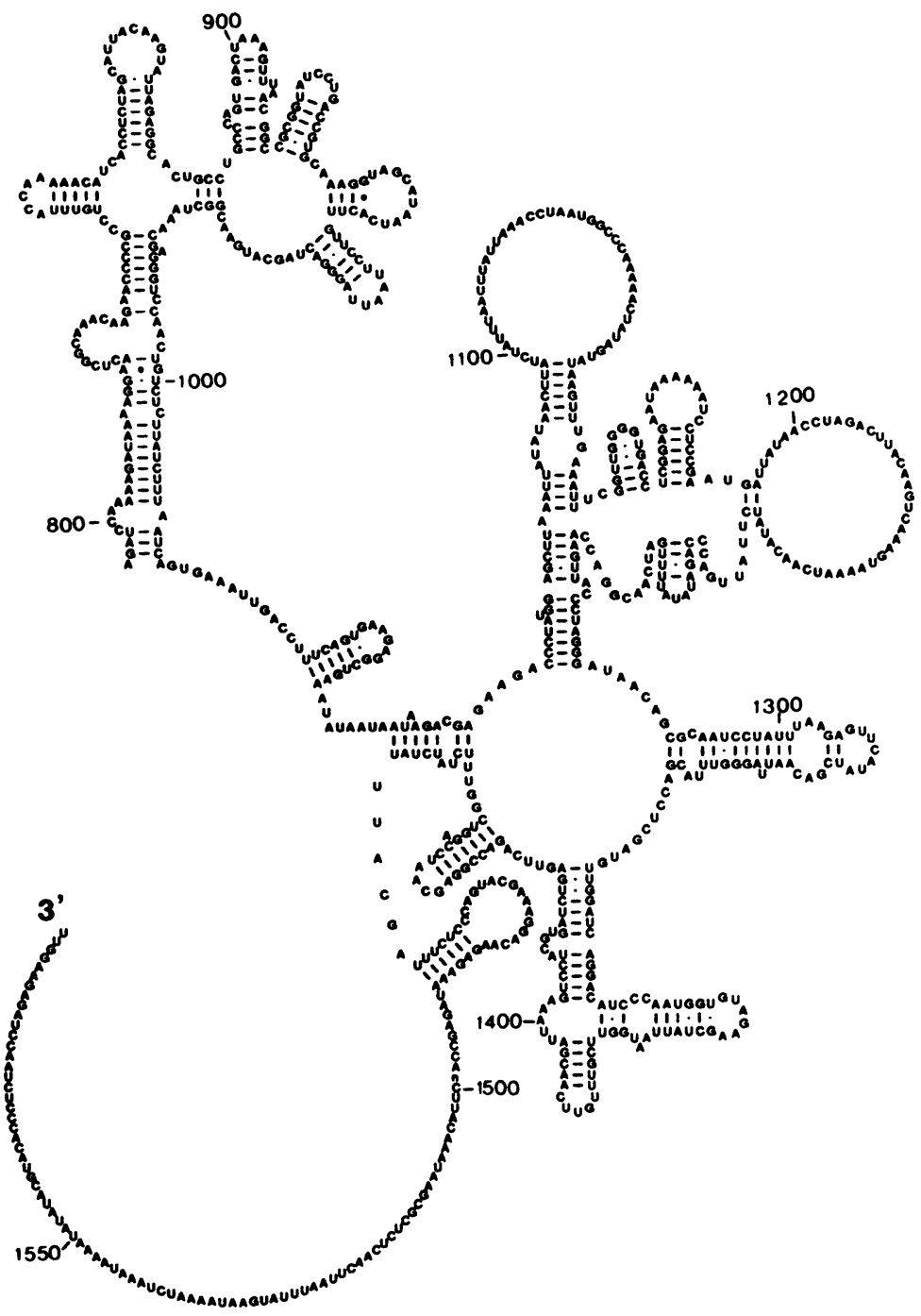

Fig.18b

Mouse 
Secondary Structure of mitochondrial 23S Ribosomal RNA: 5 'half

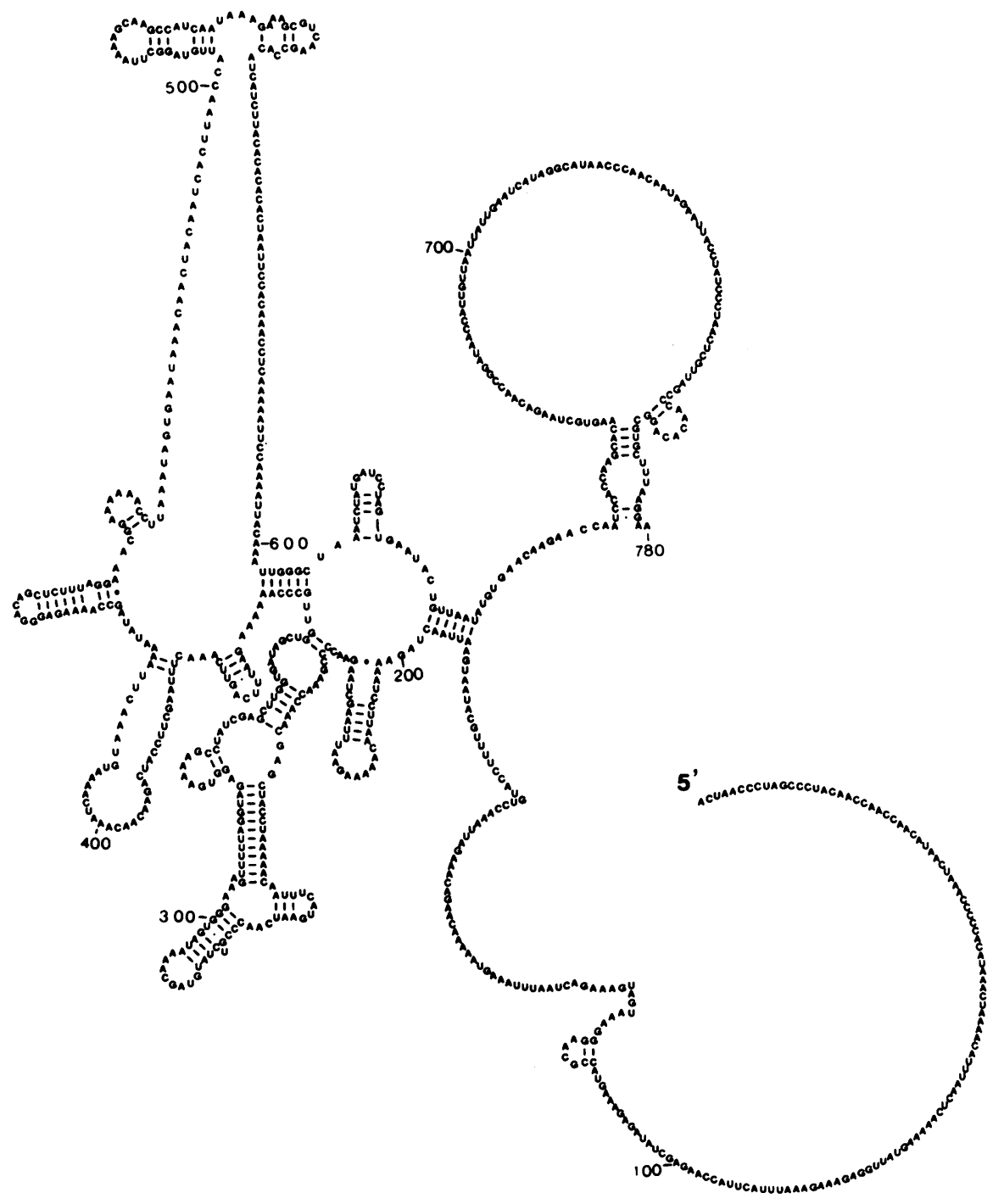

Fig. 190

Rat 
Secondary Structure of mitochondrial 23S Ribosomal RNA: 3 'half

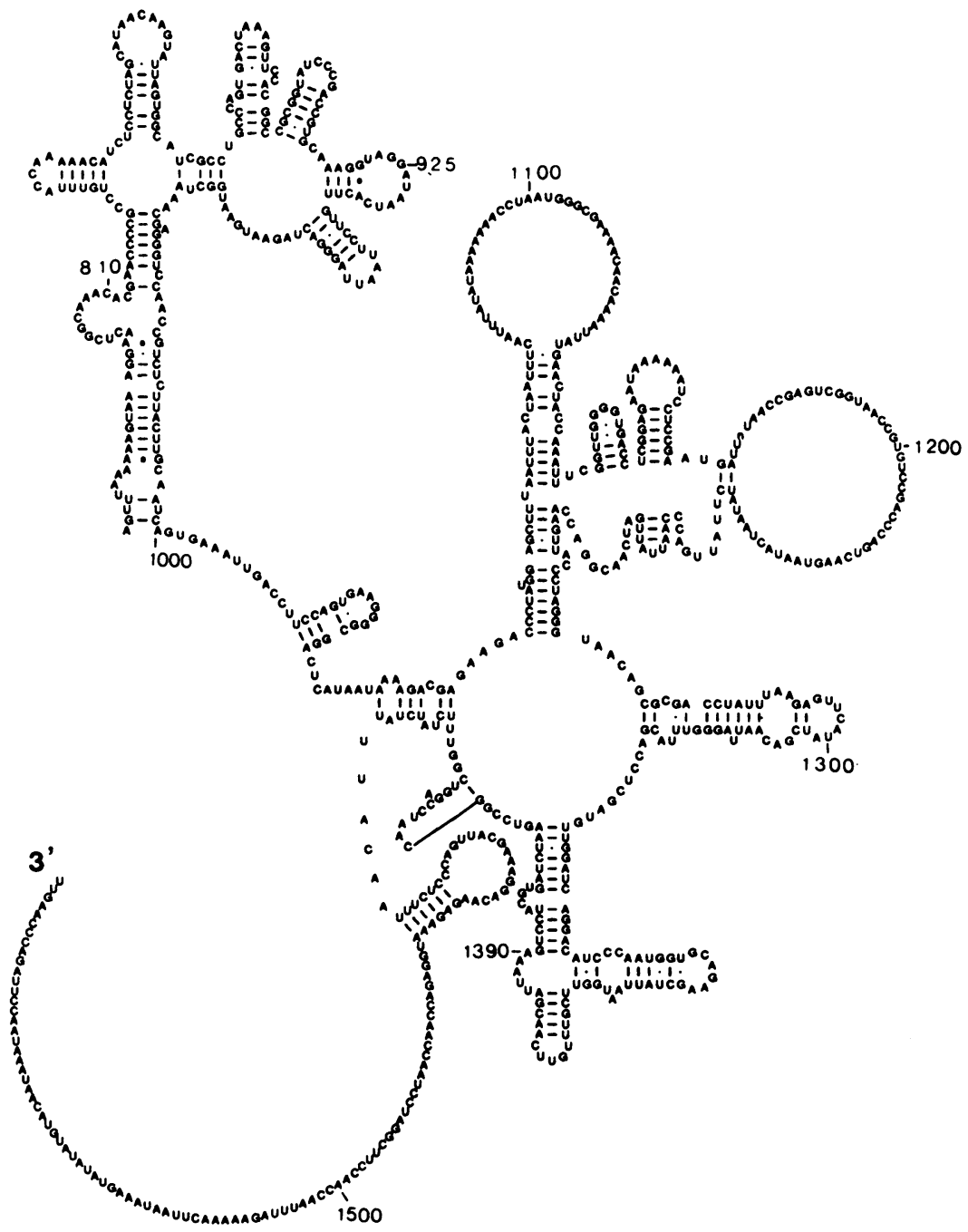

Fig.19b

Rat 
Secondary Structure of mitochondrial 235 Ribosomal RNA: 5 'half

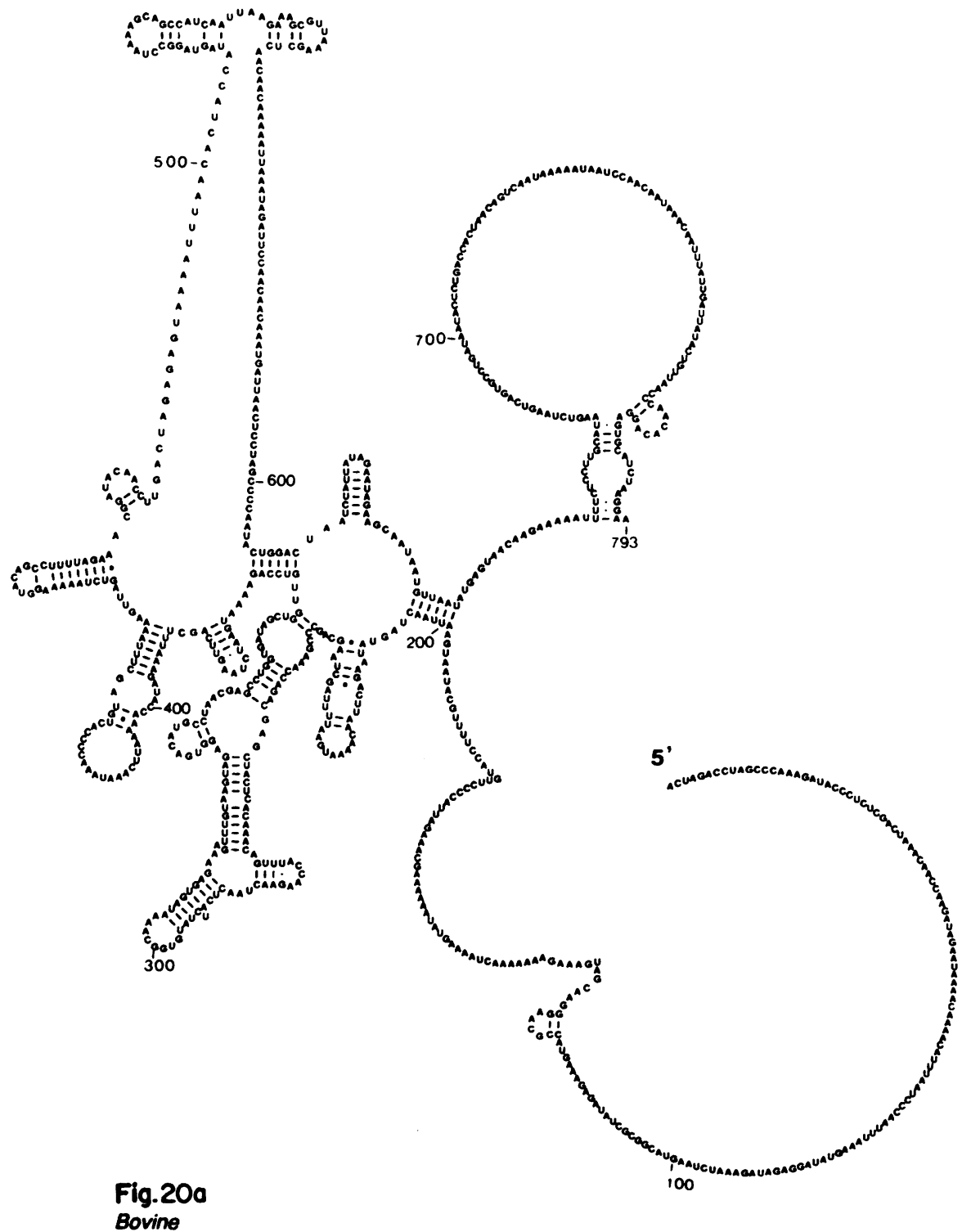

Bovine 
Secondary Structure of mitochondrial 23S Ribosomal RNA: 3 'half

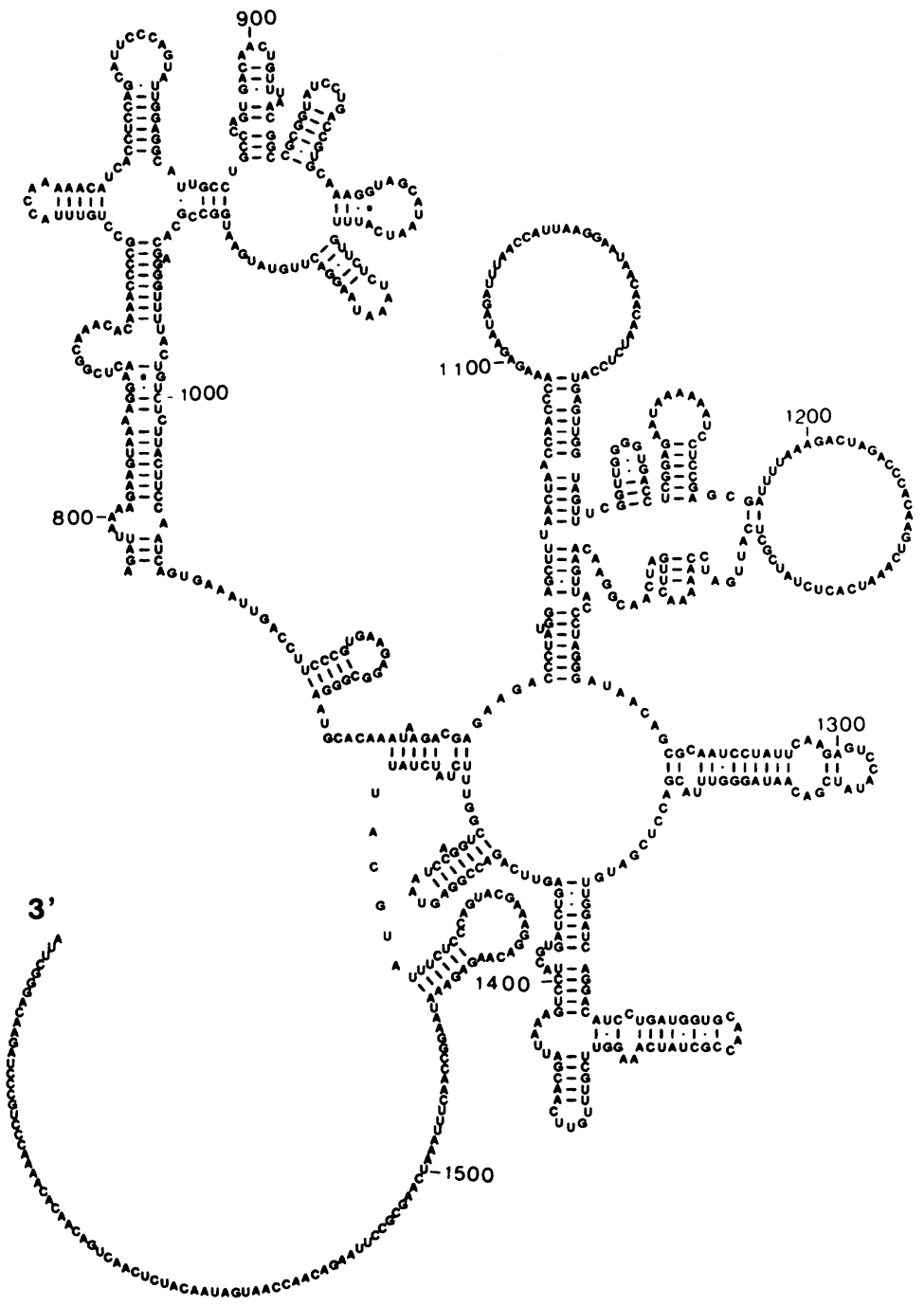

Fig. 20b

Bovine 


\section{Nucleic Acids Research}

Secondary Structure of mitochondrial 23S Ribosomal RNA: 5'half

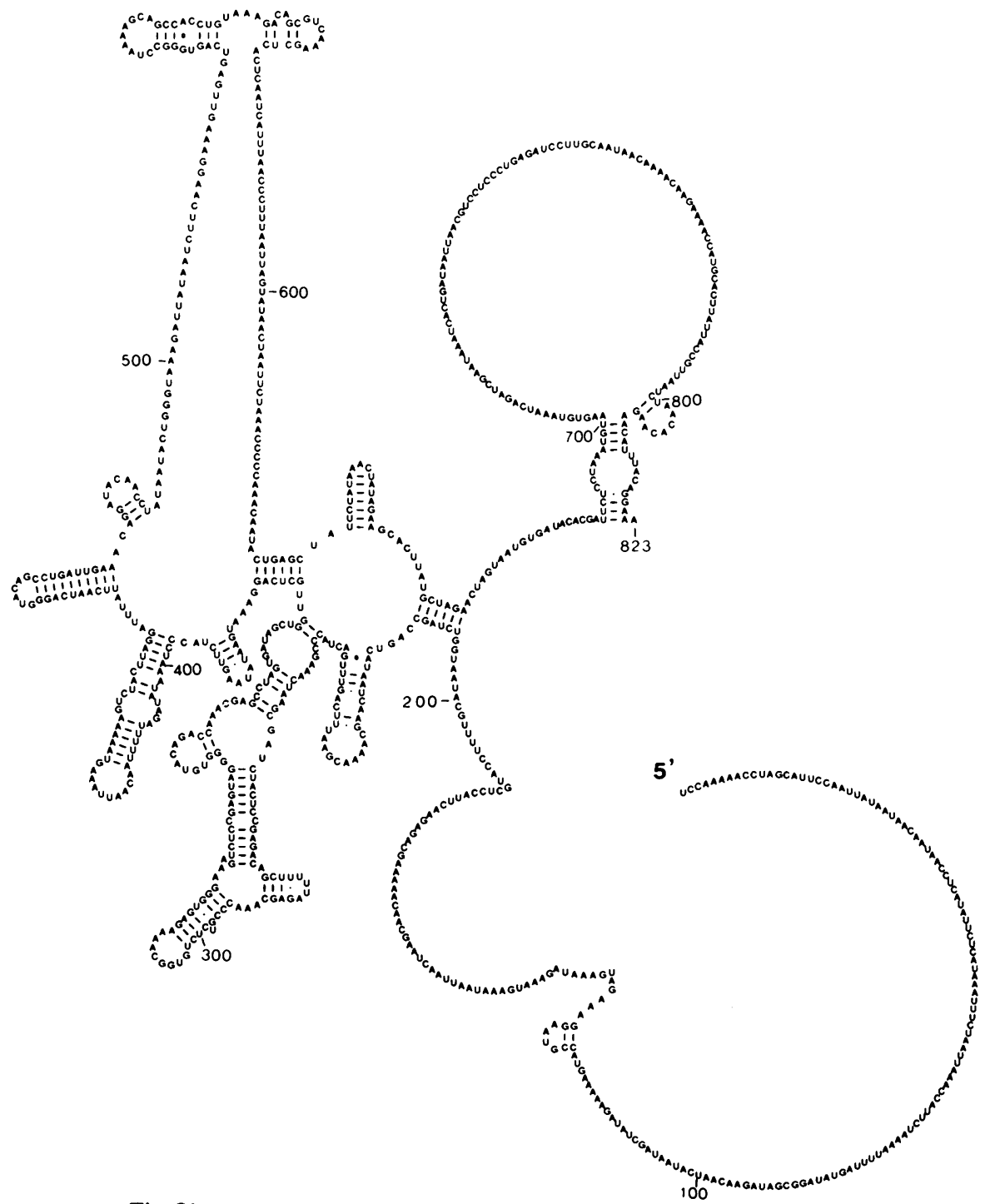

Fig.21a

Xenopus laevis 
Secondary Structure of mitochondrial 23S Ribosomal RNA: 3 'half

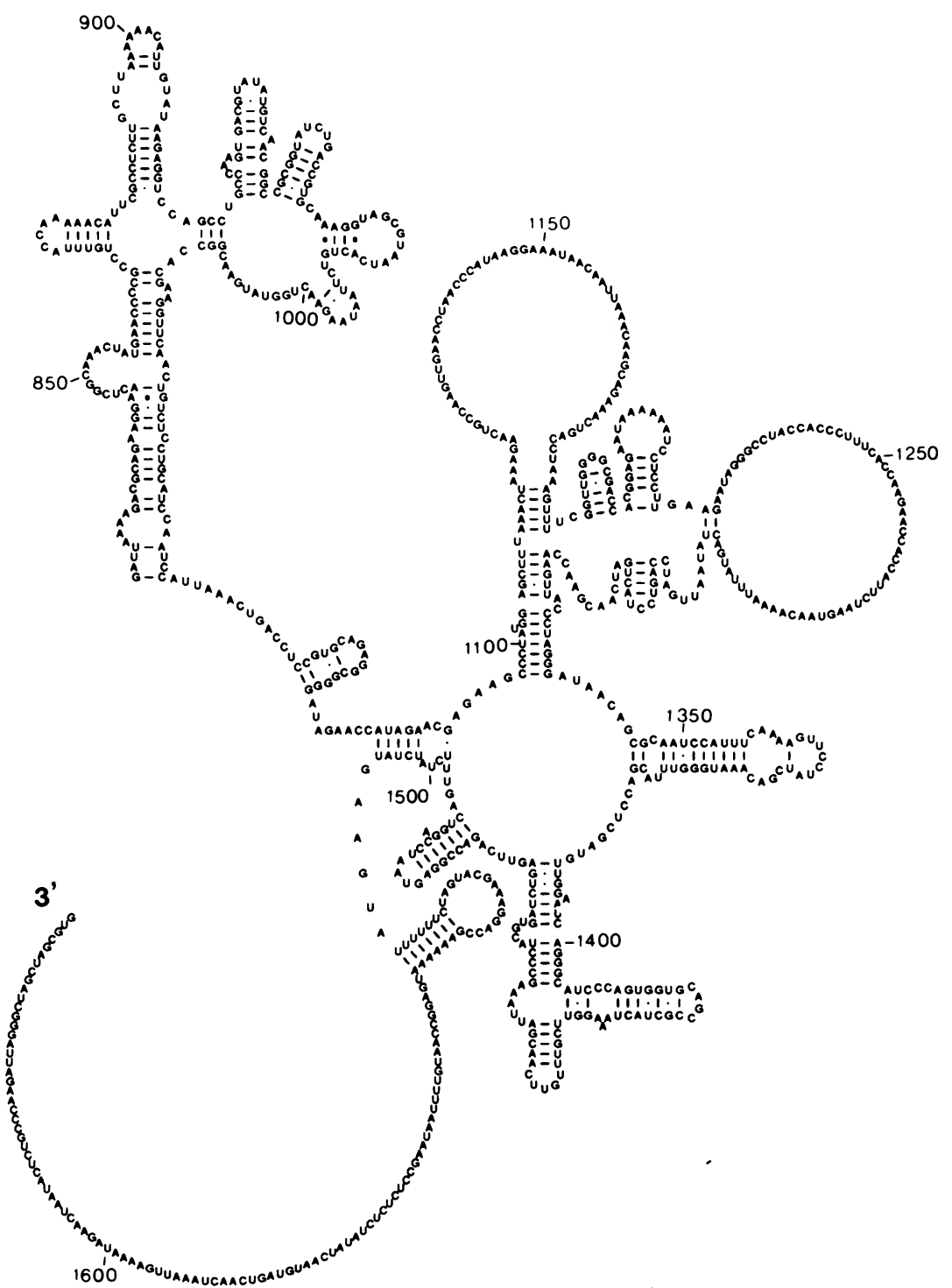

Fig.2lb

Xenopus laevis 
Secondary Structure of mitochondrial 23S Ribosomal RNA: 3'half

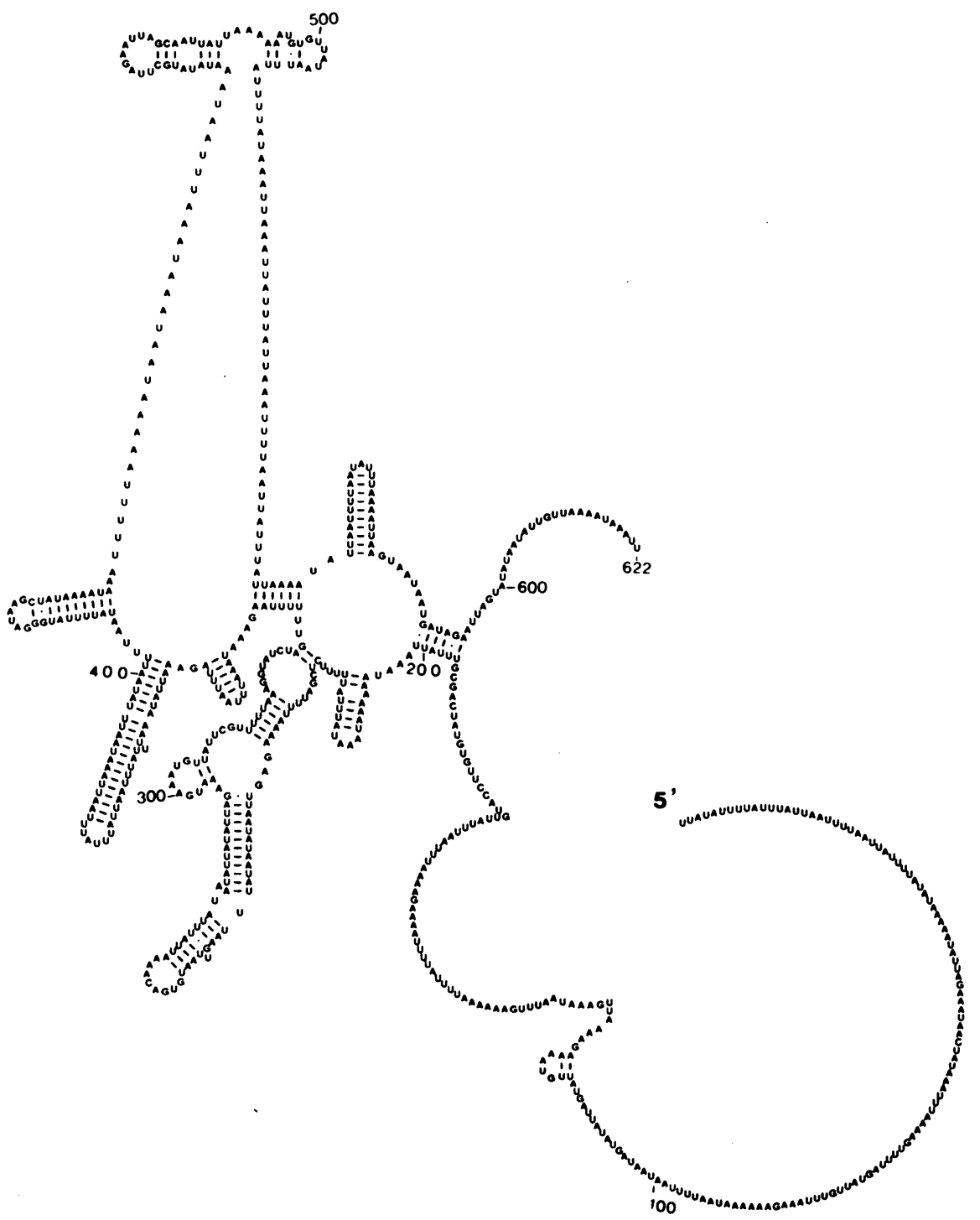

Fig.220

Drosophila yakuba 
Secondary Structure of mitochondrial 23S Ribosomal RNA: 3'half

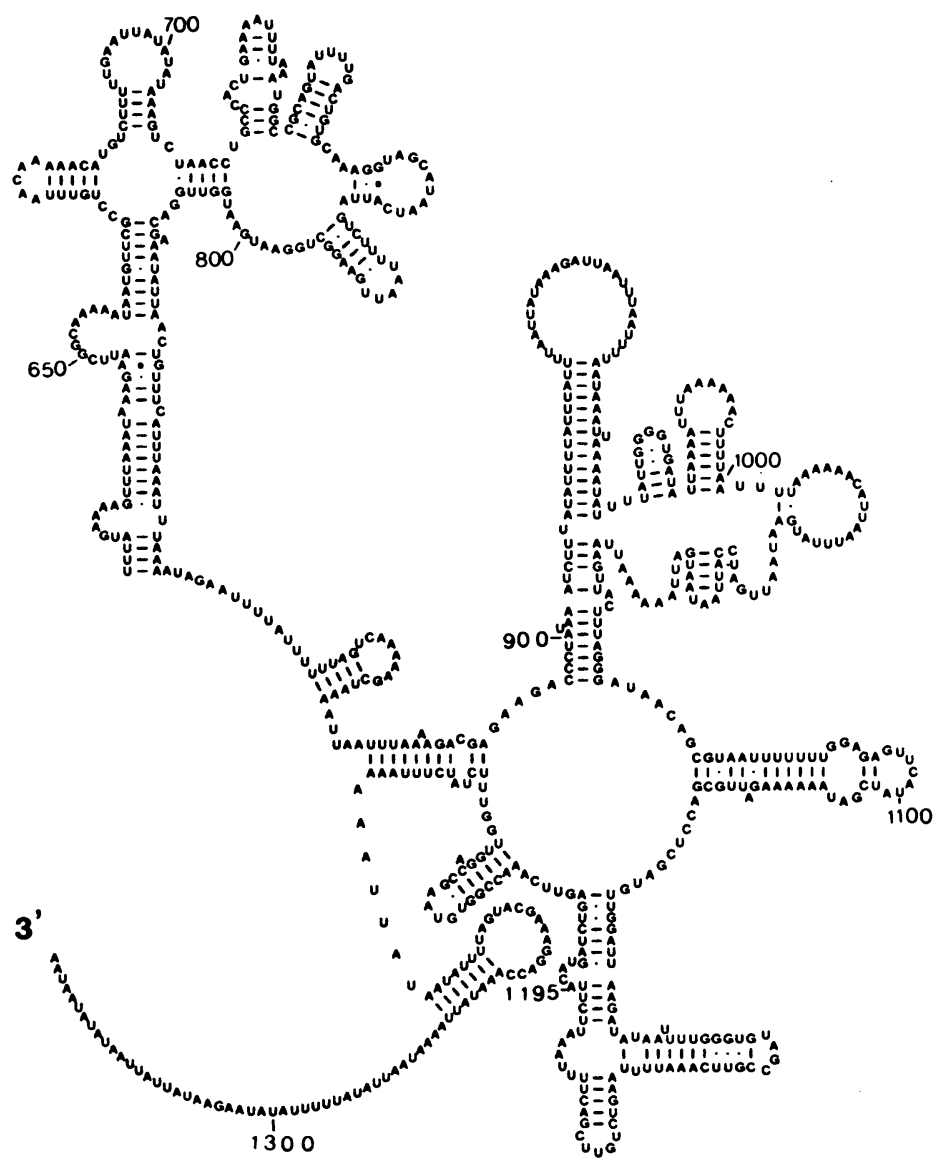

Fig.22b

Drosophila yakuba 
Secondary Structure of mitochondrial 23S Ribosomal RNA: 5'half

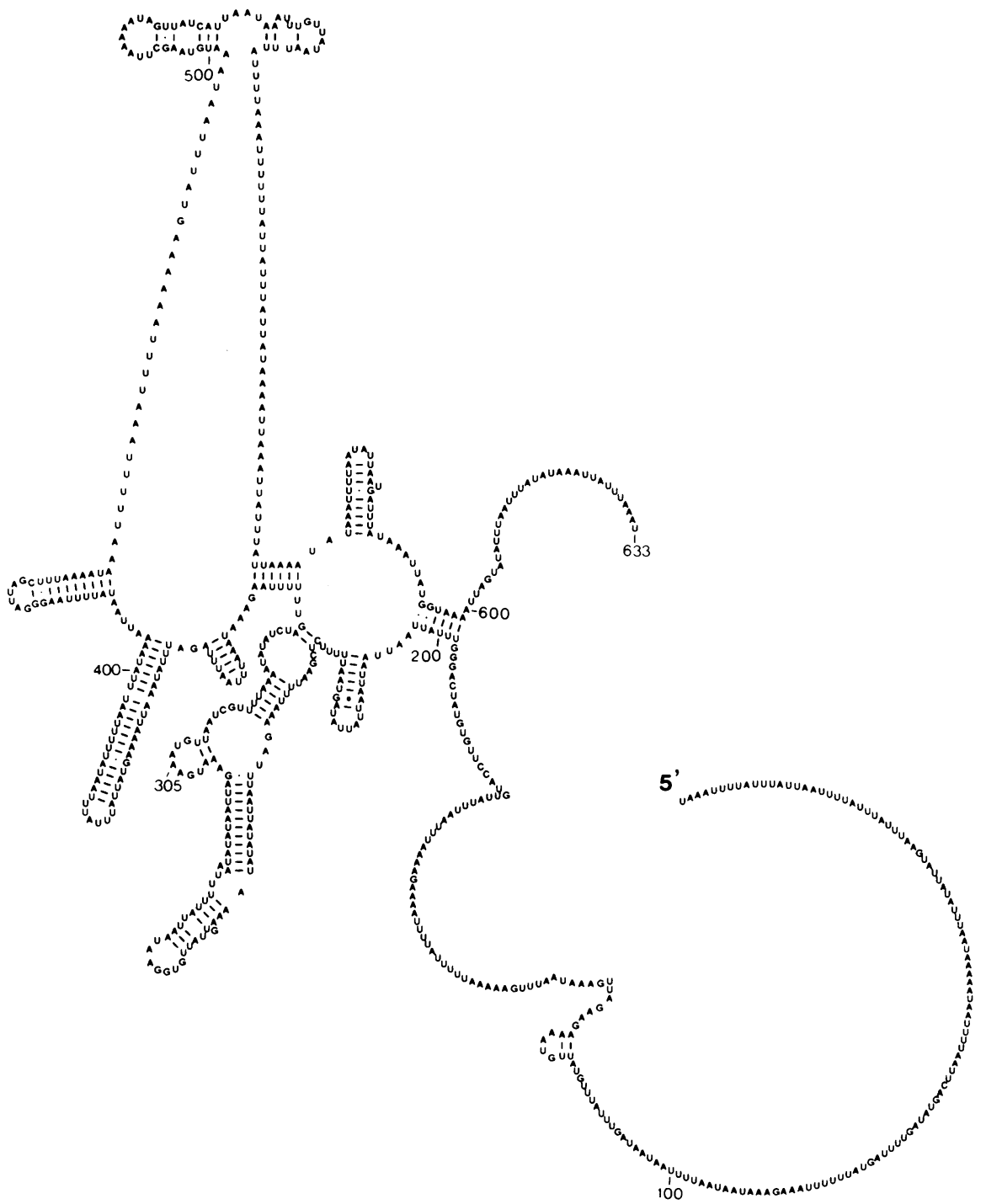

Fig.23a

Aedes albopictus: mosquito 
Secondary Structure of mitochondrial 23S Ribosomal RNA: 3'half

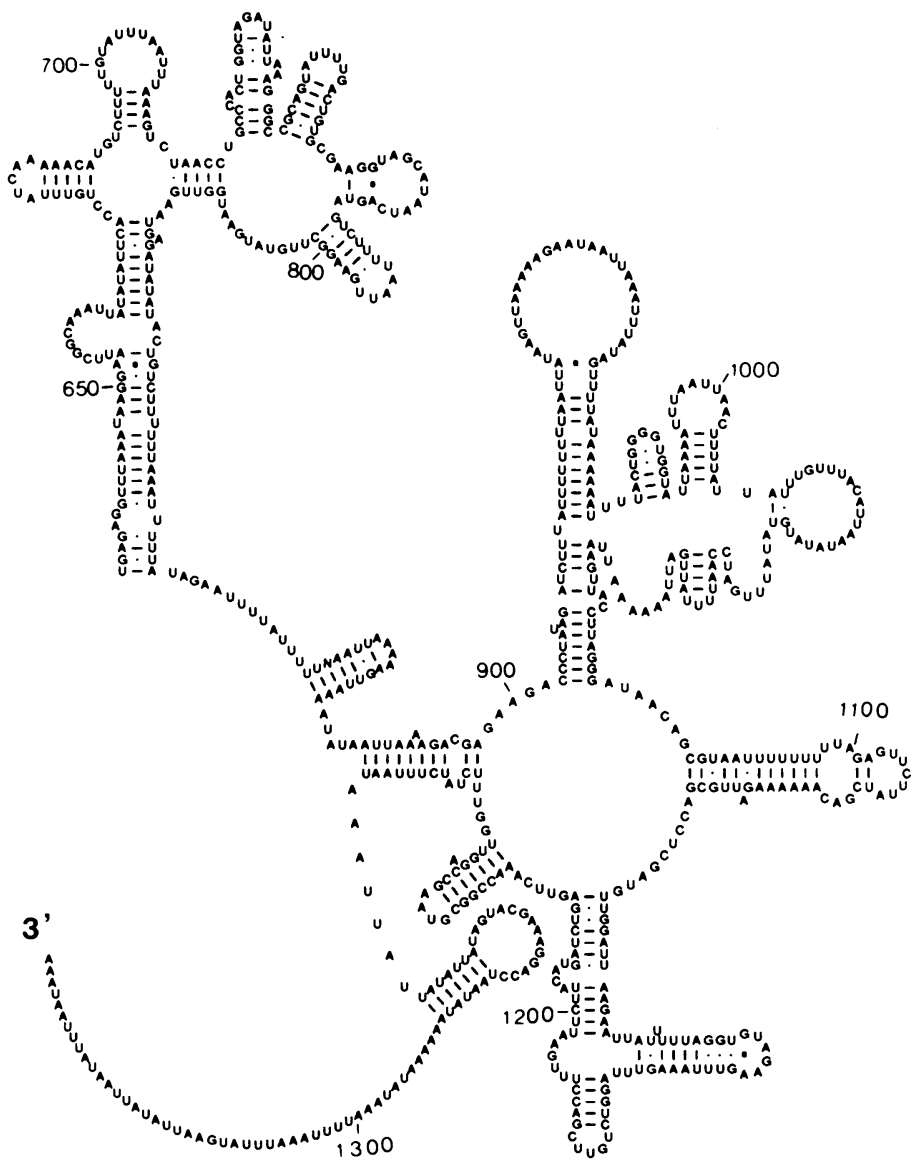

Fig.23b

Aedes albopictus: mosquito 
Secondary Structure of mitochondrial 23S Ribosomal RNA: 5'half

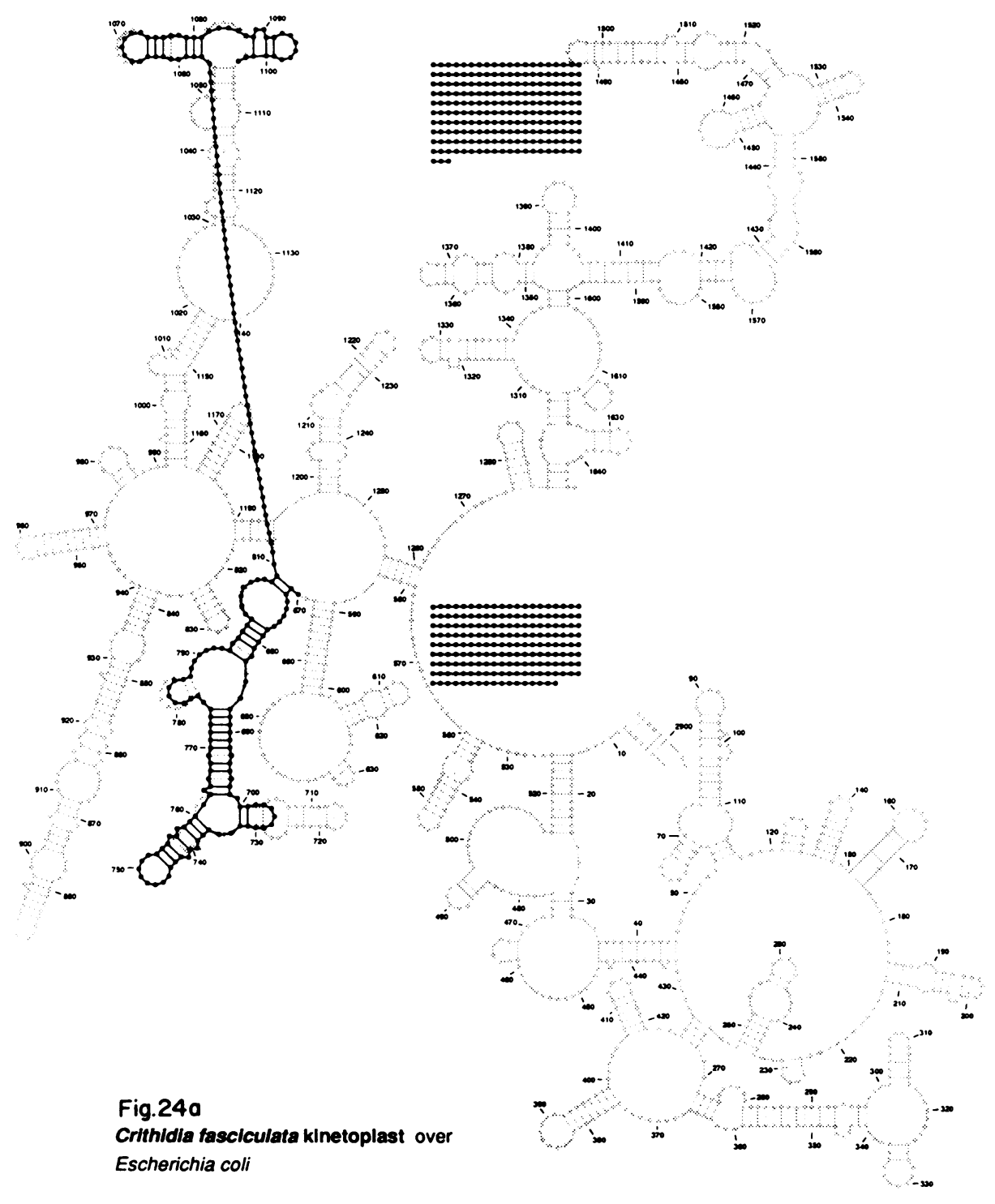


Secondary Structure of mitochondrial 23S Ribosomal RNA: 3'half

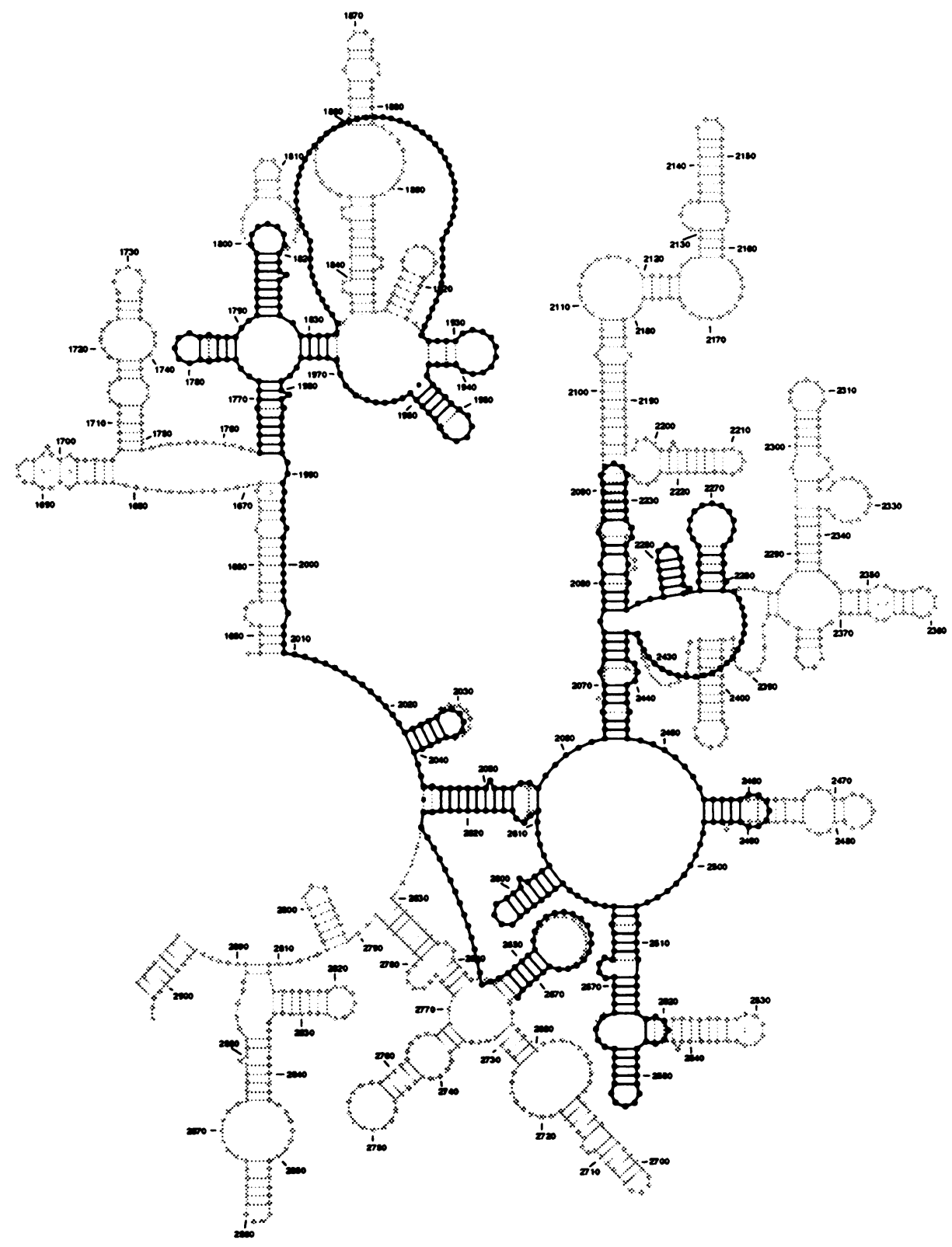

Fig.24b

Crithidla fasciculata kinetoplast over Escherichia coli 
Secondary Structure of mitochondrial 23S Ribosomal RNA: 5 'half

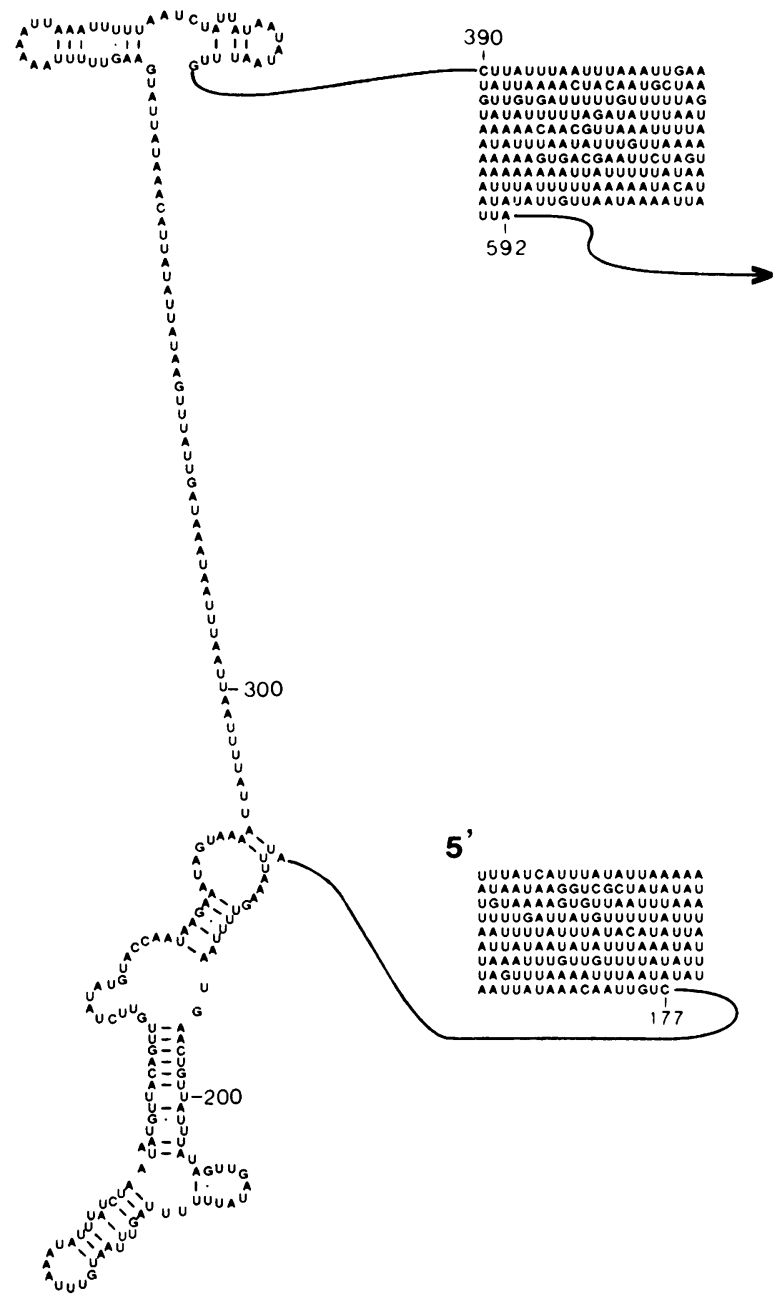

Fig.25a

Crithidia fasciculata 
Secondary Structure of mitochondrial 23S Ribosomal RNA: 3'half

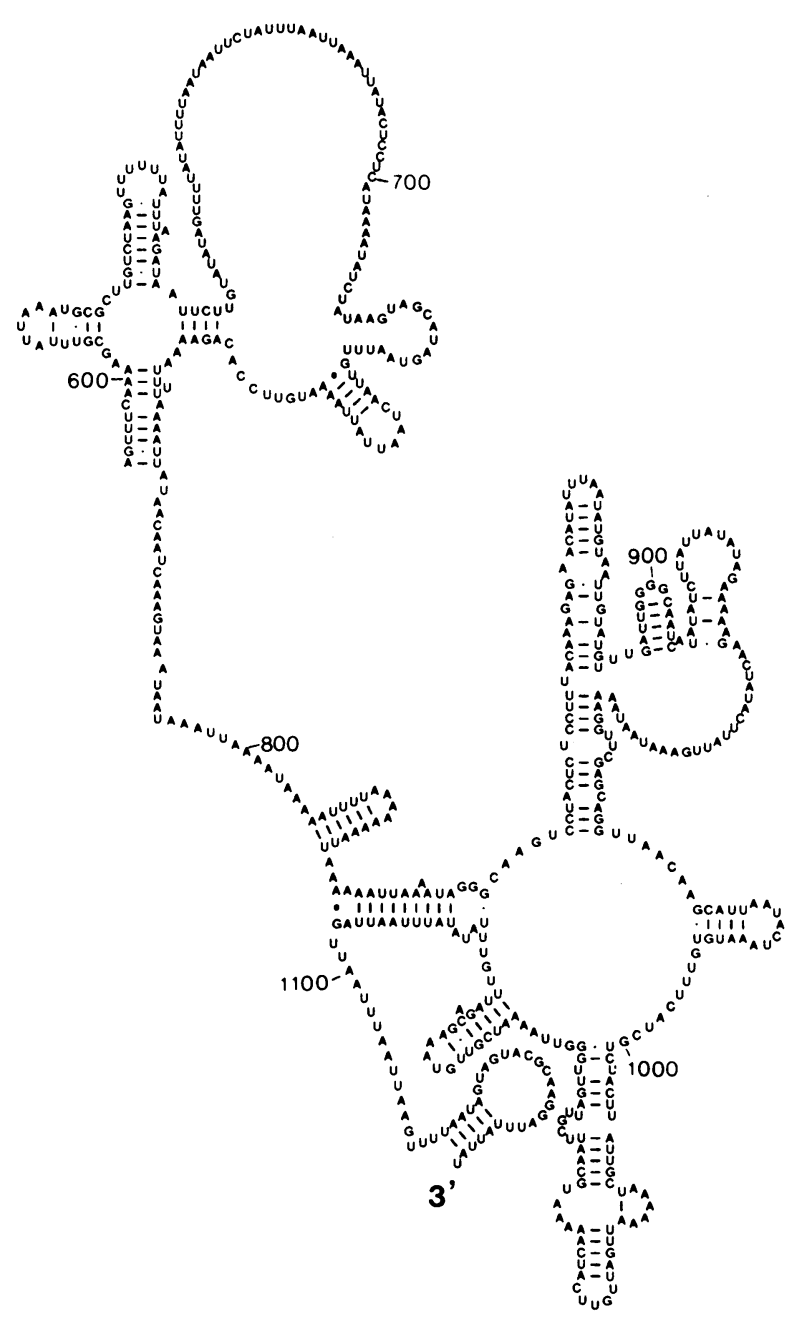

Fig.25b

Crithidia fasciculata 
Secondary Structure of mitochondrial 23S Ribosomal RNA: 5'half

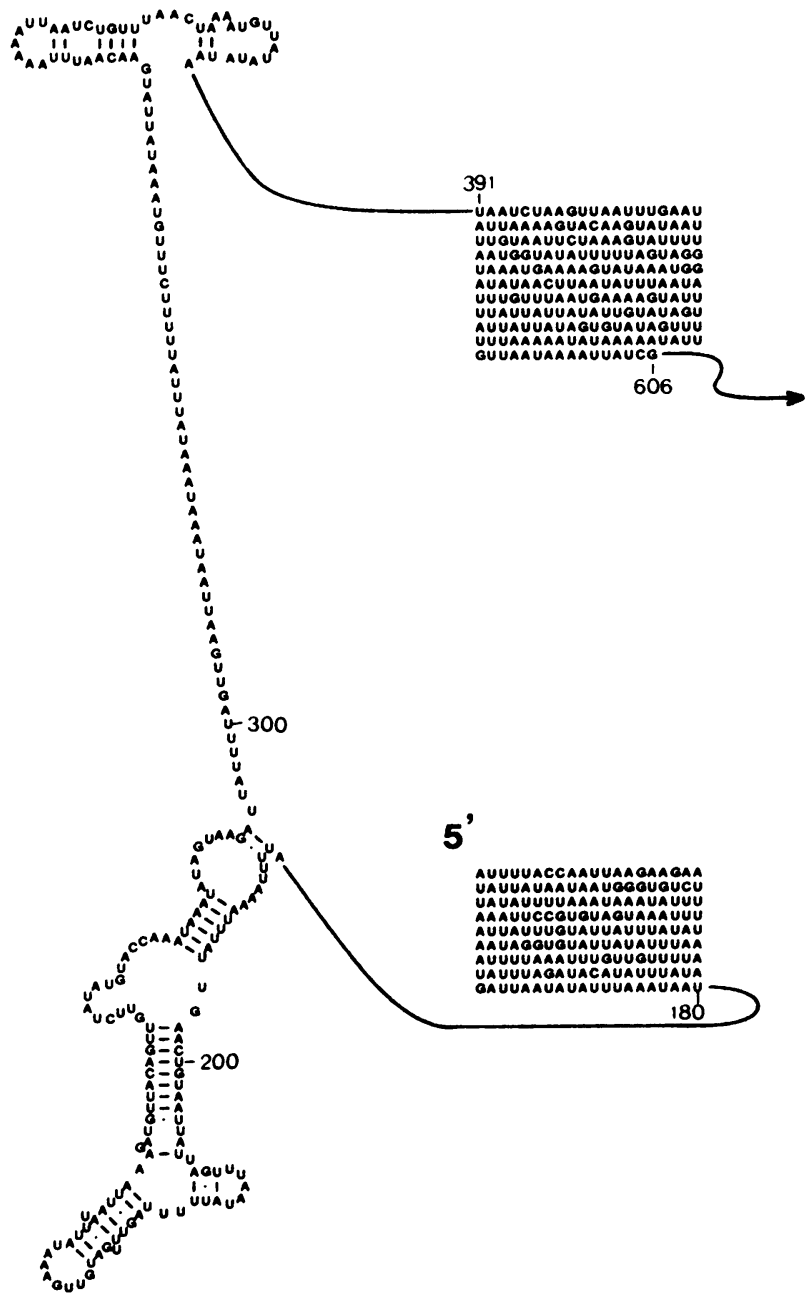

Fig.26a

Trypanosome brucei 
Secondary Structure of mitochondrial 23S Ribosomal RNA: 3'half

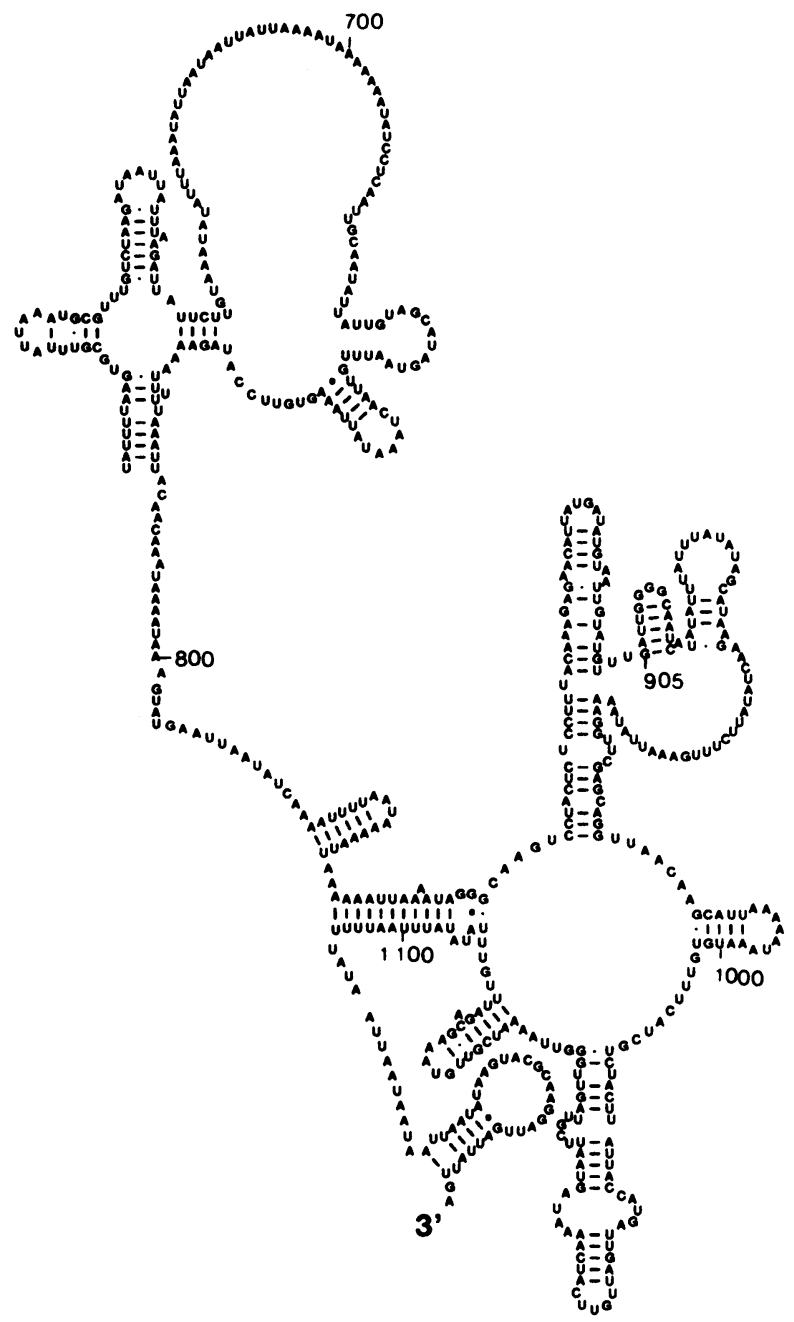

Fig.26b

Trypanosome brucei 
Nucleic Acids Research

Secondary Structure of mitochondrial 23S Ribosomal RNA: 5 'half

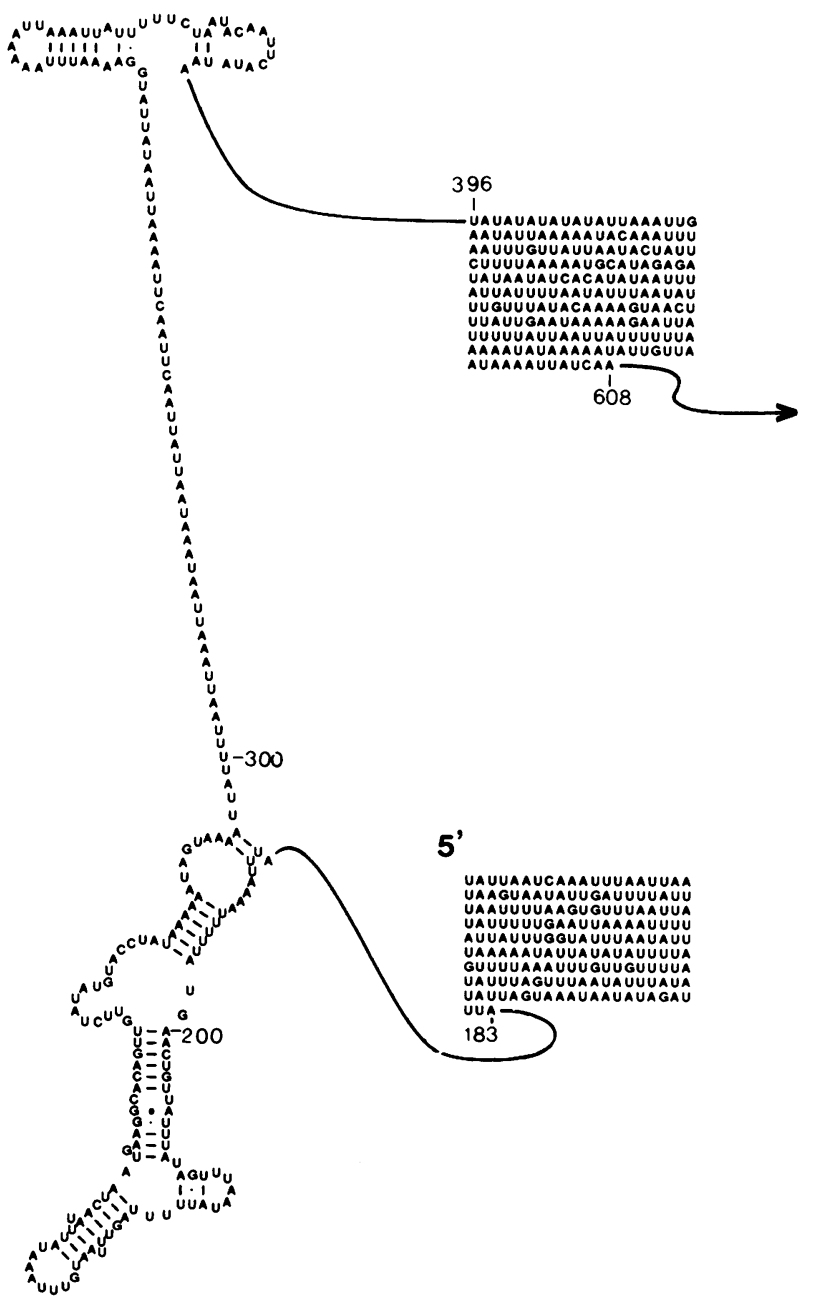

Fig.27a

Leishmania tarentolae 
Secondary Structure of mitochondrial 23S Ribosomal RNA: 3'half

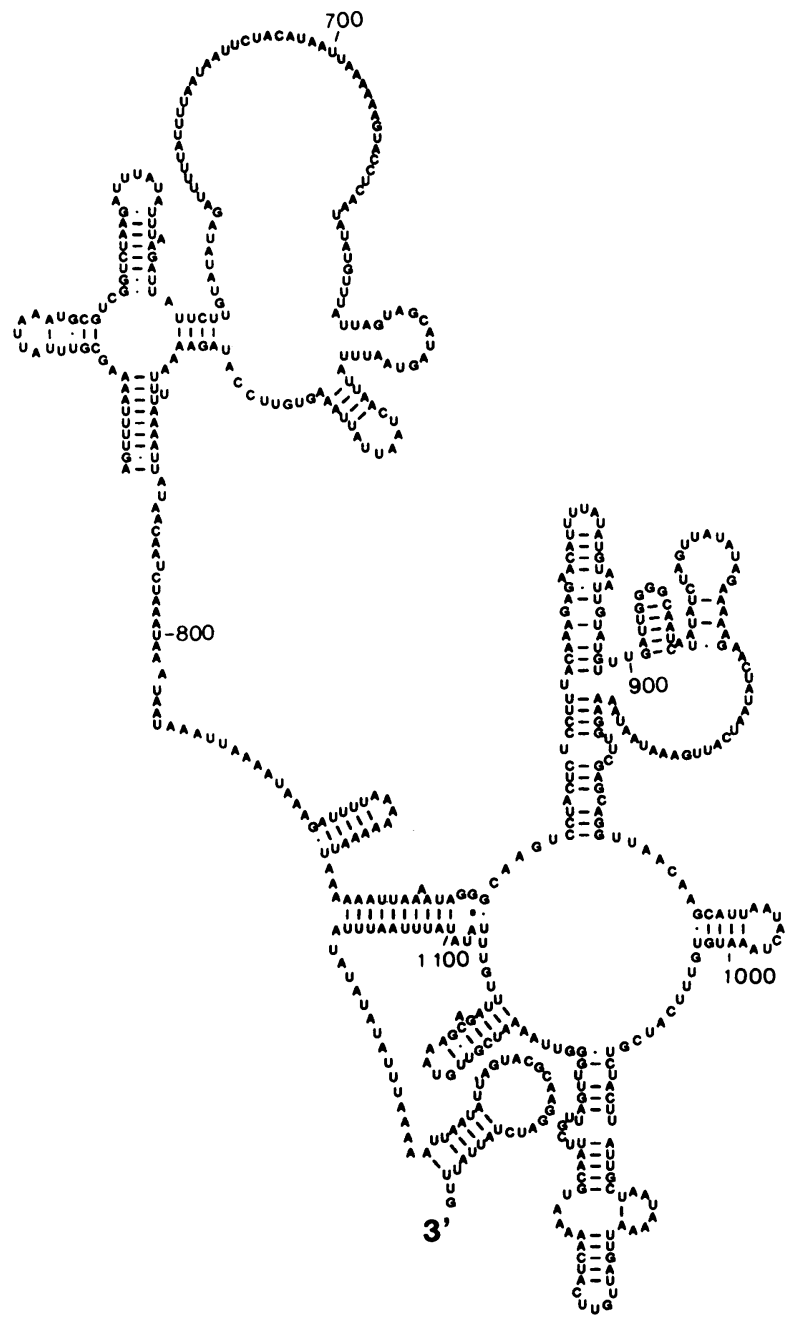

Fig.27b

Leishmania tarentolae 
Secondary Structure of archaebacterial 23S Ribosomal RNA: 5 'half

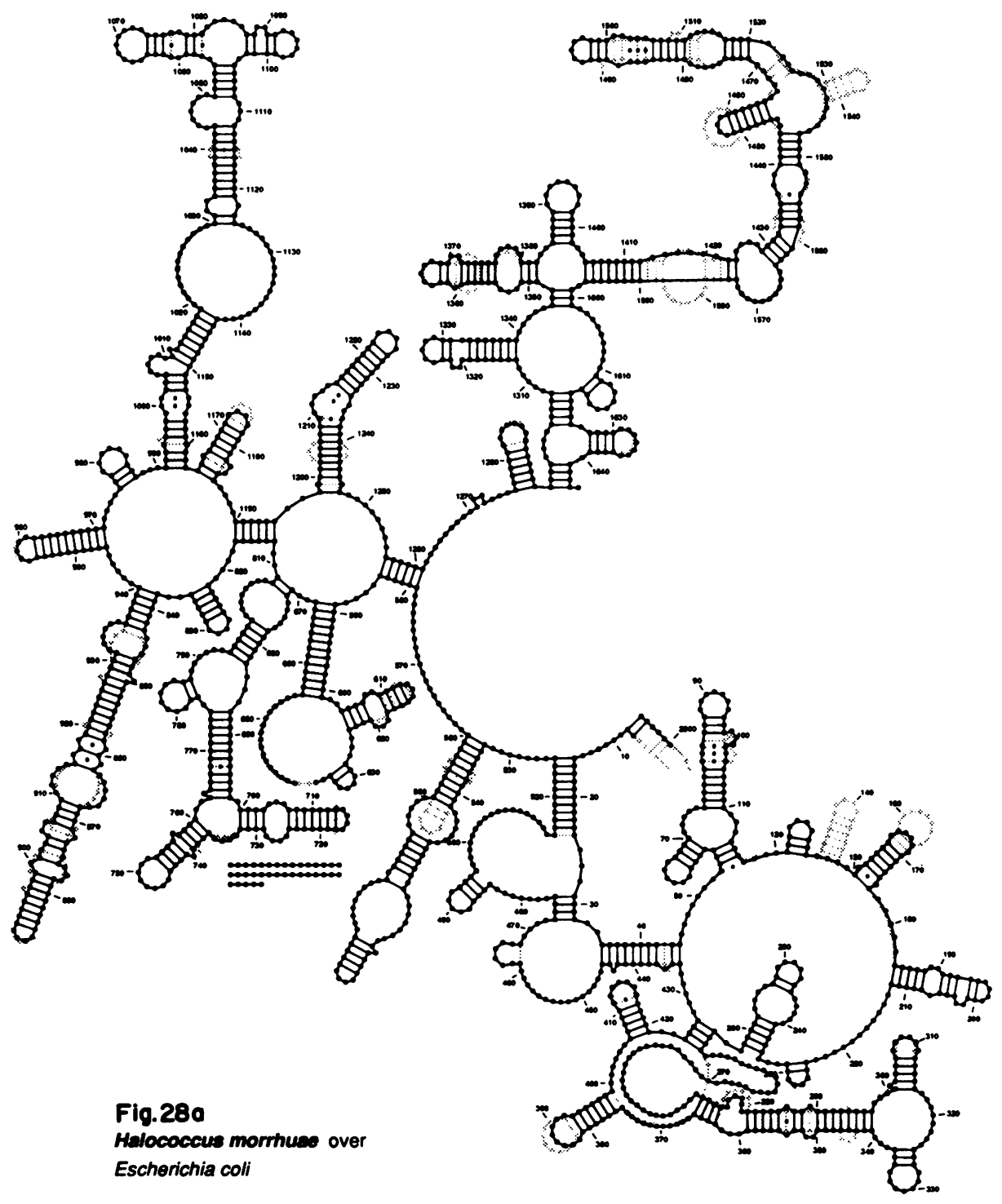


Secondary Structure of archaebacterial 23S Ribosomal RNA: 3'half

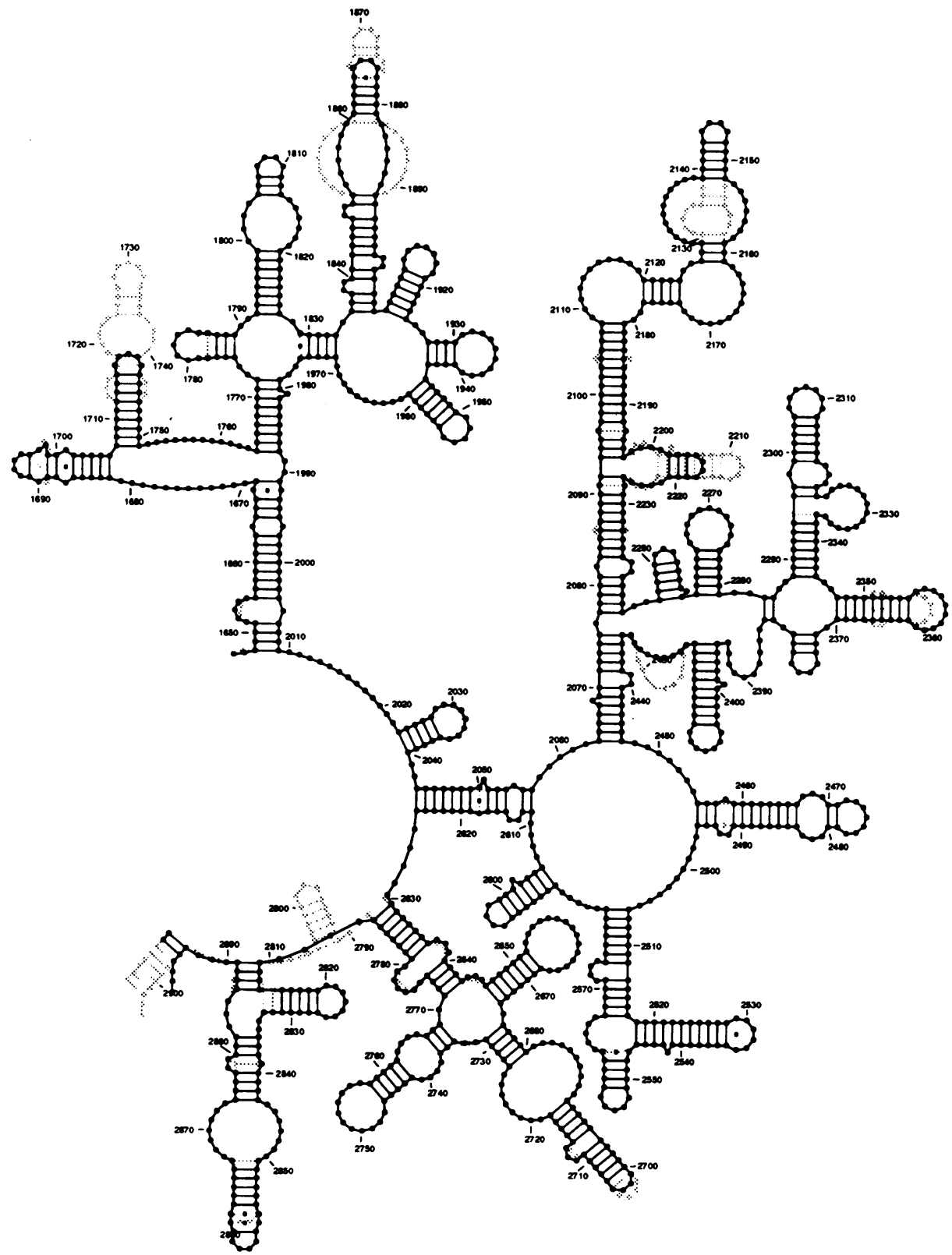

Fig. 28b

Halococcus morrhuae over Escherichia coli 
Secondary Structure of archaebacterial 23S Ribosomal RNA: 5'half

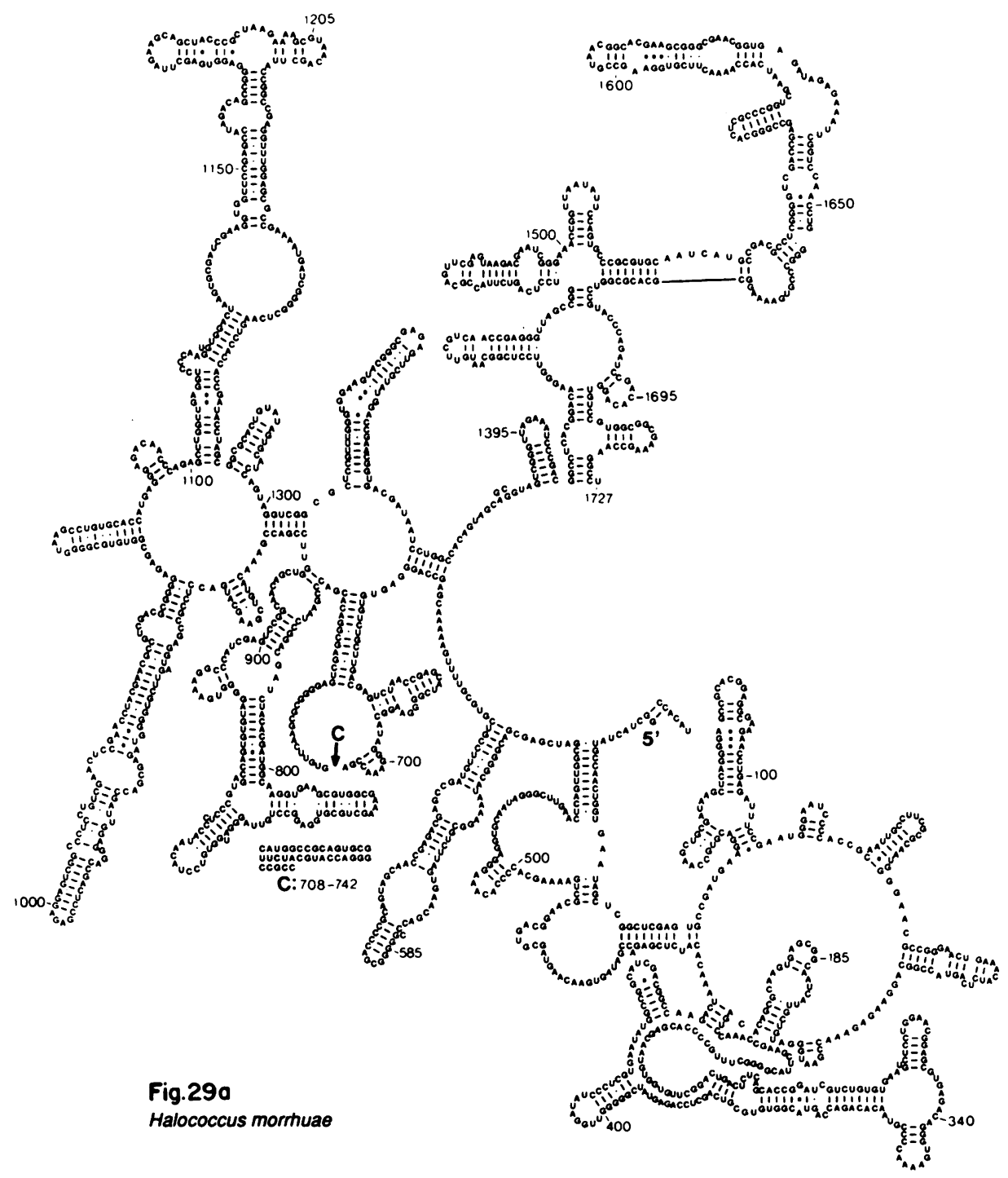


Secondary Structure of archaebacterial 23S Ribosomal RNA: 3 'half

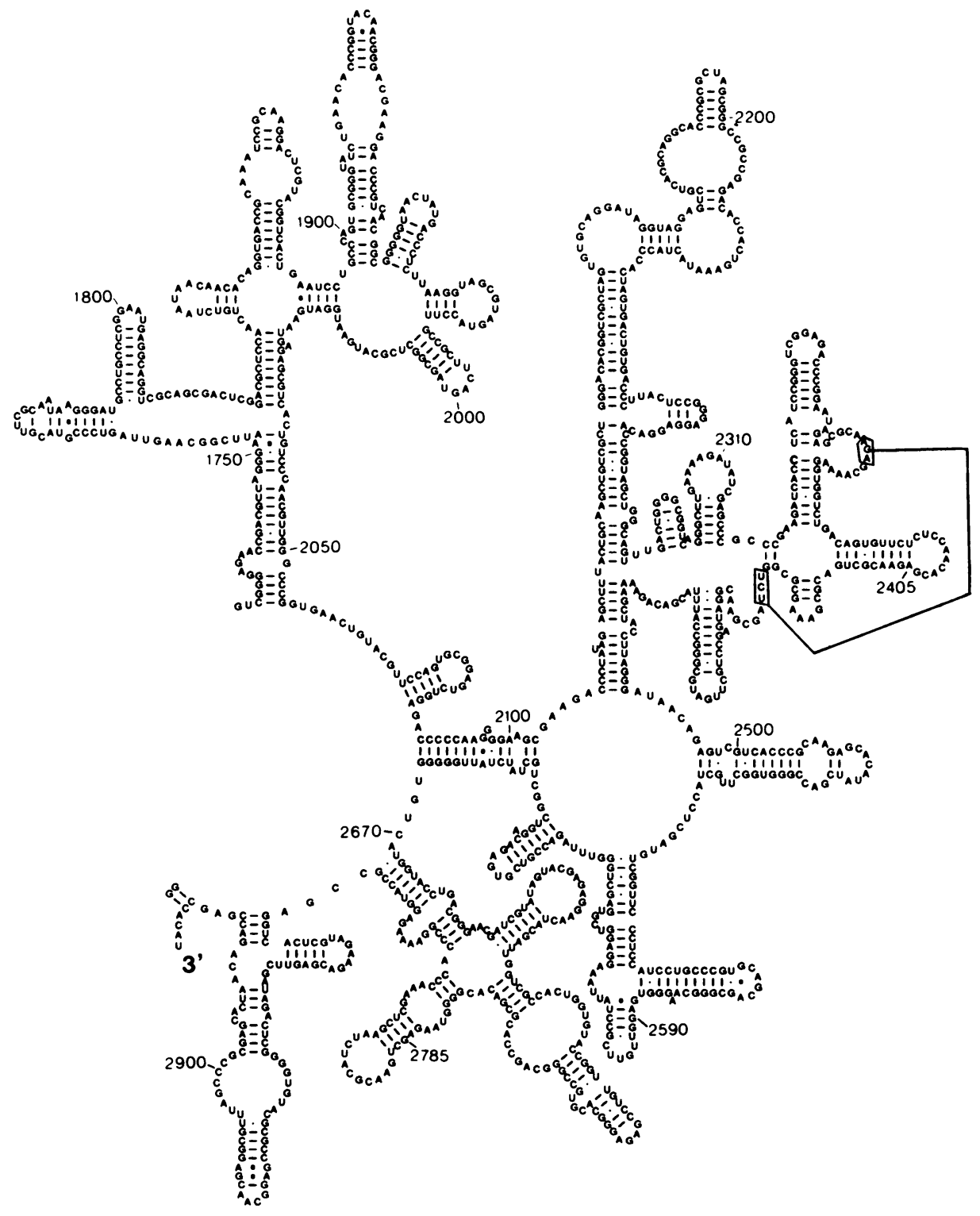

Fig.29b

Halococcus morrhuae 
Secondary Structure of archaebacterial 23S Ribosomal RNA: 5'half

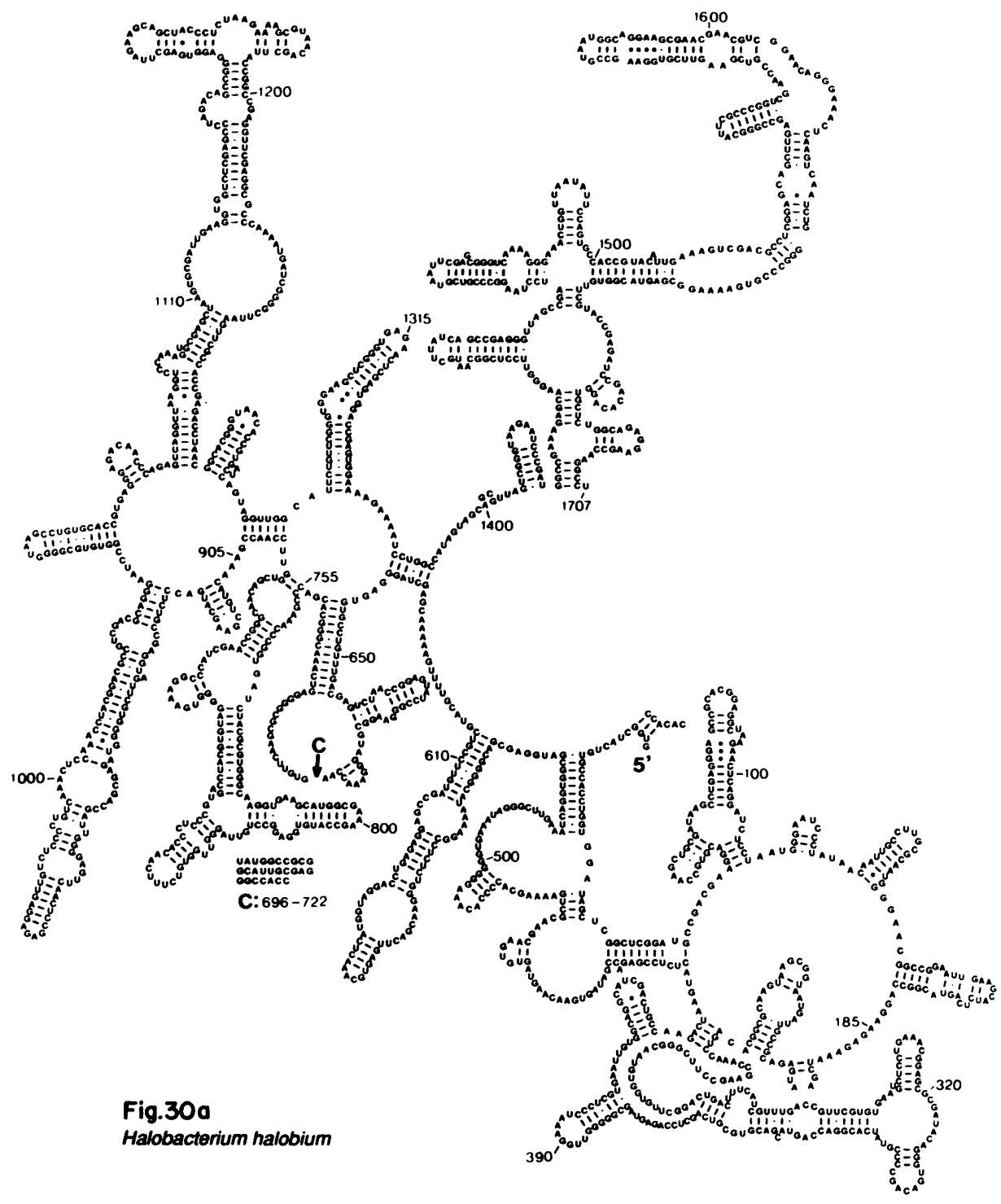


Secondary Structure of archaebacterial 23S Ribosomal RNA: 3'half

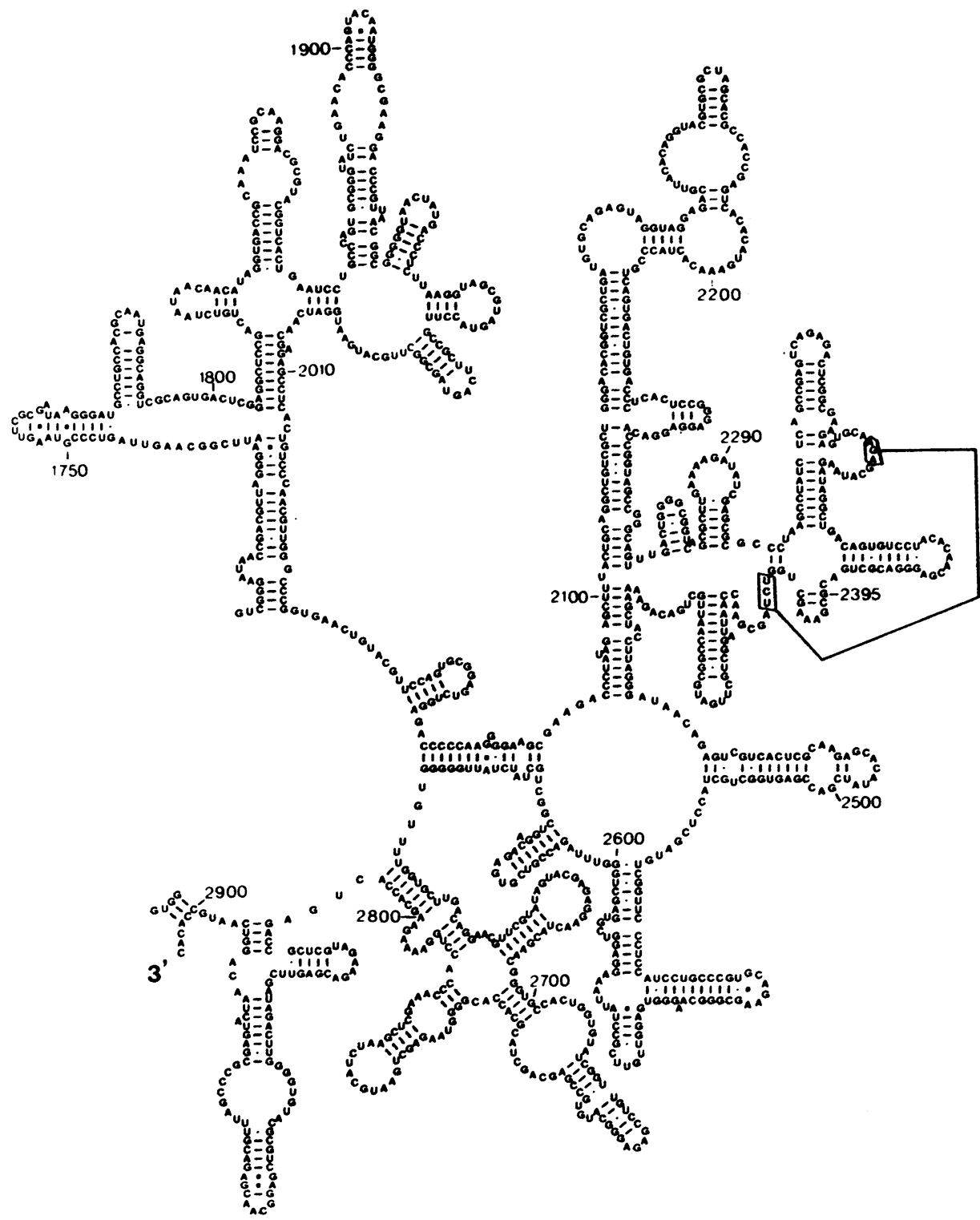

Fig.30b

Halobacterium halobium 
Secondary Structure of archaebacterial 23S Ribosomal RNA: 5'half

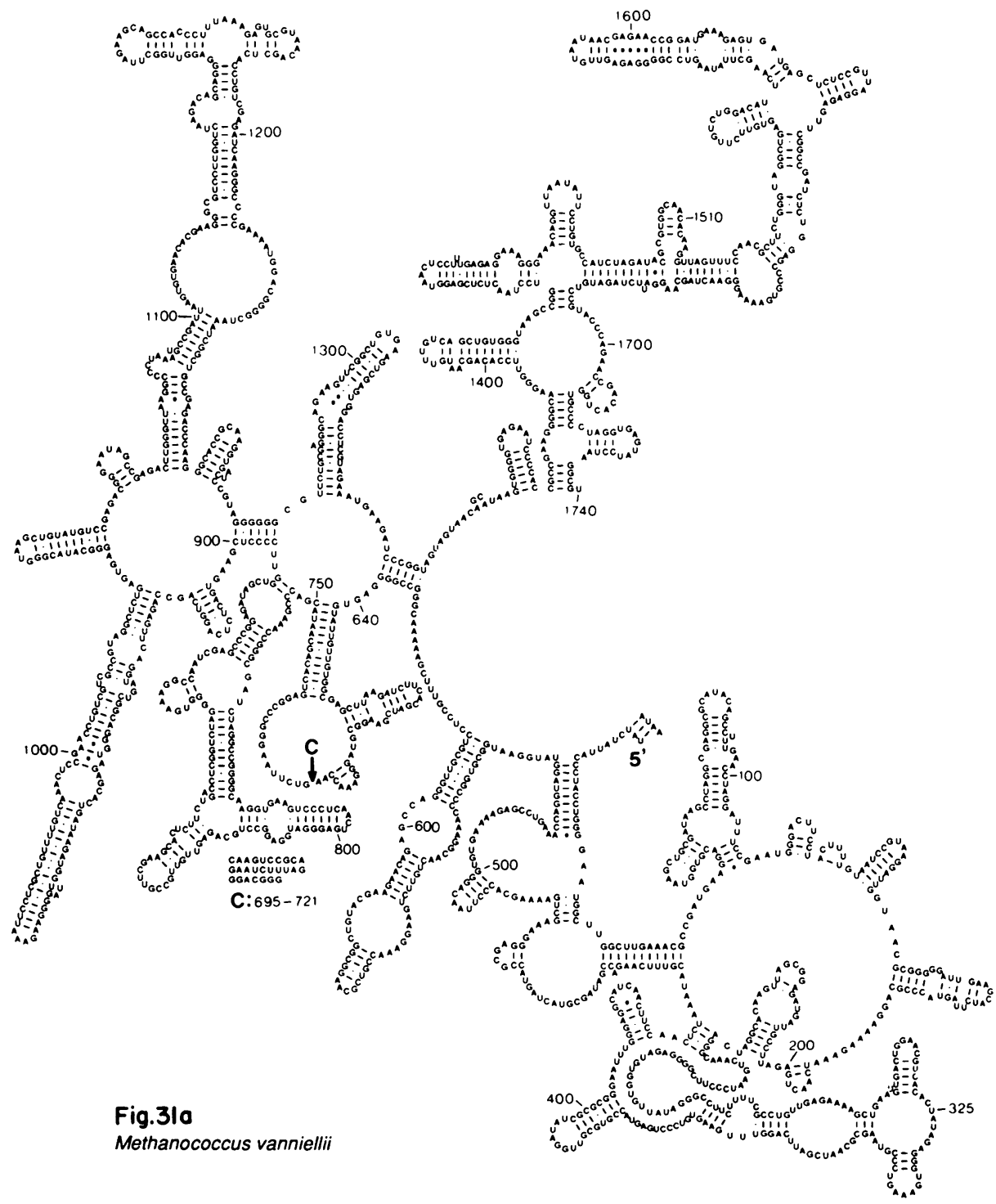


Secondary Structure of archaebacterial 23S Ribosomal RNA: 3'half

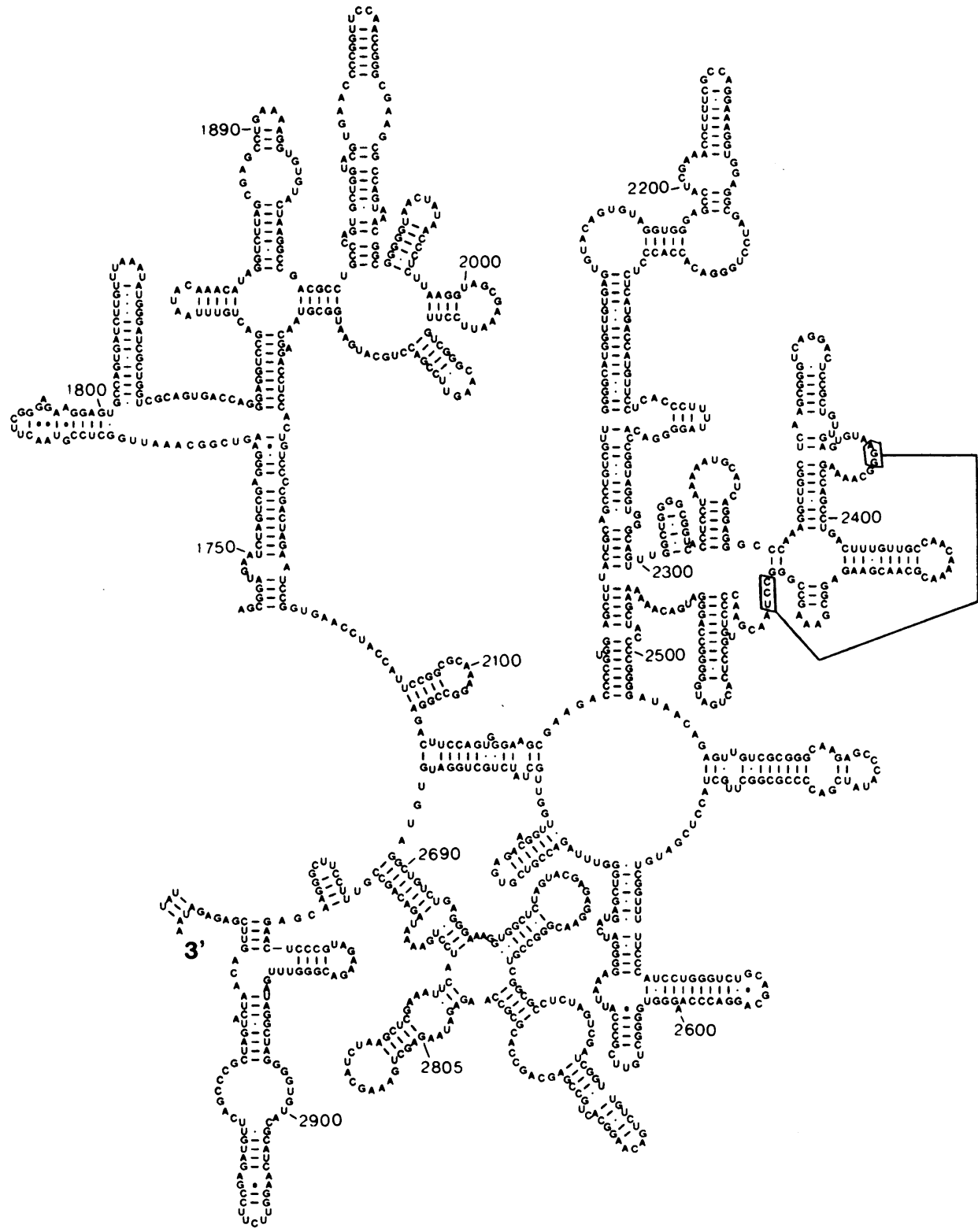

Fig.31b

Methanococcus vanniellii 
Secondary Structure of archaebacterial 23S Ribosomal RNA: 5 'half

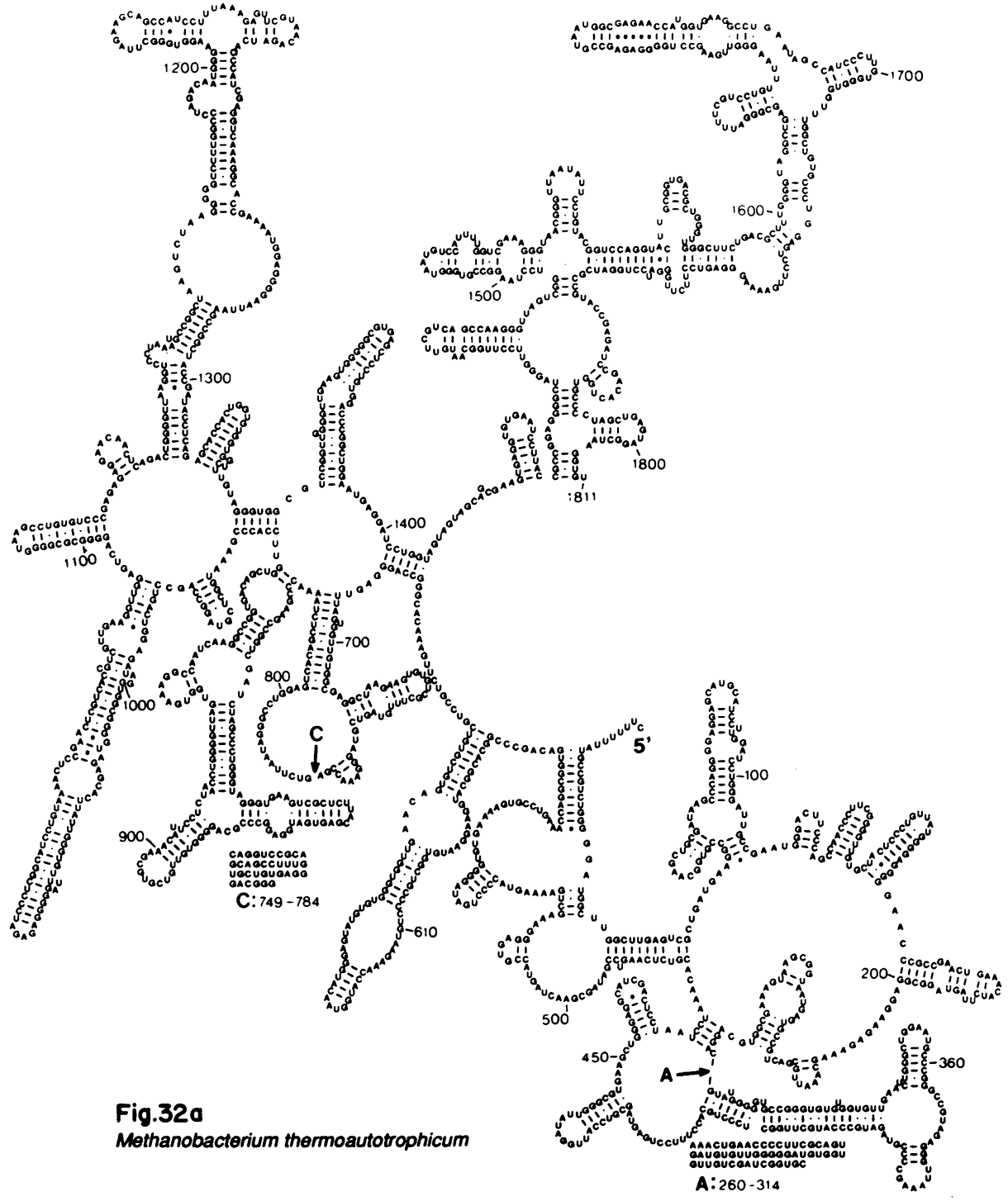


Secondary Structure of archaebacterial 23S Ribosomal RNA: 3'half

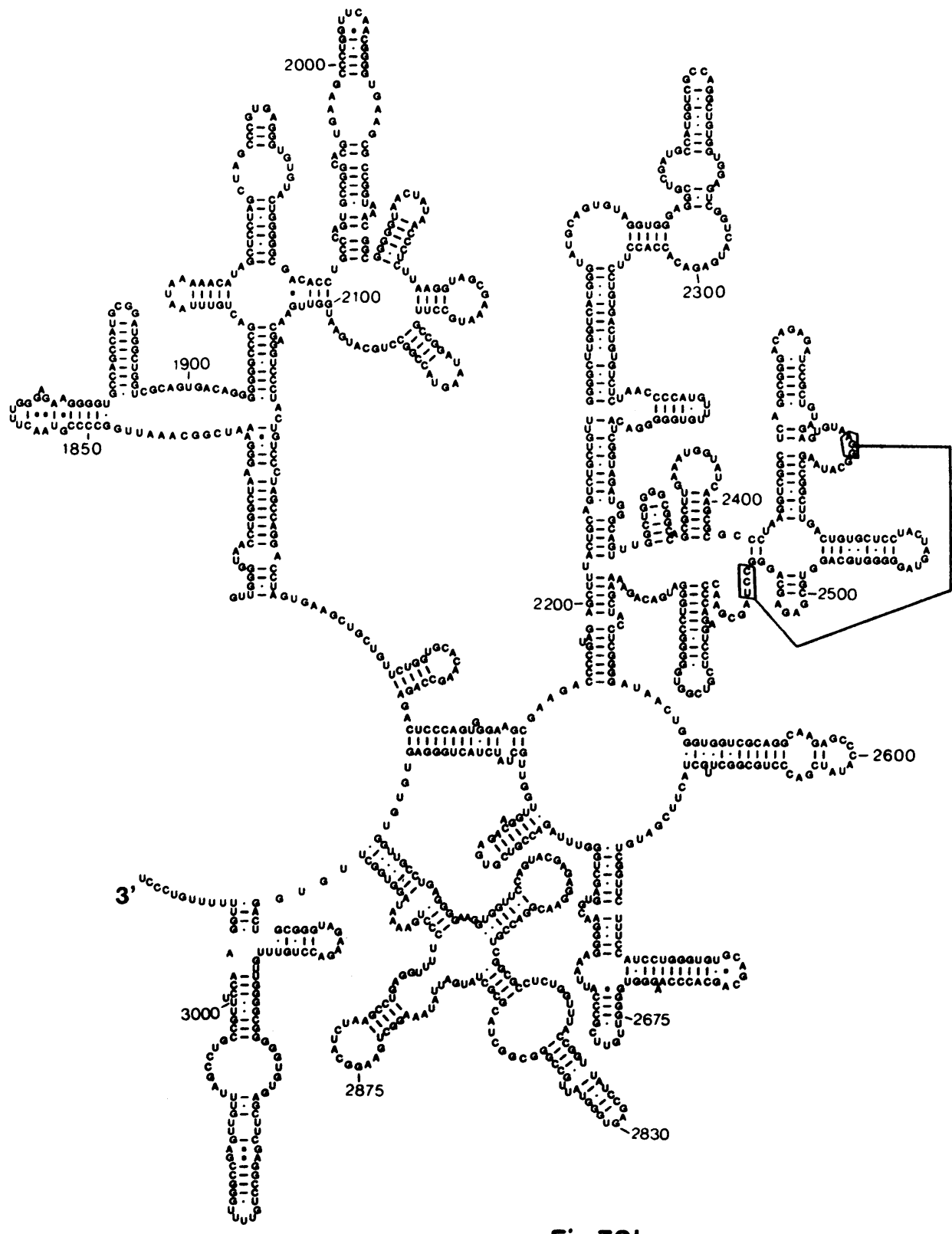

Fig.32b

Methanobacterium thermoautotrophicum 
Secondary Structure of archaebacterial 23S Ribosomal RNA: 5'half

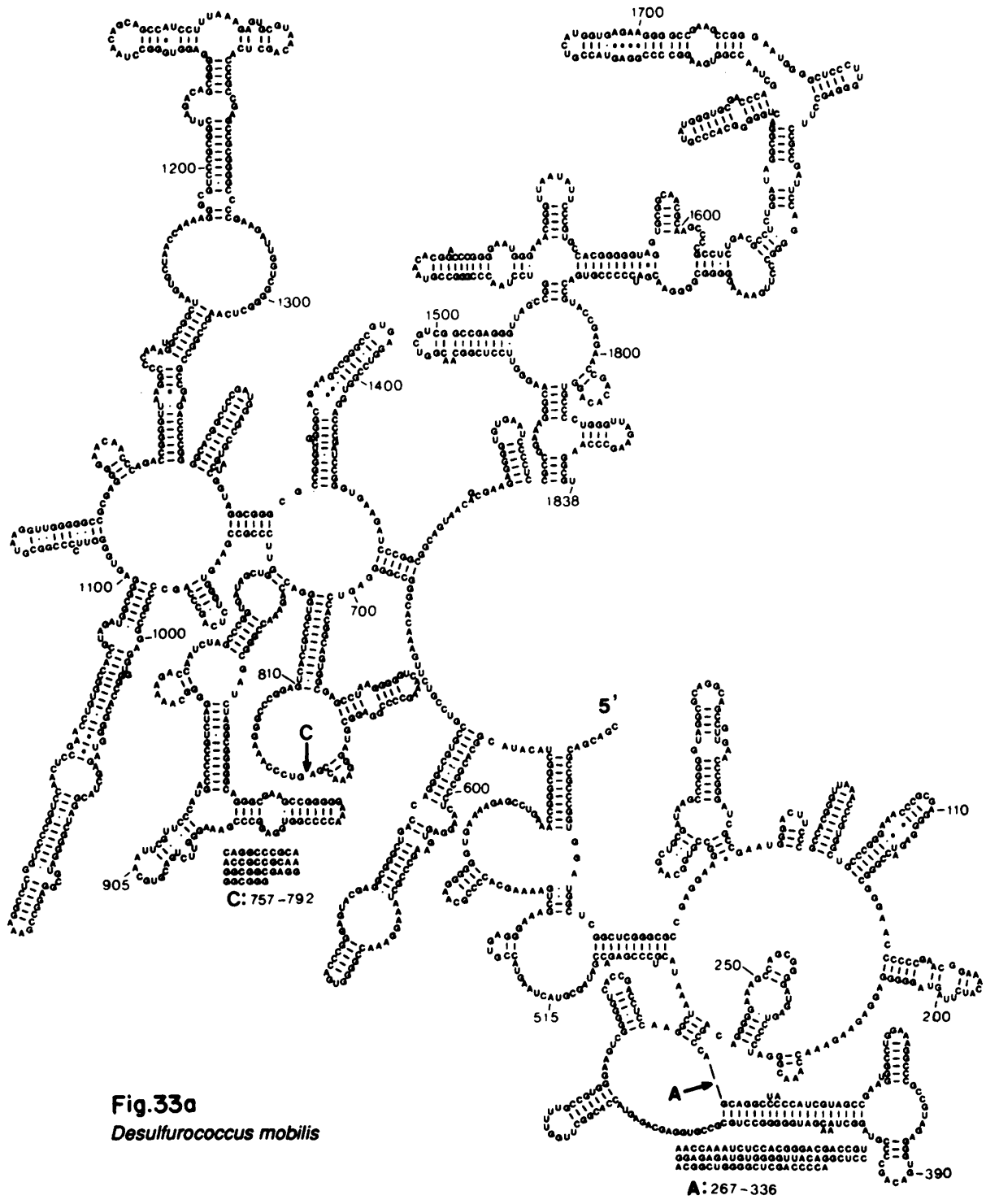


Secondary Structure of archaebacterial 23S Ribosomal RNA: 3 'half

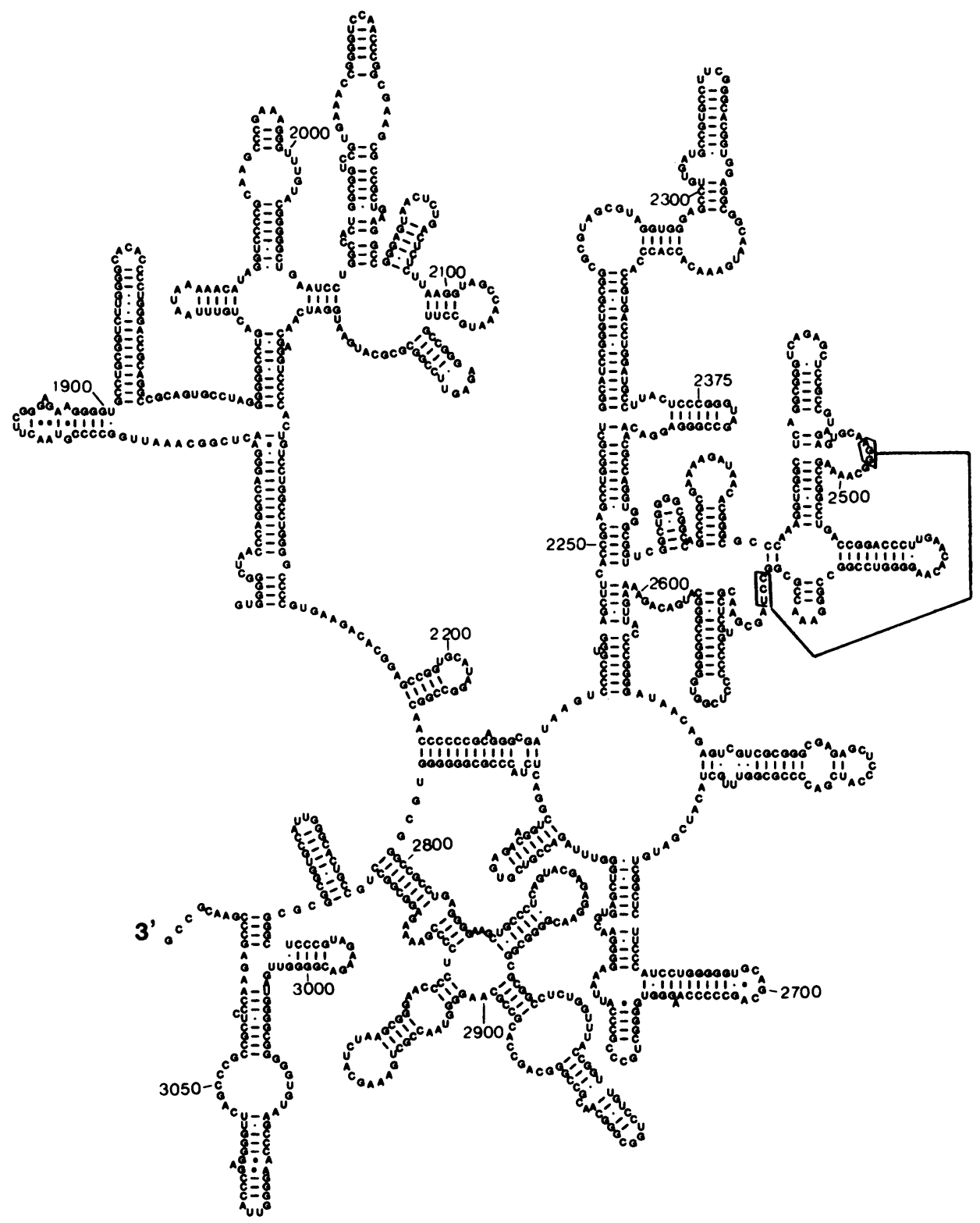

Fig.33b

Desulfurococcus mobilis 
Secondary Structure of eucaryotic 23S Ribosomal RNA: 5'half

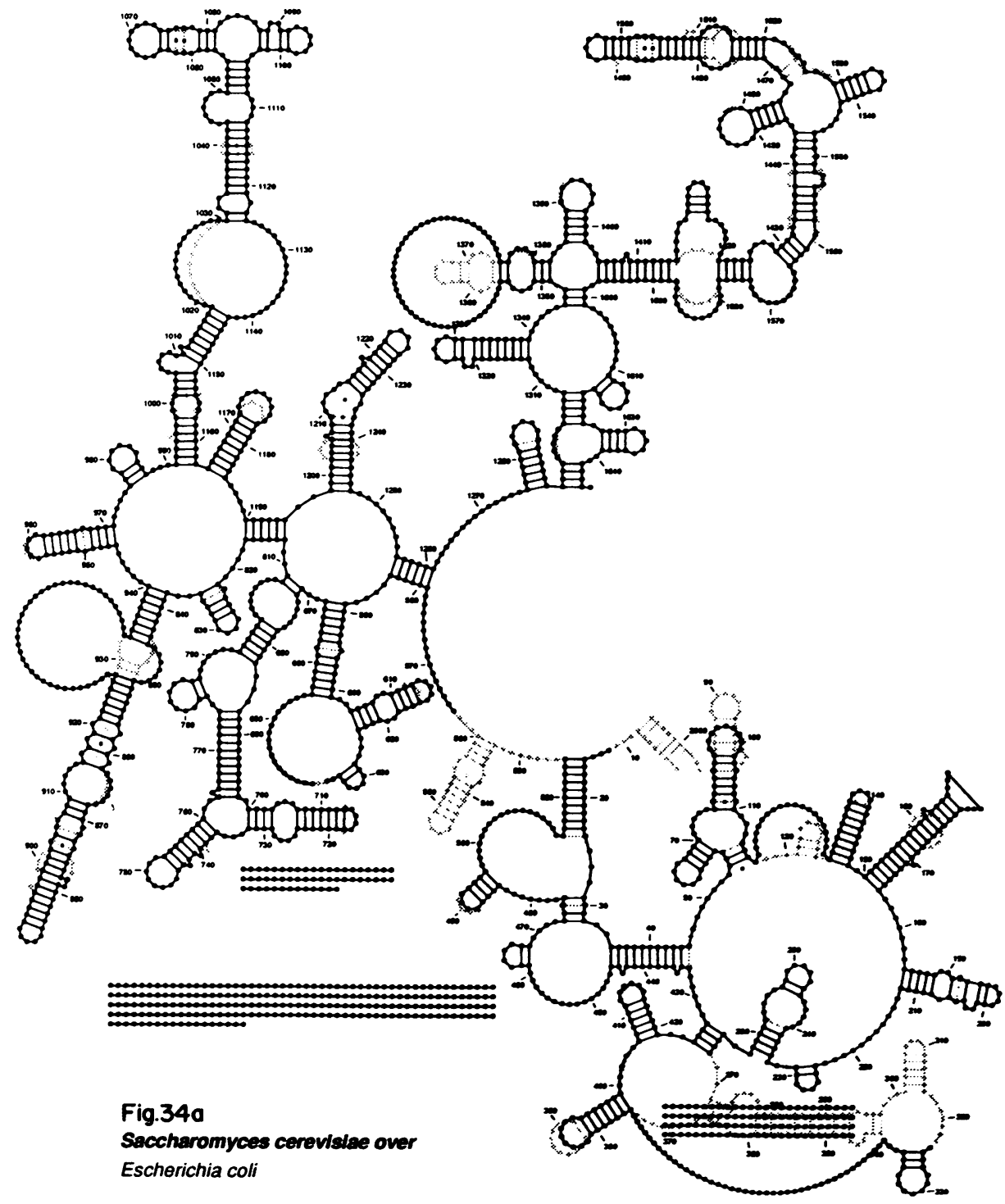


Secondary Structure of eucaryotic 23S Ribosomal RNA: 3'half

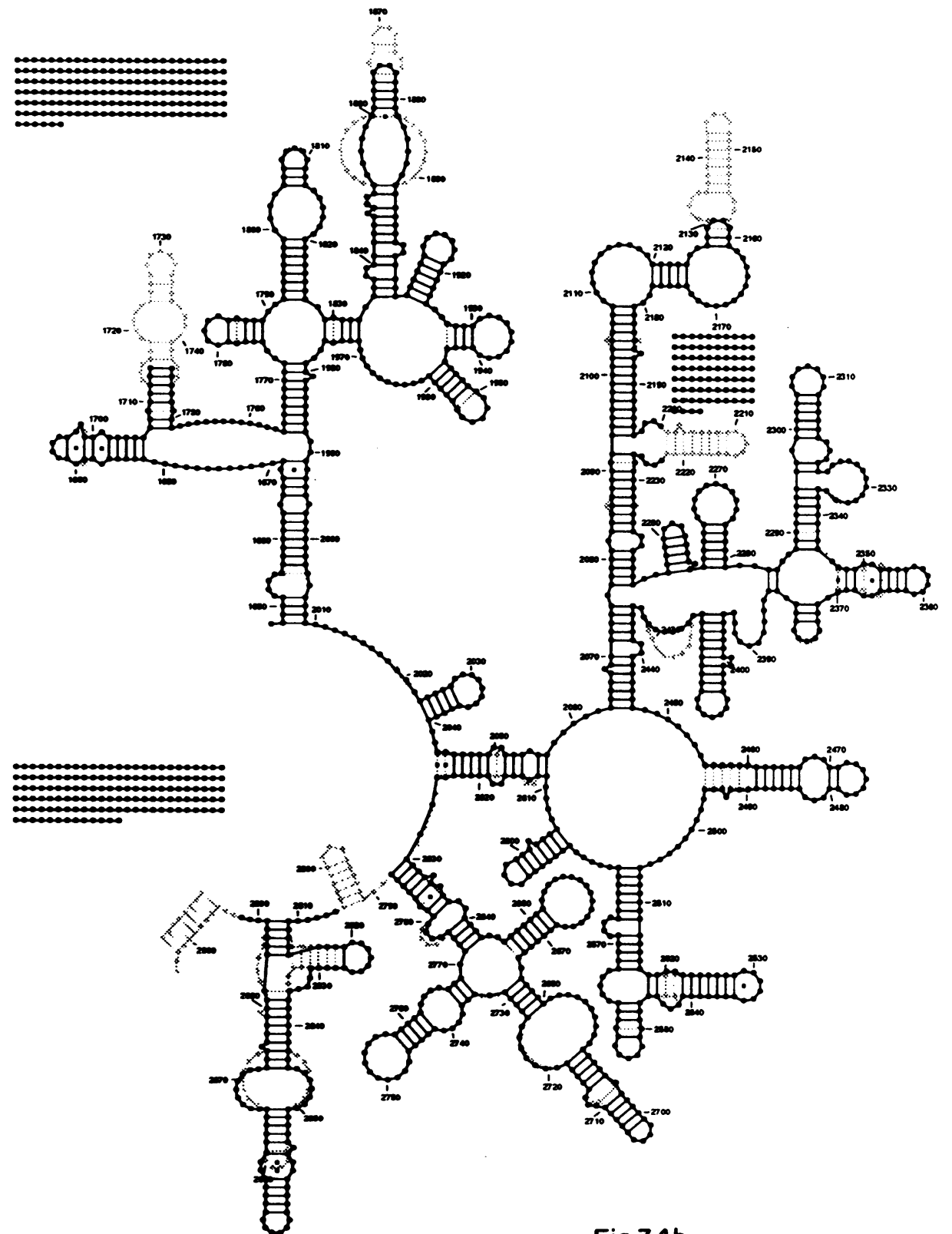

Fig.34b

Saccharomyces cerevislae over Escherichia coli 
Secondary Structure of eucaryotic 23S Ribosomal RNA: 5'half

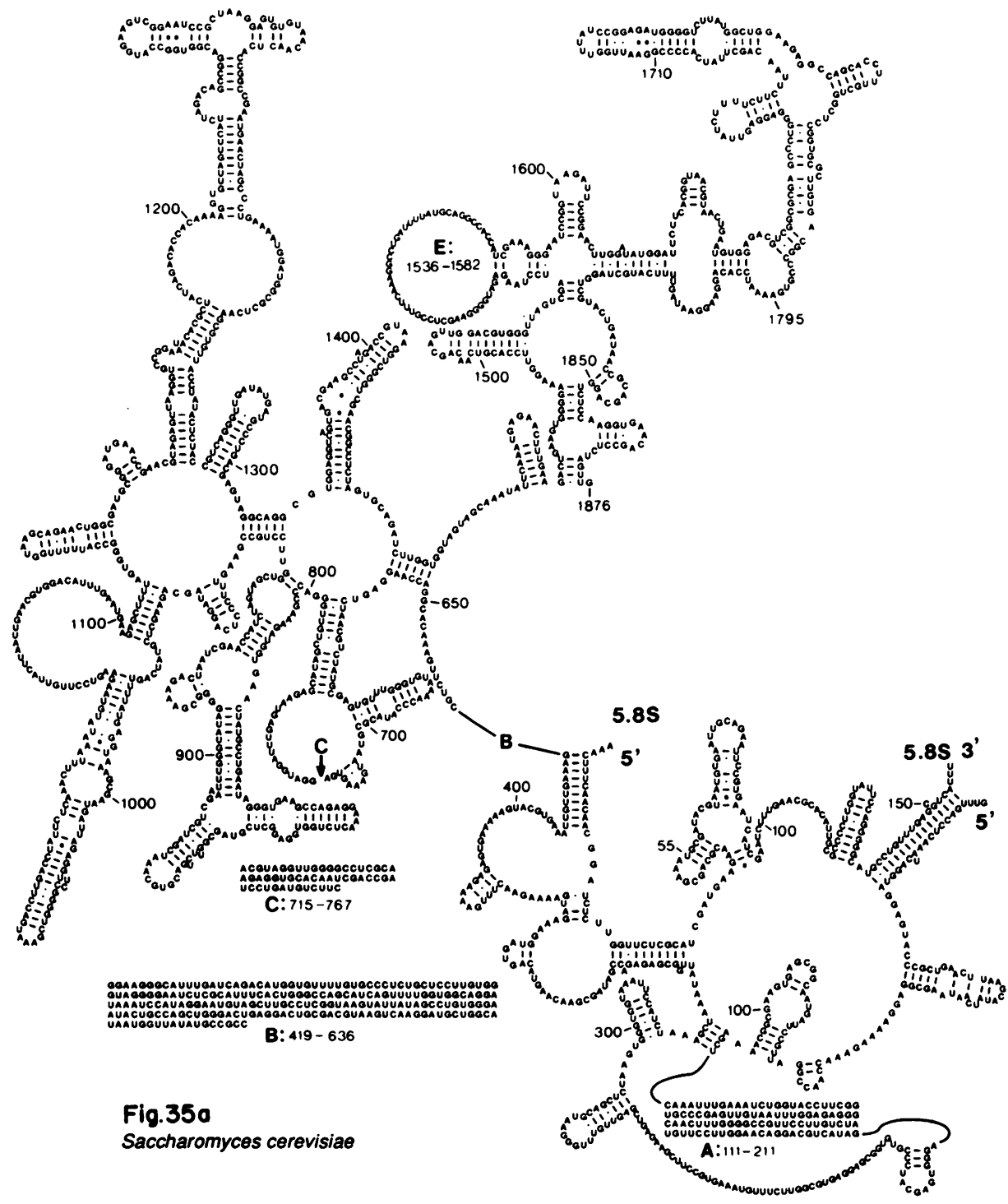


Secondary Structure of eucaryotic 23S Ribosomal RNA: 3'half

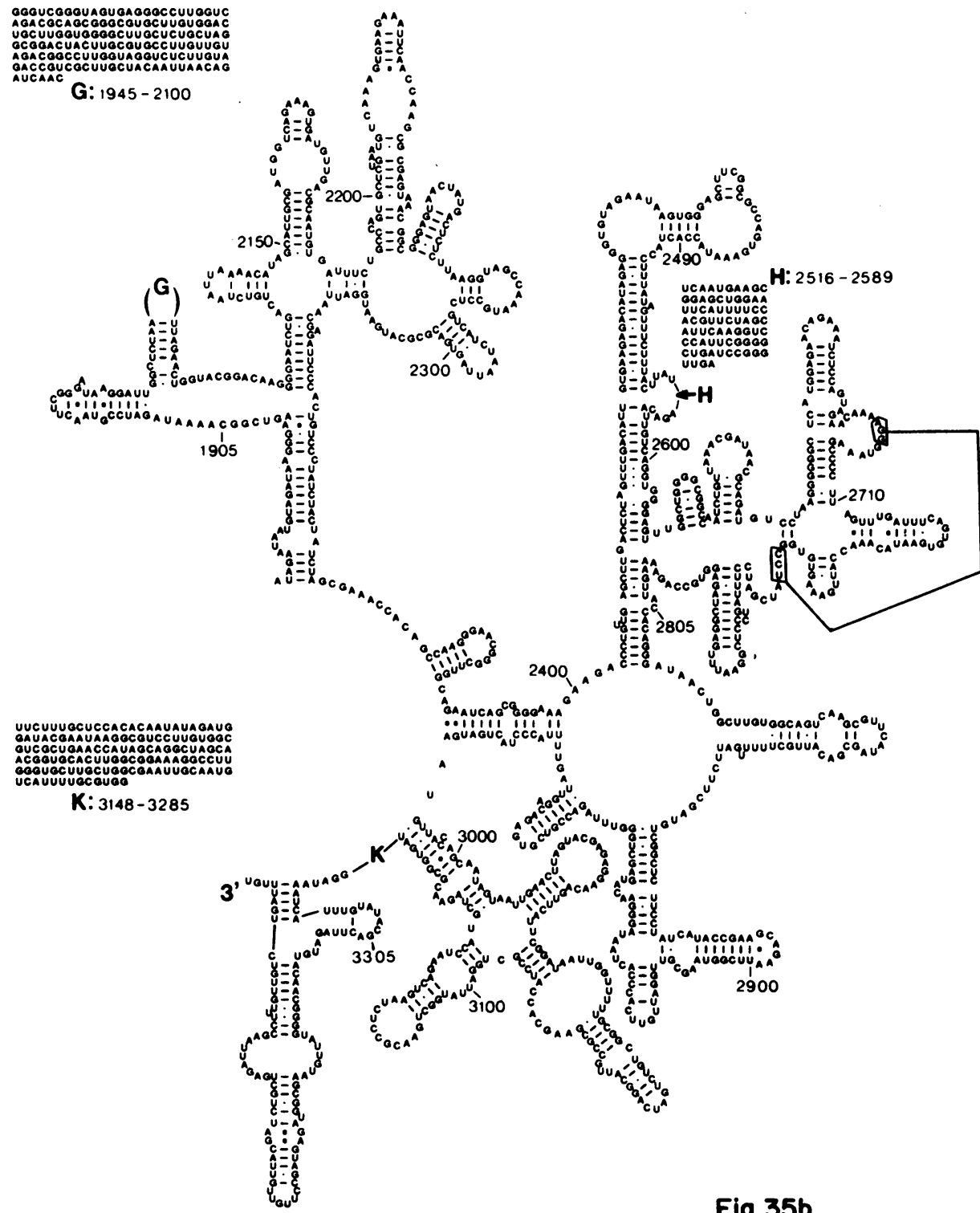

Fig.35b

Saccharomyces cerevisiae 
Secondary Structure of eucaryotic 23S Ribosomal RNA: 5'half

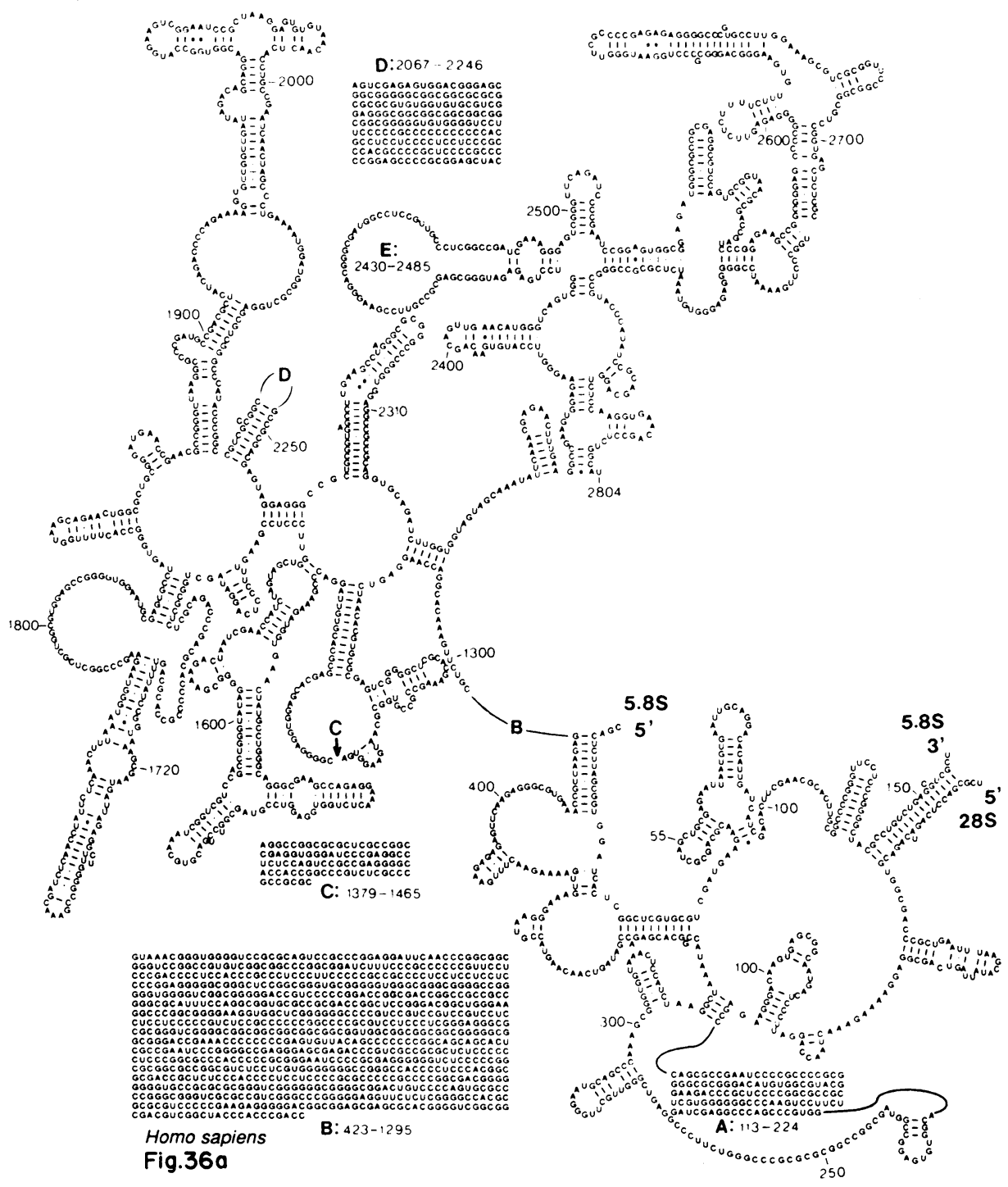


Secondary Structure of eucaryotic 23S Ribosomal RNA: 3'half

G:2874-3575

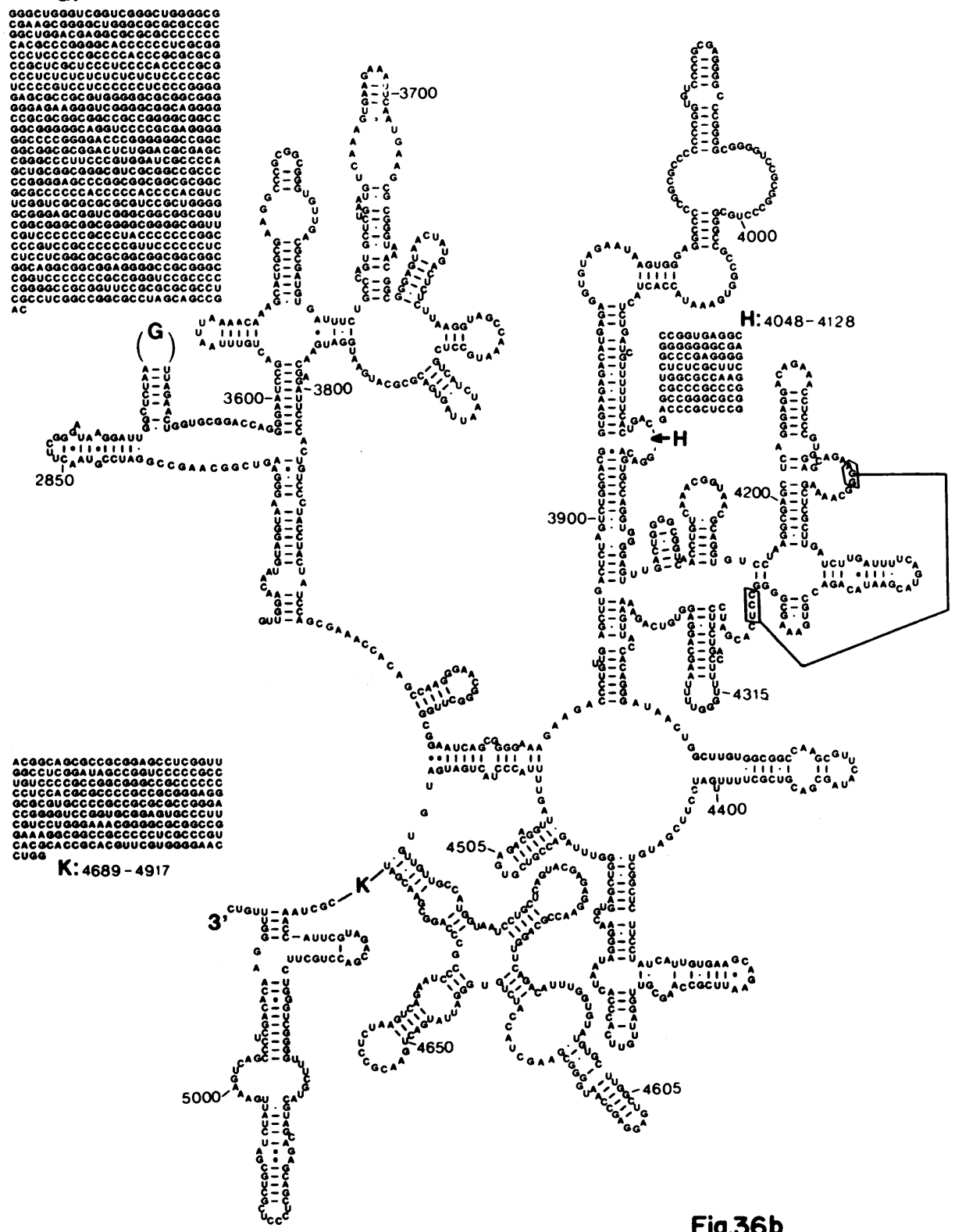

Fig.36b

Homo sapiens 


\section{Secondary Structure of eucaryotic 23S Ribosomal RNA: 5'half}

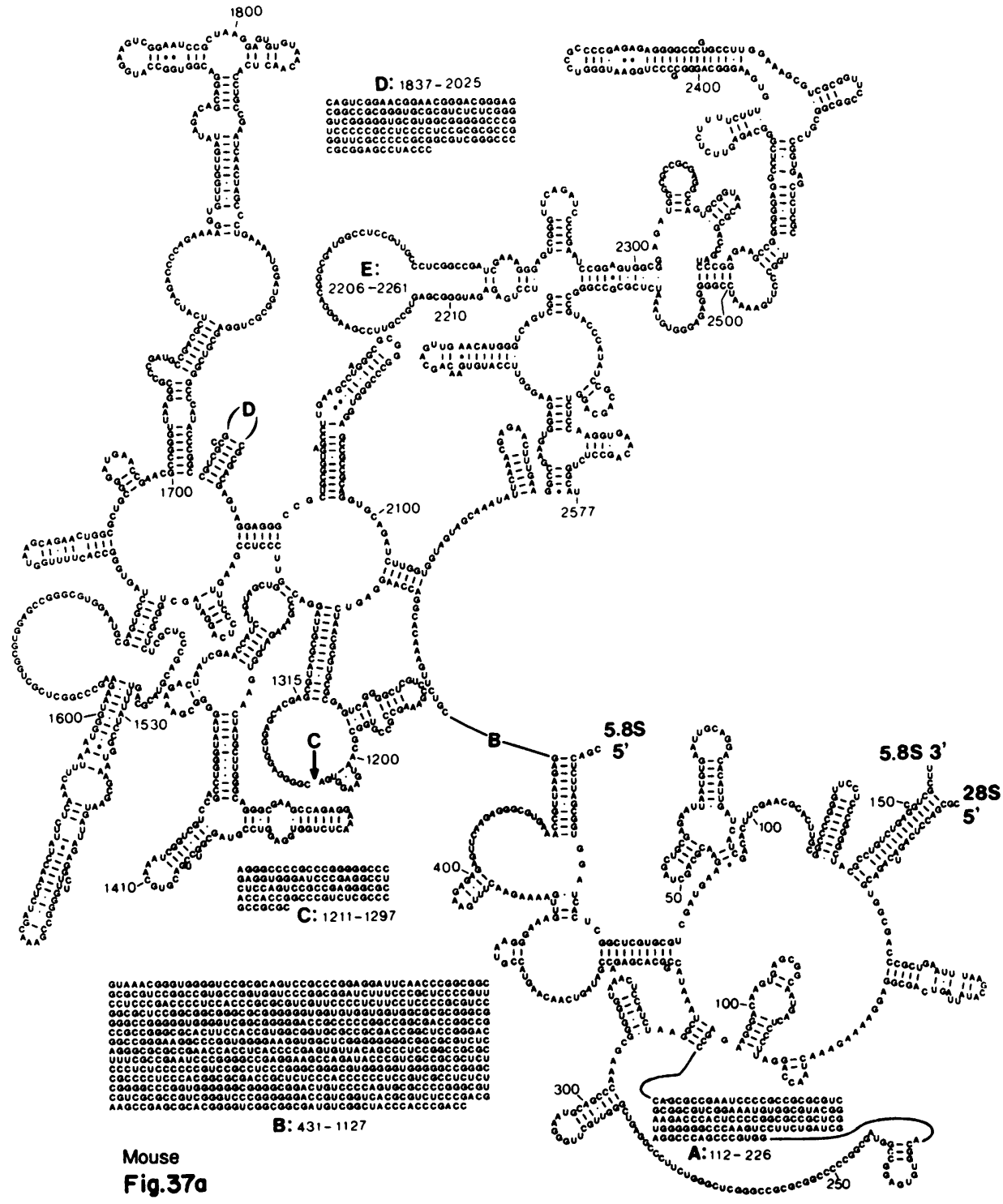


Secondary Structure of eucaryotic 23S Ribosomal RNA: 3'half

G:2648-3260

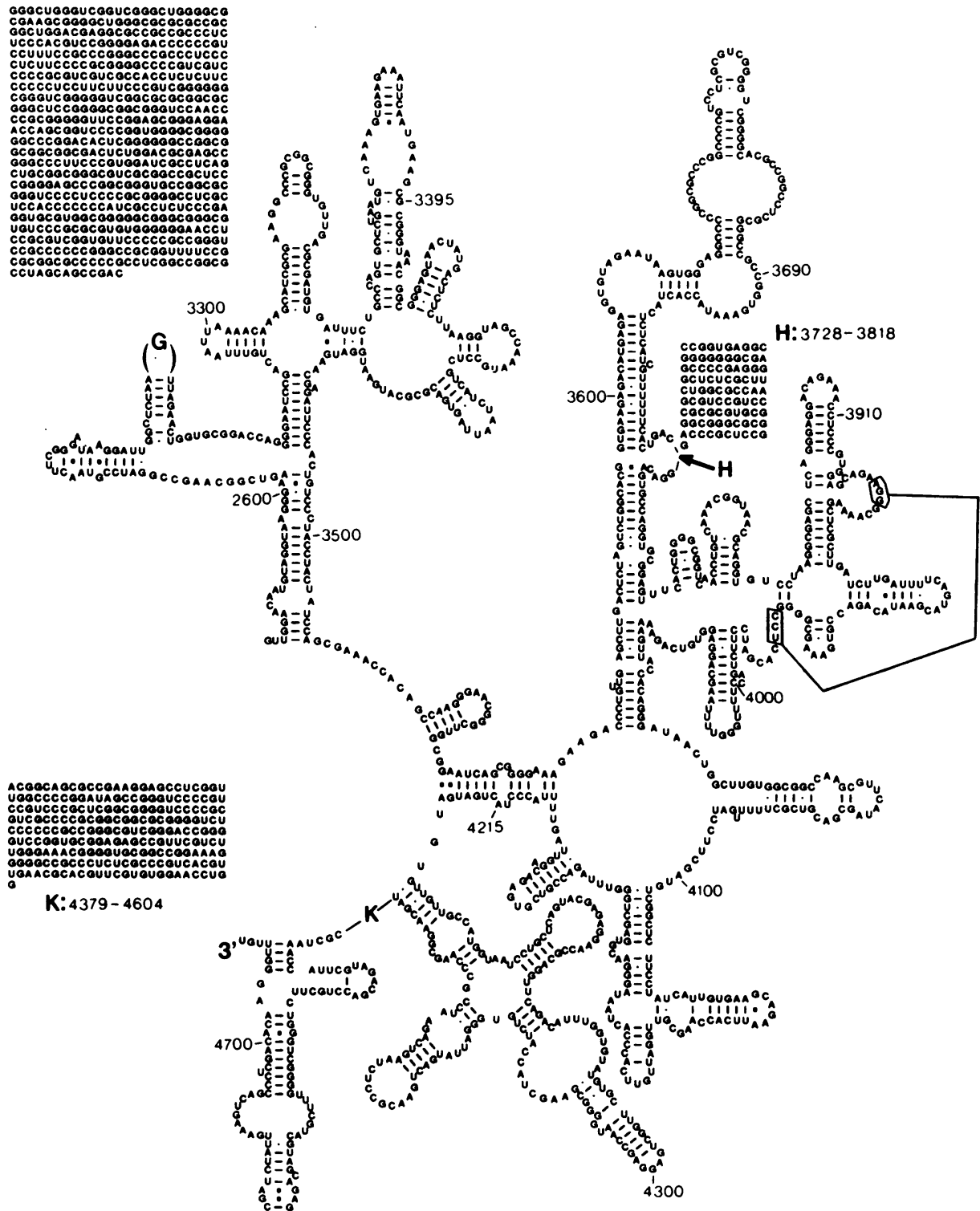

Fig.37b

Mouse 
Secondary Structure of eucaryotic 23S Ribosomal RNA: 5'half

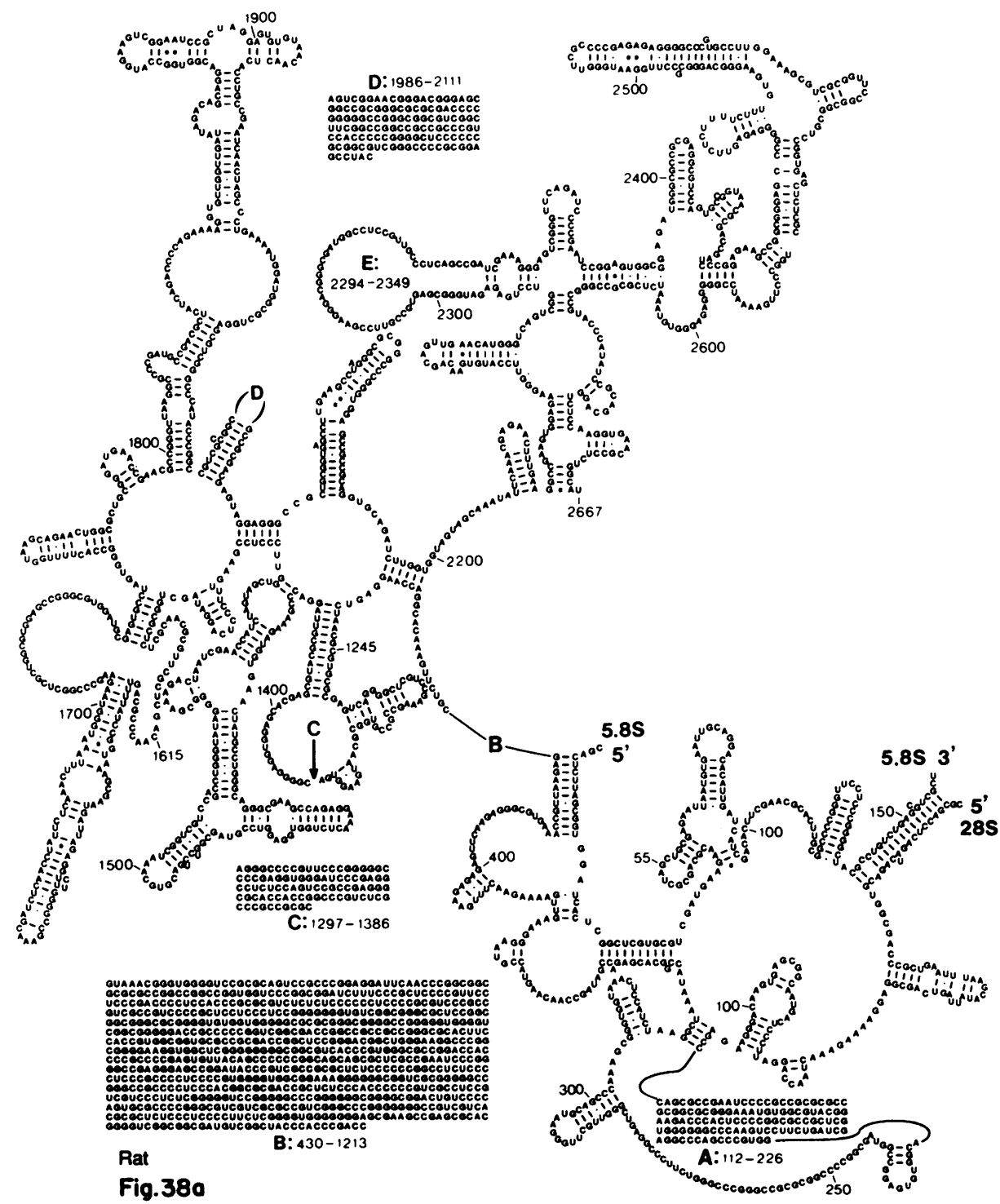


Secondary Structure of eucaryotic 23S Ribosomal RNA: 3 'half

G: $2736-3330$

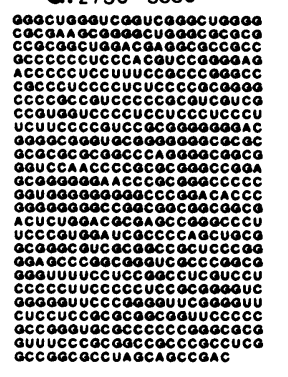

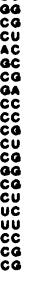
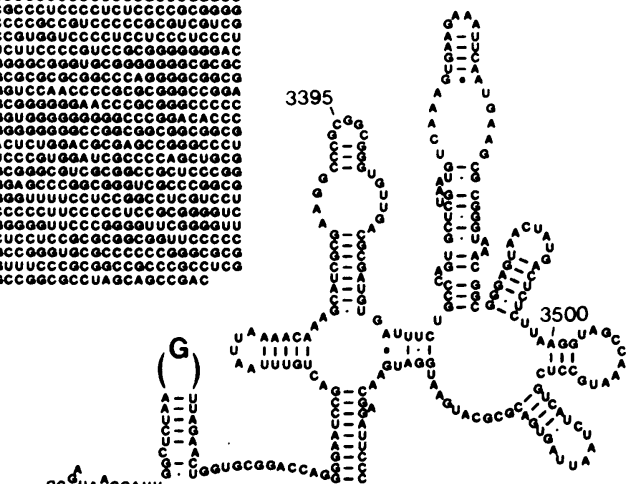

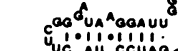

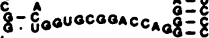

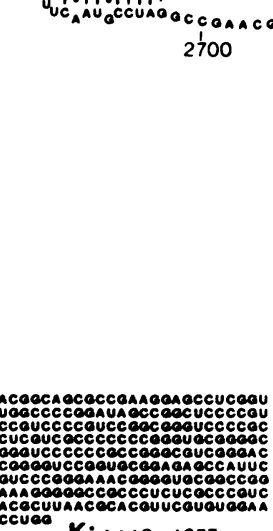

$K: 4448-4677$
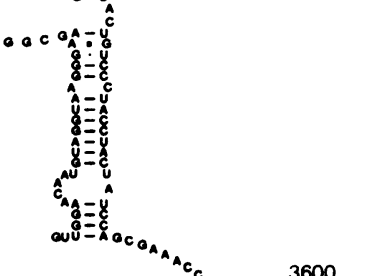

\section{(1)}

3, ve

Fig.38b

Rat 


\section{Nucleic Acids Research}

Secondary Structure of eucaryotic 23S Ribosomal RNA: 5'half

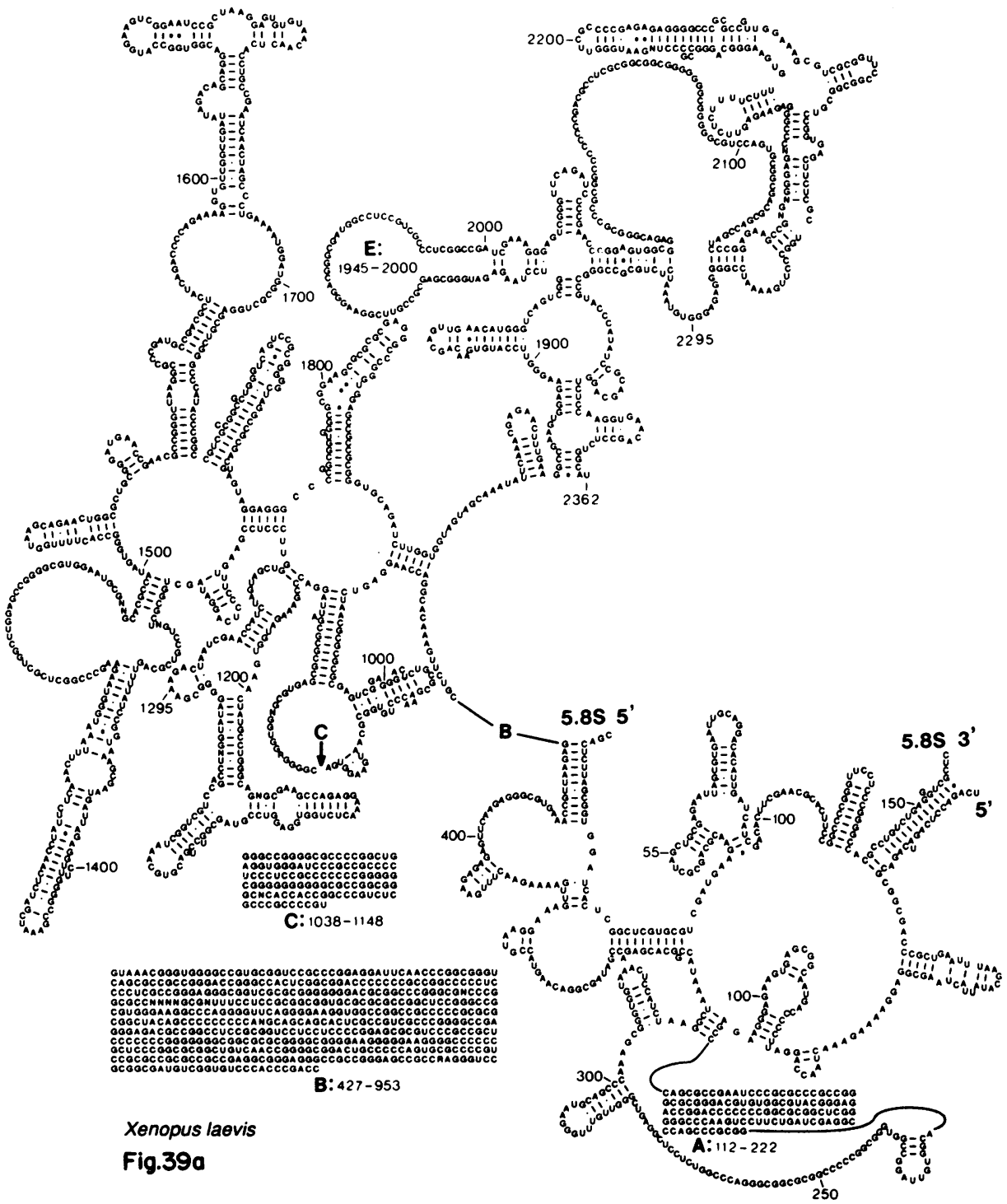


Secondary Structure of eucaryotic 23S Ribosomal RNA: 3'half

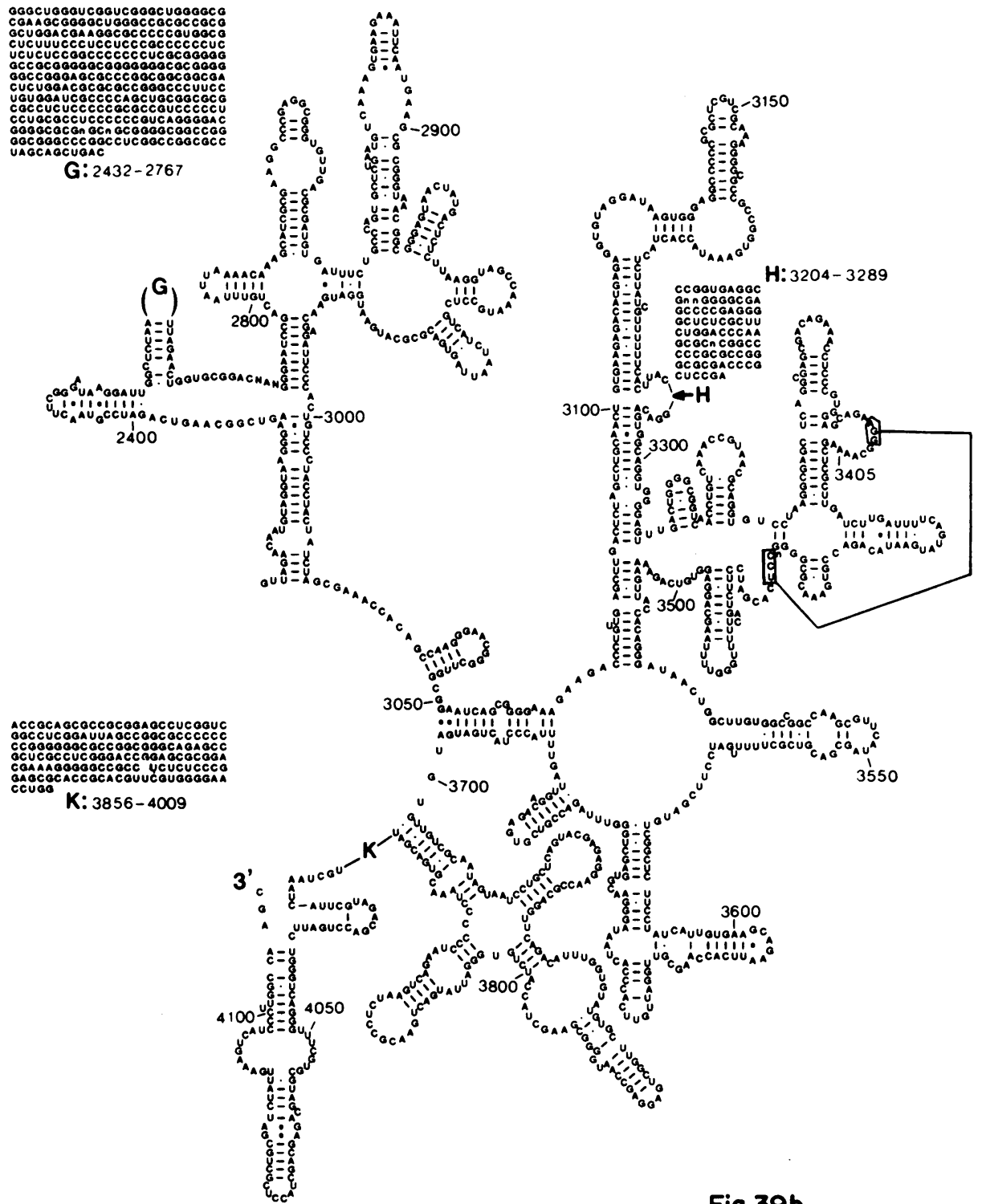

Fig.39b

Xenopus laevis 
Secondary Structure of eucaryotic 23S Ribosomal RNA: 5'half

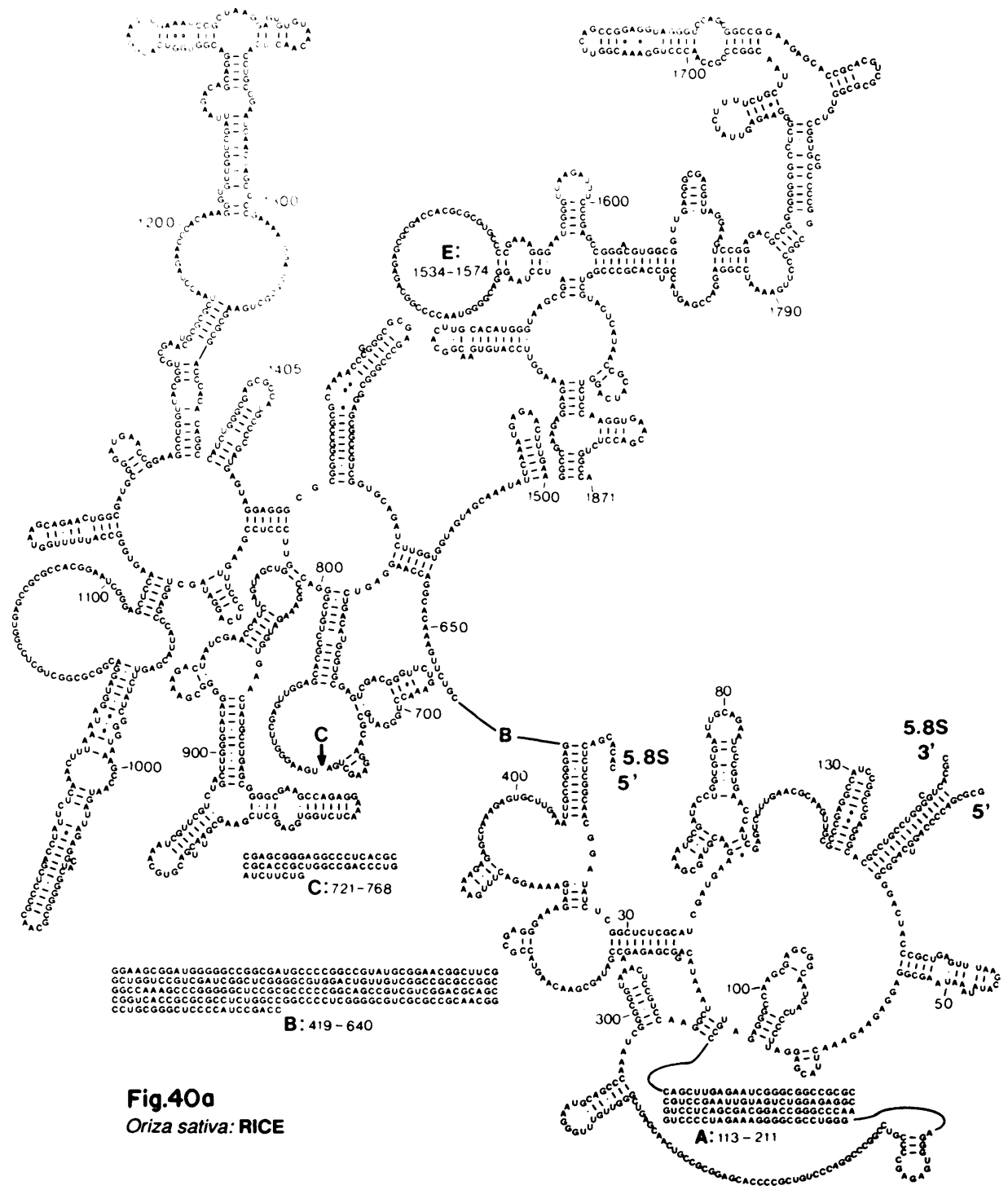


Secondary Structure of eucaryotic 23S Ribosomal RNA: 3 'half

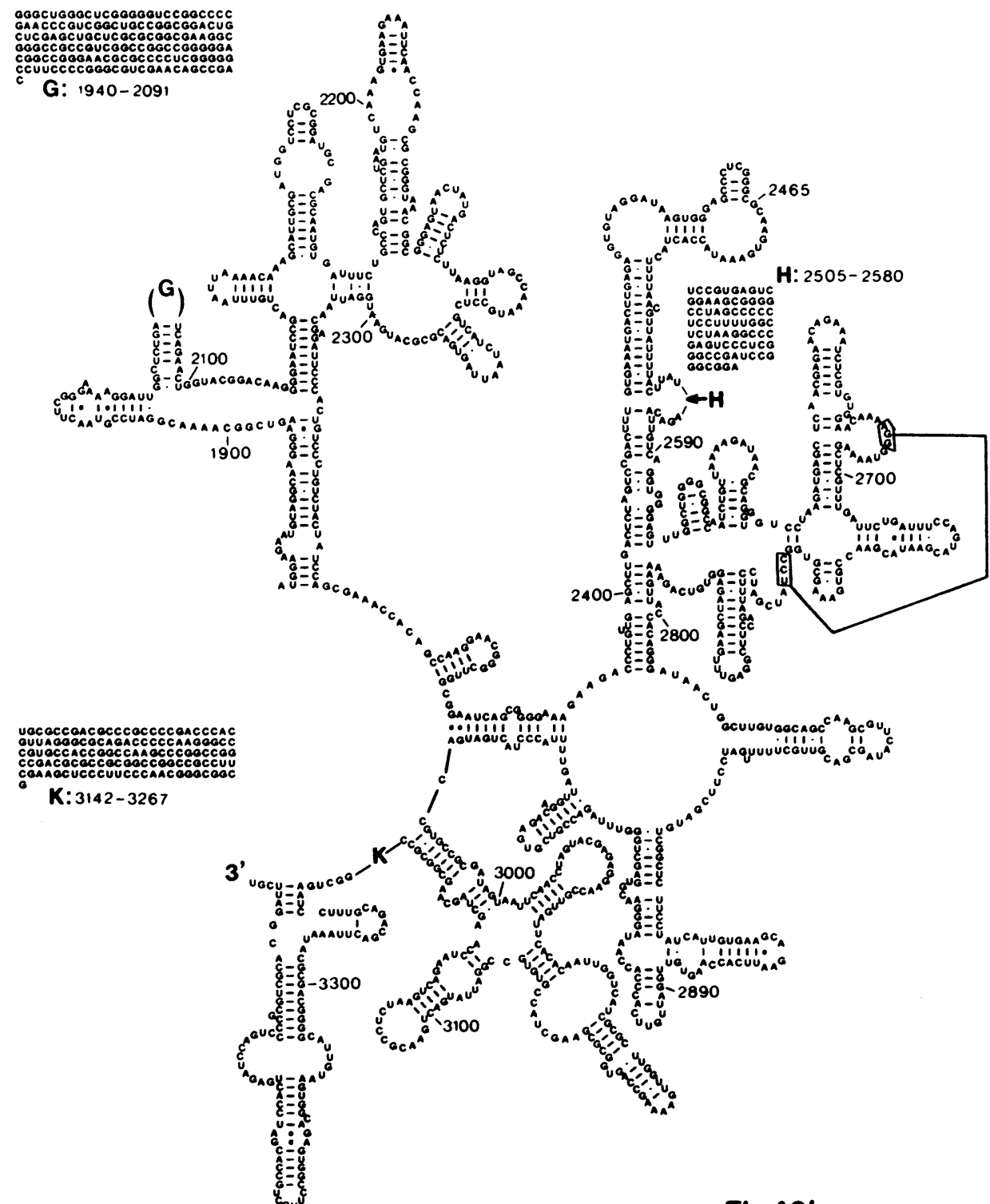

Fig.40b

Oriza sativa: RICE 
Secondary Structure of eucaryotic 23S Ribosomal RNA: 5'half

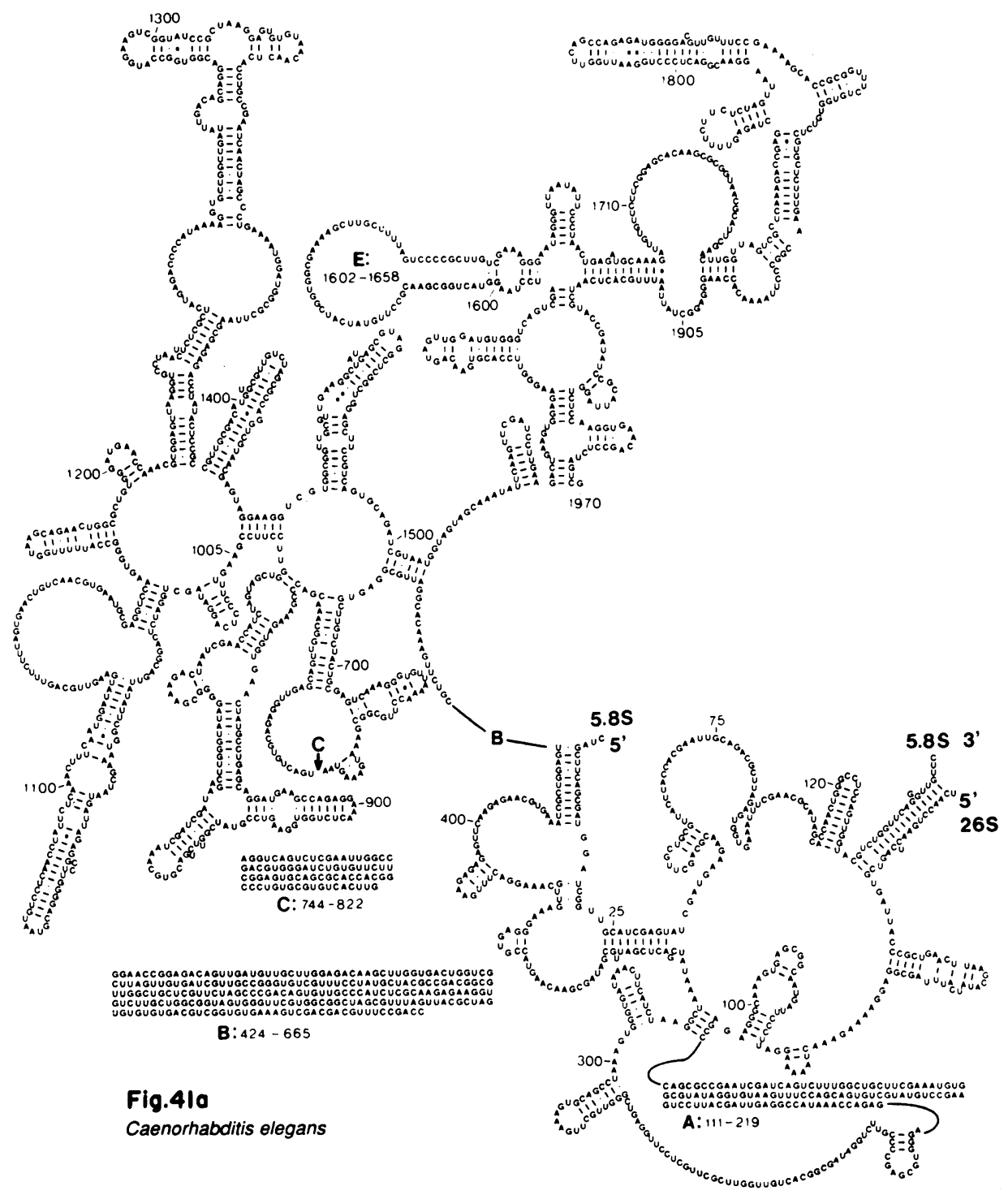


Secondary Structure of eucaryotic 23S Ribosomal RNA: 3 'half

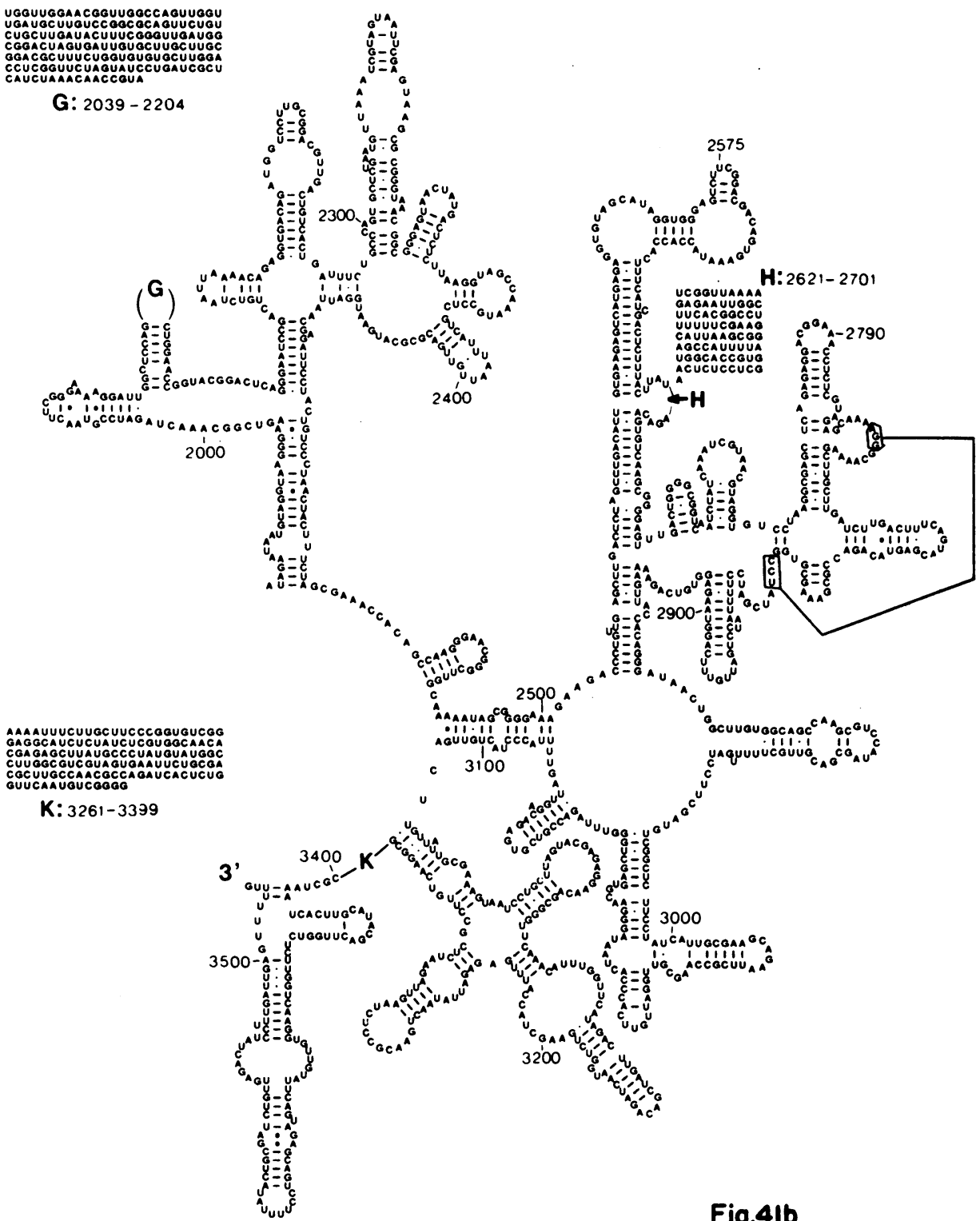

Fig.41b

Caenorhabditis elegans 
Secondary Structure of eucaryotic 23S Ribosomal RNA: 5'half

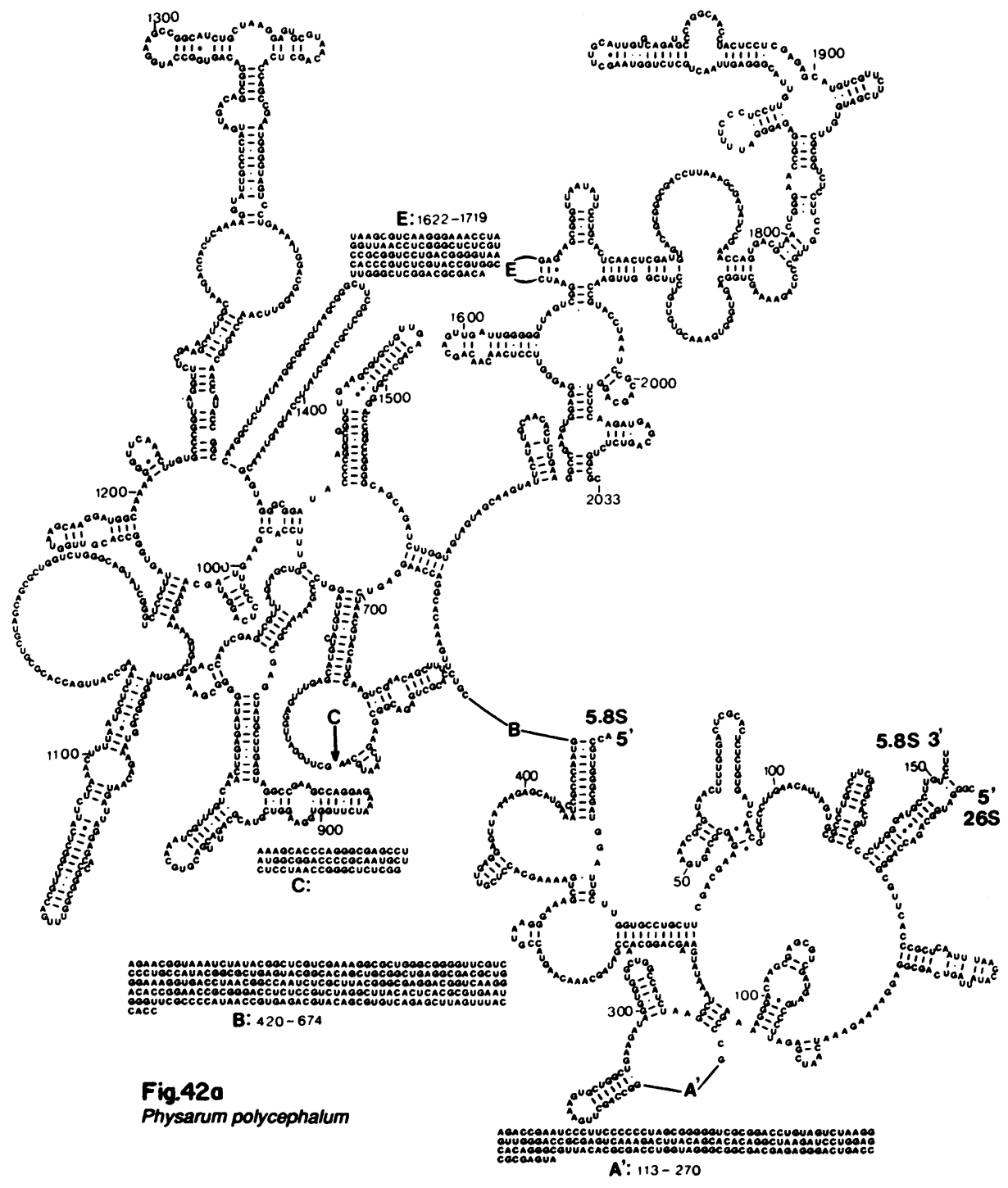


Secondary Structure of eucaryotic 23S Ribosomal RNA: 3'half

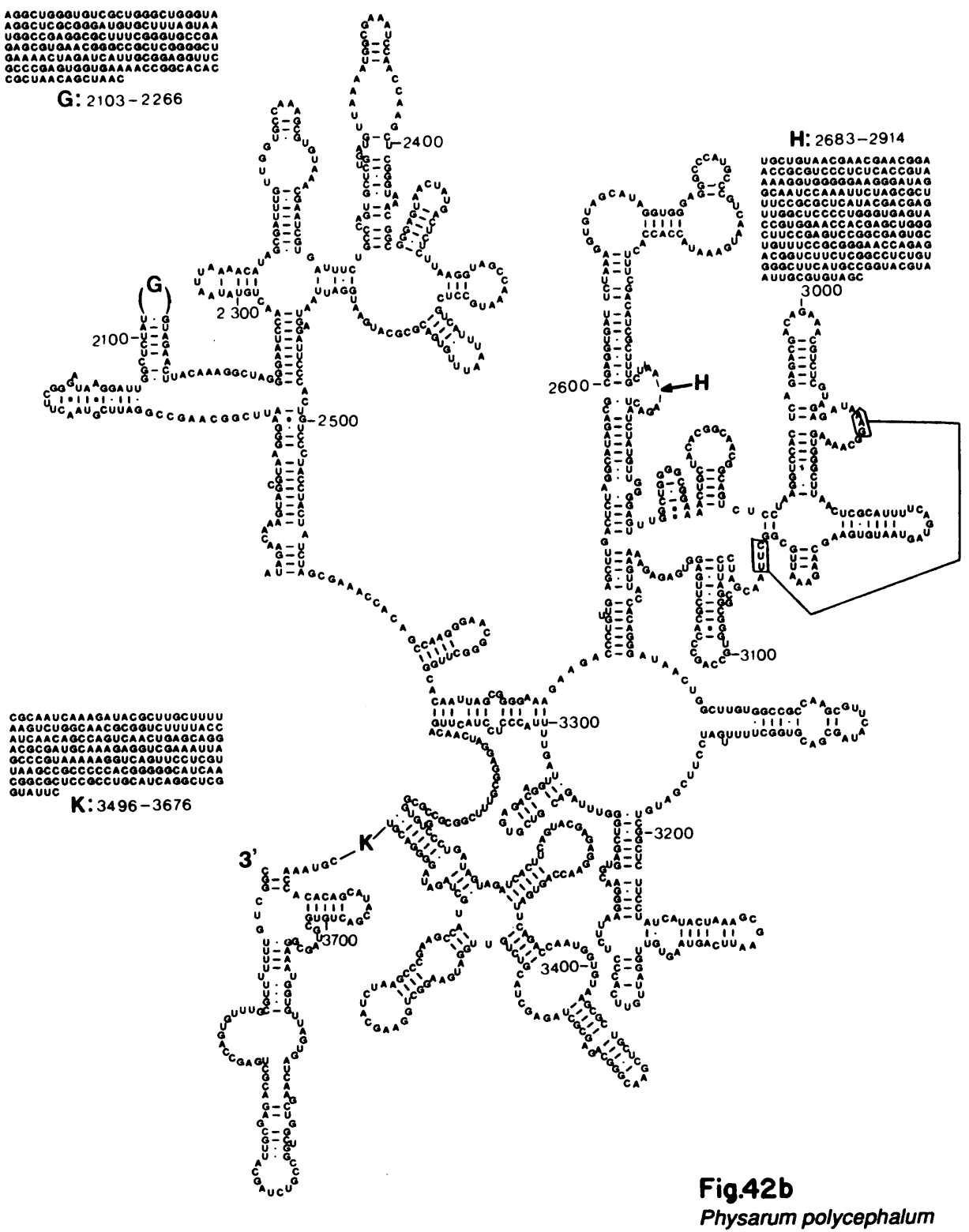

Physarum polycephalum 


\section{Nucleic Acids Research}

\section{Secondary Structure of eucaryotic 23S Ribosomal RNA: 5'half}

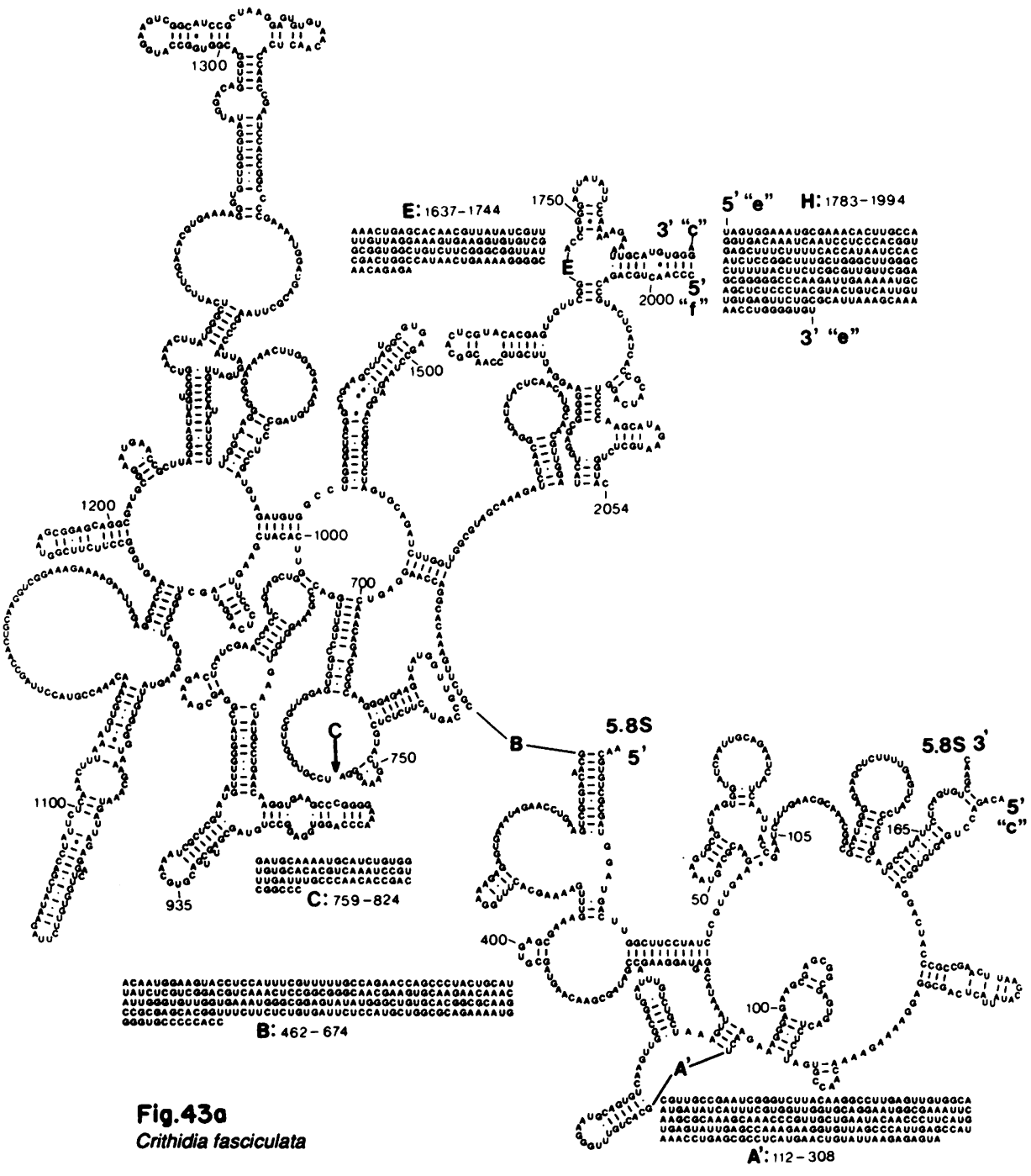


Secondary Structure of eucaryotic 23S Ribosomal RNA: 3'half

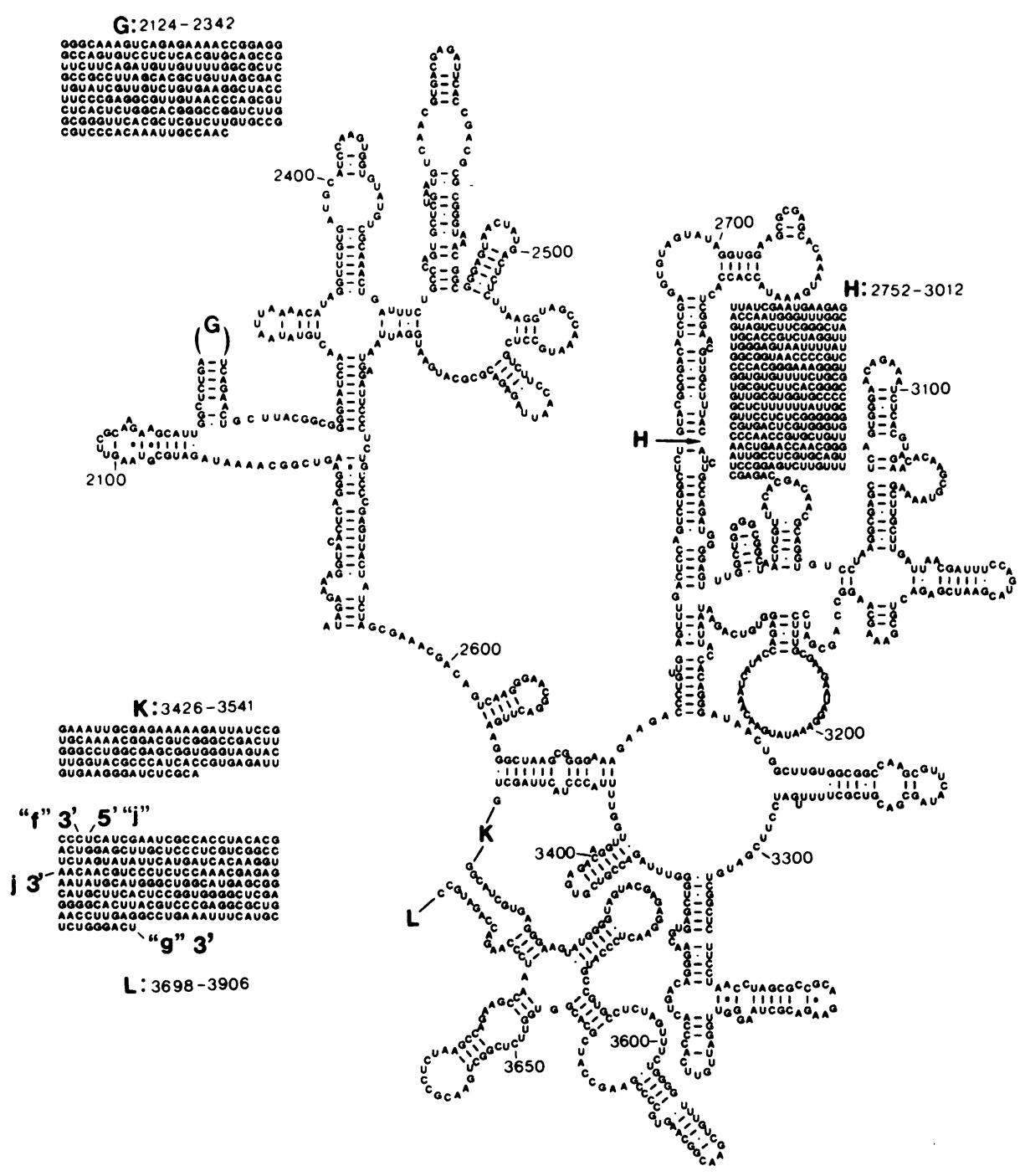

Fig.43b

Crithidia fasciculata 